\title{
Gender-biased sex selection in India: A review of the situation and interventions to counter the practice
}

Shireen J. Jejeebhoy

Population Council

Sharmistha Basu

Population Council

Rajib Acharya

Population Council

A.J. Francis Zavier

Population Council

Follow this and additional works at: https://knowledgecommons.popcouncil.org/departments_sbsr-pgy

Part of the Demography, Population, and Ecology Commons, Family, Life Course, and Society

Commons, Gender and Sexuality Commons, and the International Public Health Commons

How does access to this work benefit you? Let us know!

\section{Recommended Citation}

Jejeebhoy, Shireen J., Sharmistha Basu, Rajib Acharya, and A.J. Francis Zavier. 2015. "Gender-biased sex selection in India: A review of the situation and interventions to counter the practice." New Delhi:

Population Council. 


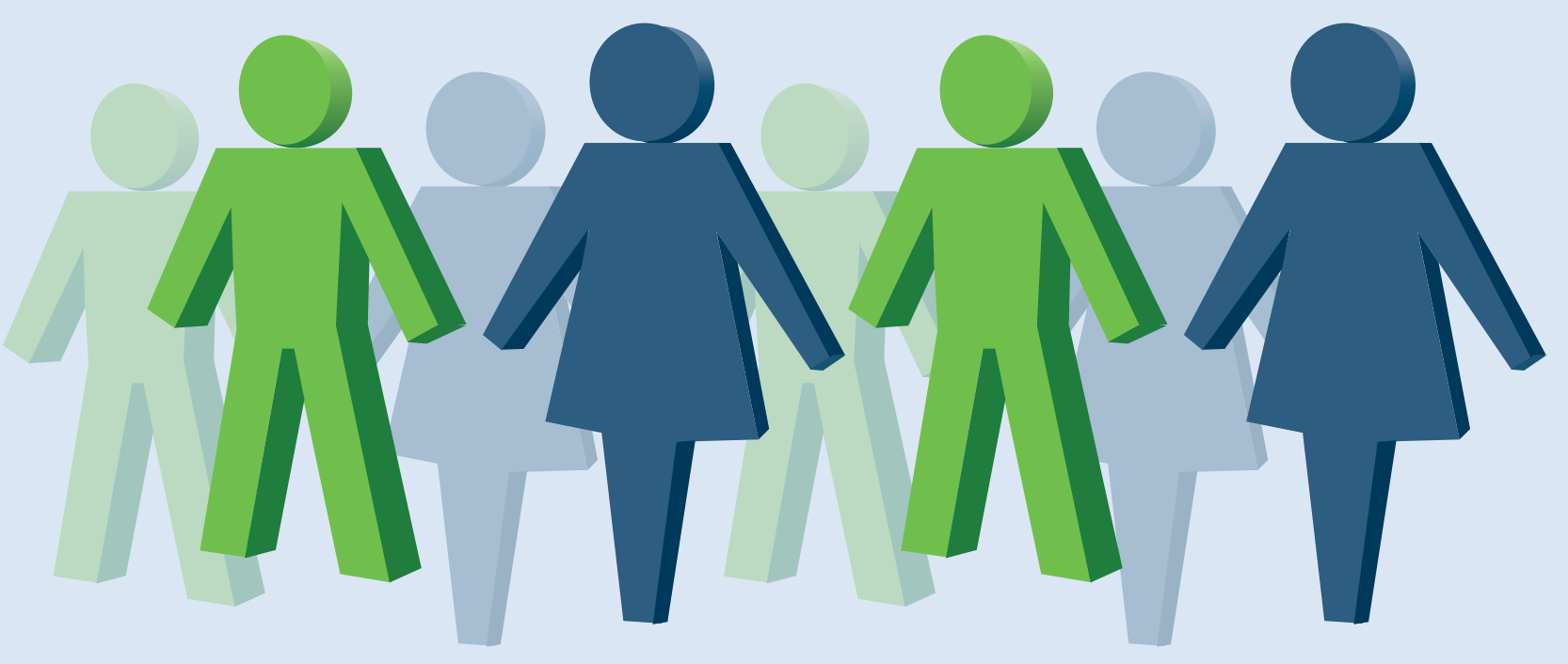

\section{GENDER-BIASED SEX SELECTION IN INDIA: A REVIEW OF THE SITUATION AND INTERVENTIONS TO COUNTER THE PRACTICE}

Shireen J Jejeebhoy Sharmistha Basu Rajib Acharya A J Francis Zavier 


\section{POPULATION
COUNCIL
Ideas. Evidence. Impact.}

The Population Council confronts critical health and development issues-from stopping the spread of HIV to improving reproductive health and ensuring that young people lead full and productive lives. Through biomedical, social science, and public health research in 50 countries, we work with our partners to deliver solutions that lead to more effective policies, programs, and technologies that improve lives around the world. Established in 1952 and headquartered in New York, the Council is a nongovernmental, nonprofit organization governed by an international board of trustees.

\section{Population Council}

Zone 5A, Ground Floor

India Habitat Centre, Lodi Road

New Delhi, India 110003

Phone: 91-11-24642901

Email: info.india@popcouncil.org

Website: www.popcouncil.org

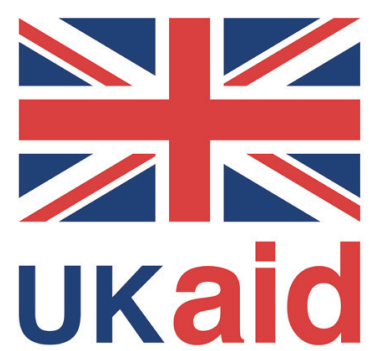

from the British people

This review has been funded by UK aid from the UK Government; however the views expressed do not necessarily reflect the UK Government's official policies.

Suggested citation: Jejeebhoy, S. J., S. Basu., R. Acharya and A. J. F. Zavier. 2015. Gender-biased sex selection in India: A review of the situation and interventions to counter the practice. New Delhi: Population Council. 


\section{GENDER-BIASED SEX SELECTION IN INDIA: \\ A REVIEW OF THE SITUATION AND INTERVENTIONS TO COUNTER THE PRACTICE}

Shireen J Jejeebhoy

Sharmistha Basu

Rajib Acharya A J Francis Zavier 


\section{Table of Contents}

List of Tables

List of Figures and Maps vii

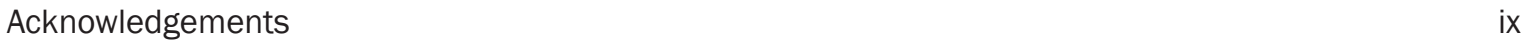

Chapter 1 Introduction 1

Chapter 2 Addressing gender-biased sex selection: laws and policies 6

Chapter 3 Trends and geographic variation in the sex ratio at birth and the child sex ratio 11

Chapter 4 Socioeconomic patterns, underlying factors and social consequences 24

Chapter 5 Implementing the PCPNDT Act and other efforts to reverse the trend of adverse sex ratios at birth

Chapter 6 Concluding remarks 49

$\begin{array}{ll}\text { References } & 53\end{array}$

$\begin{array}{ll}\text { Authors } & 61\end{array}$

Technical Advisory Group Members $\quad 62$

$\begin{array}{ll}\text { Field Investigators } & 63\end{array}$ 


\section{List of Tables}

$\begin{array}{ll}\text { Table 3.1: } & \text { Trends in the child sex ratio, India, 1951-2011 } \\ \end{array}$

Table 3.2: Child sex ratio, 2011, and sex ratio at birth, 2010-2012, major states, India 13

Table 3.3: Sex ratio at birth (implied) by state and district, India, 2004-2010 17

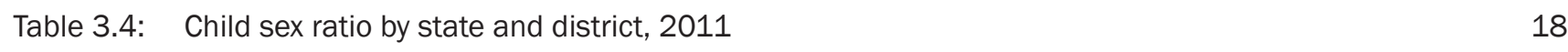

Table 3.5: Decadal change in the child sex ratio, selected states, India, 2001 and 2011

Table 3.6: Sex ratios at birth by rural-urban residence, India, SRS, 2002-2004 to 2010-2012 22

Table 3.7: Child sex ratios by rural-urban residence, India, 2001 and 201122

Table 4.1: $\quad$ Desired and actual sex ratio at birth by major states, India 27

Table 5.1: Initiatives to ensure that the PCPNDT Act is implemented 33

Table 5.2: Advocacy, communication initiatives and community mobilisation efforts to ensure effective implementation of the PCPNDT Act and promote gender equality

Table 5.3: Selected central and state government schemes for increasing the value of the girl child and counter disadvantages faced by girls 


\section{List of Figures}

Figure 1.1: Three preconditions for gender-biased sex selection 3

Figure 3.1: Sex ratio at birth, three-year moving averages (females per 1,000 males), India, SRS, 1984-2012 12

Figure 3.2: Trend in the child sex ratio of major states, India, 1991, 2001 and 2011

Figure 3.3: Trend in the sex ratio at birth of major states, India, 2002-2004, 2006-2008 and 2010-2012 15

Figure 5.1: Incidence of sex-selective abortions registered under the PCPNDT Act, India, 2001-2012 32

\section{List of Maps}

Map 3.1: Statewise sex ratios at birth in rural and urban areas, India, SRS, 2010-2012 


\section{Acknowledgements}

We are grateful to UKaid for supporting a regional initiative to shed light on the issue of gender biased sex selection in Bangladesh, India, Nepal and Pakistan, and make evidence-based recommendations for actions that hold promise for responding to adverse sex ratios at birth in these settings.

This study has benefited immeasurably from the inputs of many. In particular, we are grateful to Nupur Barua, UKaid; and Ena Singh, Dhanashri Brahme, K.M. Sathyanarayana, and Sanjay Kumar, UNFPA for sharing their valuable insights with us, helping us locate key resources, and generously providing us unpublished data. We would also like to express our thanks to our partners, Ubaidur Rob, Population Council, Bangladesh; Mahesh Puri and Anand Tamang, Centre for Research, Environment, Health and Population Activities (CREHPA), Nepal, and Zeba Sathar, Population Council, Pakistan, for helping to shape the structure of our literature reviews.

We were privileged that T.V. Sekher and Dhanashri Brahme, both with wide experience and insights into the situation with regard to gender biased sex selection in India, agreed to review an earlier draft of this report. Their constructive criticism and suggestions are much appreciated, and have been incorporated into this final report. This review of literature has also benefitted from comments made by members of its Technical Advisory Group on an earlier version of this report; we are particularly grateful to P.M. Kulkarni and Ena Singh for their comments and recommendations.

At the Population Council, several colleagues have supported us in both the technical and administrative aspects of this study. We are grateful to M.A. Jose and Komal Saxena for conducting a search of the literature relating to our topic; their support and success in identifying many of the wide range of articles and papers included in this review is much appreciated.

Jyoti Moodbidri was responsible for editing the manuscript and Komal Saxena was responsible for reviewing the manuscript and for preparing it for publication. We are grateful to both for their contribution and careful attention to detail which have made the report more readable and clear.

Shireen J Jejeebhoy

Sharmistha Basu

Rajib Acharya

AJ Francis Zavier 


\section{Chapter 1 Introduction}

The sex ratio denotes the male to female ratio of a population and is represented internationally as the number of males per 100 females. In India, it is denoted by the number of females per 1,000 males. The sex ratio can be expressed in various forms: sex ratio at birth, child sex ratio or juvenile sex ratio, and sex ratio of the general population. The biologically normal sex ratio at birth is 105 male births per 100 female births (952 female births per 1,000 male births) under natural circumstances, affirming a male advantage at birth. However, because females have an advantage over males in terms of mortality at most ages, under normal circumstances, the male sex ratio declines during childhood and eventually evens out at 100 . The child sex ratio or juvenile sex ratio is defined as the sex ratio in a specific age group, typically $0-6$ or $0-4$ years, and the global norm suggests that the sex ratio at birth (105 male births per 100 female births or 952 female births per 1,000 male births) persists among children as well (United Nations Population Fund, 2013).

Amartya Sen's 1990 essay highlighted that 'more than 100 million women are missing' globally (Sen, 1990). More recently, the number of "missing girls," that is, girls in relation to the number of boys who should have constituted the child population but are missing has been estimated to have reached some 117 million in 2010, most of them being from China and India (United Nations Population Fund, 2012). In these settings, the sex ratio at birth and the juvenile or child sex ratio are far from those expected under natural circumstances. The situation in India is particularly disturbing; in 2012, the sex ratio at birth stood at 908 female births per 1,000 male births (110 male births per 100 female births) (Office of the Registrar General, India, 2013a), and the child sex ratio, as of 2011, had plummeted to 918 females aged 0-6 per 1,000 males (109 males per 100 females), from an already dismal 927 in 2001, and 945 in 1991 (Office of the Registrar General and Census Commissioner, India, 2013).

Estimates from India suggest some 10 million gender-biased sex-selective abortions had taken place in the period 1981-2005, amounting to five percent of the female population aged below 15 (Kulkarni, 2007). Indeed, recent studies have noted that as a result of sex-selective abortion, about 0.5-0.6 million girls are missing each year (Jha et al., 2006; United Nations Population Fund, 2010). There is clearly an urgent need to arrest this trend; unfortunately, insufficient programme or research attention has been paid to identifying promising practices that may be effective in doing so.

This review is a first step towards filling this gap, with a specific focus on India. Its objectives are twofold. First, it highlights the situation with regard to the sex ratio at birth and the juvenile or child sex ratio, including geographic and other disparities. Second, it synthesises promising approaches through which efforts have been made to address the practice of gender-biased sex selection. The findings are expected to draw attention to gaps in evidence and outline areas of research that are needed to arrive at evidence-based recommendations for action, and provide evidence-based guidance to help both policy-makers and donors to determine feasible and effective interventions that may hold promise.

This review, focused on India, is part of a programme of work supported by UKAid in four South Asian countries Bangladesh, India, Nepal and Pakistan to better understand how best to respond to adverse sex ratios at birth in South Asia. More specifically, the Population Council and partner, Center for Research on Environment Health and Population Activities (CREHPA), have embarked on a programme of work that has two broad aims. The first is to synthesise at country-level, what is known about levels, trends and correlates of unbalanced sex ratios at birth as well as programmes and initiatives that have a potential for reversing the trend. The second is to build on the insights of the first, and probe, through primary research, the perspectives of stakeholders about such programmes and initiatives in selected settings, and thereby assess the extent to which a programme or initiative is promising and may be scaleable.

\section{Methodology}

In preparing this report, we have reviewed published and unpublished, qualitative and quantitative studies on the situation in India since the 1990s, when the phenomenon of adverse sex ratios at birth was first highlighted, as 
well as programme documents describing efforts that address gender-biased sex selection. Documents have been perused that cover two broad areas. First, we reviewed studies that discuss sex ratios at birth among children and of the population, as appropriate, and the factors underlying skewed sex ratios. Second, we perused interventions and/ or programmatic and policy-related initiatives addressing gender-biased sex selection that have been undertaken by the government, civil society organisations or international organisations, and were designed or have the potential to reduce the imbalance in sex ratios.

We acknowledge that while data are available that confirm unbalanced sex ratios at birth in India and the likely factors underlying this trend, evidence is relatively sparse about specific initiatives undertaken to halt the practice of gender-biased sex selection, and even fewer evaluations that assess the effectiveness of programmes and policies in preventing this practice. What is available tends to be descriptive and much of it focuses on relatively small geographic areas; data are, therefore, limited in their ability to determine impact and findings are typically not representative of the state or country, more generally. All sex ratios in this report are presented in terms of the number of females per 1,000 males, following the definition commonly used in India.

\section{Background}

Distorted sex ratios at birth, among children and in the population at large are observed in patriarchal settings characterised by hierarchical gender relations, limited female agency and a strong preference for sons. They are observed in several countries aside from India. Sex ratios at birth are most skewed in China (848 in 2011), with ratios ranging from 777 in Anhui province to 860 in Hong Kong and, more recently, in such countries as Vietnam (899 in 2010) and, in Western Asia, in Azerbaijan (858 in 2011), Armenia (870 in 2010) and Georgia (880 in 2009-11) (United Nations, 2013); South Korea also exhibited a hugely skewed sex ratio at birth in the 1980s, but succeeded in reversing this trend, from a low of 862 in 1993-94 to 943 by 2009 (Kim, 2013; United Nations, 2013). In countries of South Asia other than India, too, there are indications of skewed sex ratios at birth. For example, while UN estimates suggest that the sex ratio at birth in Bangladesh is within normal limits (952 females per 1,000 males), other researchers have suggested lower ratios (917) (United Nations, 2013; National Institute of Population Research and Training, Mitra and Associates and ICF International, 2013). In Nepal, the sex ratio at birth is 943 , with considerable regional variation (Central Bureau of Statistics, 2012). While Pakistan's sex ratio at birth is normal (975), there are some settings (Sind, for example and some urban pockets) that are found to display a disturbed sex ratio at birth (National Institute of Population Studies and ICF International, 2013). ${ }^{1}$

Juvenile or child sex ratios in India have been unbalanced and far from those expected under natural circumstances for many decades, but the leading factor accounting for this imbalance has not always been an unbalanced sex ratio at birth. Up to the 1980s, it was post-natal discrimination against girls through differential feeding and health care patterns, on the one hand, and infanticide on the other, that resulted in the excess mortality of girls compared to boys and, thereby, an unbalanced sex ratio. Since the 1980s, however, there has been a gradual shift and, today, the bulk of differences in the juvenile sex ratio results from the unbalanced sex ratio at birth, ${ }^{2}$ fuelled by gender-biased sex selection and termination of pregnancies carrying a female foetus. As a result, large parts of India may have an excess of young men by up to 20 percent by 2030 (Hesketh, Lu and Xing, 2011). Indeed, the proportion of India's population residing in states in which the child sex ratio is below 920 girls per 1,000 boys increased from 11 in 1991 to 43 in 2001 (Office of the Registrar General and Census Commissioner, India, 2004) to 51 in 2011 (Office of the Registrar General and Census Commissioner, India, 2013).

Gender disparities in the sex ratio of the population were noted from colonial times (UN Women, 2014). For example, the 1891 census report, General Report on the Census of India (1891), observed such a discrepancy. Even earlier, the practice of infanticide of girls had been documented in Rajasthan (UN Women, 2014) and Punjab (Snehi, 2003). More recent assessments using census data from 1961 onwards (Visaria, 1971; Miller 1981; 1989) have reiterated

\footnotetext{
${ }^{1}$ Sex ratios at birth in equivalent international standards (males/100 females) are as follows: China: 117.8; Anhui province: 128.7 ; Hong Kong: 116.2; Vietnam: 111.2; Azerbaijan: 116.5; Armenia: 114.2; Georgia: 113.6; South Korea (1993-94): 116; South Korea (2009): 106; Bangladesh: 105 (2012); and 109 (2011); Nepal (2012): 106; Pakistan (2013): 102.5

2 The third possible factor influencing the juvenile sex ratio, namely an undercount or age misreporting of girls, has no more than a nominal effect on the juvenile sex ratio, and the trend in deliberately misrepresenting daughters has declined in recent years such that this component is irrelevant in accounting for observed sex ratios (Premi, 2002; Bhat, 2002; Kulkarni, 2007).
} 
distorted sex ratios, and confirmed that they resulted from gender-biased mortality rather than gender-biased migration or age misreporting. Underlying factors have largely included the practice of hypergamy, on the one hand, and the need to provide large dowries on the other (Miller, 1981). Several authors have documented discrimination against girls in health care and feeding practices while others have more directly, provided evidence of reported infanticide practices (Das Gupta 1995; Miller, 1981; 1989; Snehi, 2003). Indeed, such practices as burying the infant alive, poisoning her, starving her, or choking her by placing paddy husk in her mouth have been documented (Snehi, 2003; George, 1997; Sekher and Hatti, 2010).

More recently, the wide availability of medical technologies such as ultrasound, and more recently even preconception techniques that permit the detection of the sex of the foetus, the practice of achieving a small family while ensuring the desired number of sons has led many parents to undergo tests to detect the sex of their foetus and terminate pregnancies in which the foetus is found to be female (Bhat, 2002; Kulkarni, 2014). Several countries in Asia in which this practice has been observed have passed laws that forbid the disclosure of the sex of the foetus: Korea (1987), China (1989), India (1994), and Nepal (2002) (Ganatra, 2008). Notwithstanding these laws, the practice continues in several settings, including India.

In short, distortions in the sex ratio at birth are attributed to the convergence of three interlinked factors, namely the persistence of patriarchal norms and inegalitarian gender roles and consequent son preference, fertility decline and declining family size preferences, and technological advances that permit the detection of the sex of the foetus (Guilmoto, 2011), as presented in diagrammatic form (Figure 1.1) below.

Figure 1.1: Three preconditions for gender-biased sex selection

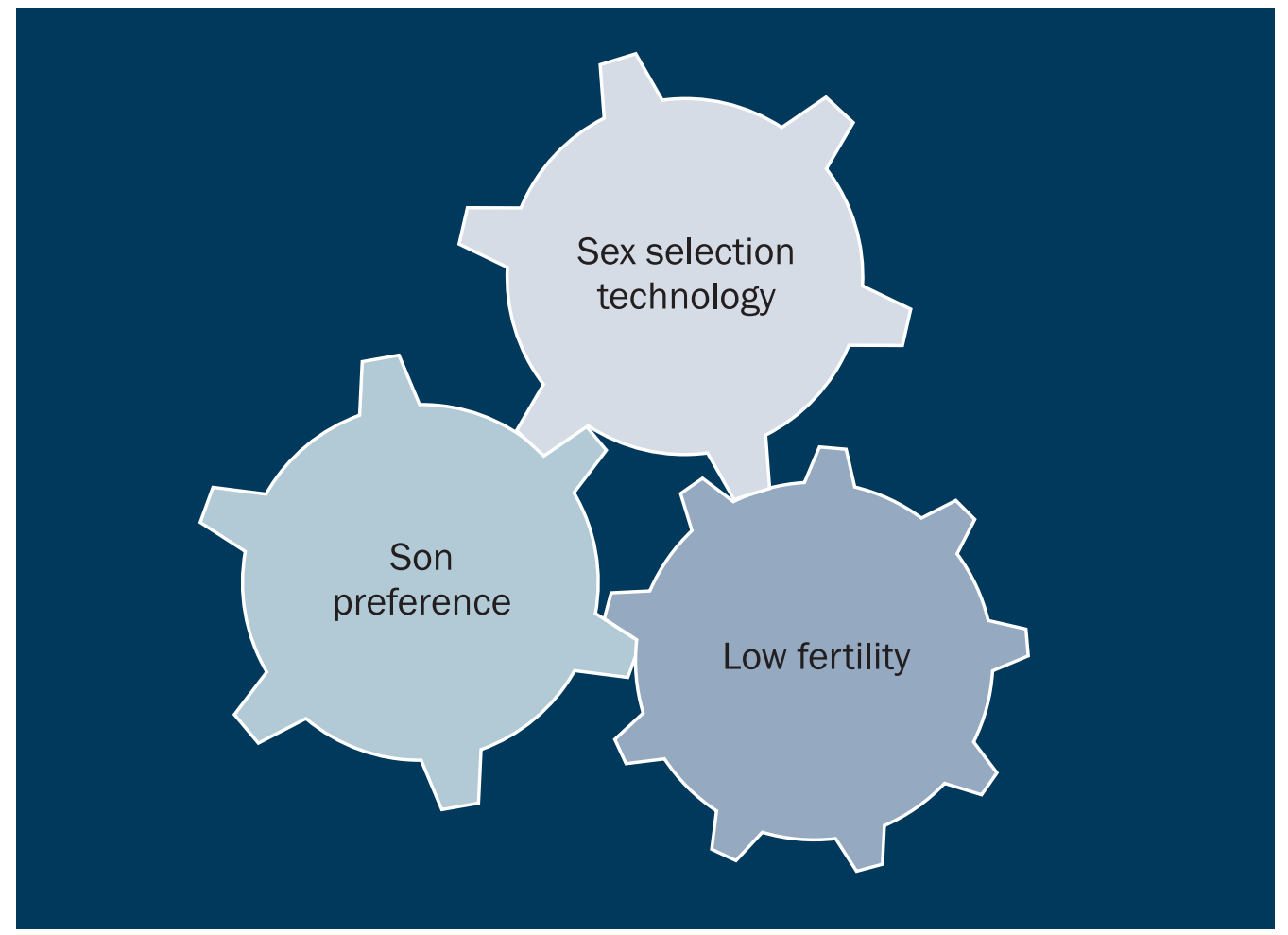

Source: Guilmoto, 2011.

Pre-natal diagnostic techniques have been available since the 1970s that detect genetic abnormalities in a foetus and, at the same time, can detect the sex of the foetus. These techniques became commonly available in India only in the 1990s (Arnold, Kishor and Roy, 2002). Today, technological advances in the form of ultrasonography, amniocentesis, chorionic villus sampling and, more recently, simple blood tests and even pre-conception methods, have made it possible to detect the sex of the foetus and enable couples to achieve the desired sex composition 
of their children, in collusion with unscrupulous medical practitioners willing to circumvent laws forbidding the disclosure of the sex of the foetus (George, 2002). At present, ultrasonography is used most commonly in India as it is most widely available, inexpensive, non-invasive and easy-to-use; it is also a technology supported by medical practitioners to detect foetal defects, and thus is a legitimate technology used by pregnant women (United Nations Population Fund, 2012). However, rapid advances in technology may make the identification of the sex of the foetus possible through a blood test early in pregnancy or even at conception stage; while these methods are not currently available for the most part in India, they offer an almost undetectable way of experiencing a sex-selective pregnancy, and are likely already undertaken by wealthy Indians who travel abroad to take advantage of the availability of such techniques (United Nations Population Fund, 2012). We note, however, that increased availability of these technologies is not, on its own, a sufficient condition for the promotion of sex-selective abortion (Ganatra, 2008; Sen, 2009). Indeed, in south Indian states, prenatal diagnostic techniques are widely available and used, but not misused; as a result, although the use of these techniques is greater in the southern than in the north Indian states, imbalances in the sex ratio at birth have not been as pronounced (Bhat and Zavier, 2007).

Together with the advance of new technologies has been a sharp decline in fertility and family size preferences across the nation. For example, in India, the total fertility rate among women aged 15-44, fell from 3.36 in 1990-1992 to 2.84 in 1998-1999, and further to 2.66 in 2005-2006, and reached 2.4 in $2010-2012$ (Office of the Registrar General, India, 2013a). Over the period 1990-1992 to 2005-2006, moreover, the ideal number of children preferred by women fell from 2.9 to 2.4, and was even lower (2.0) among the youngest age group (ages 15-19) (International Institute for Population Sciences and Macro International, 2007). The "squeezing" effect of fertility decline in the presence of persistent son preference is evident from analyses suggesting that the probability of having only female children increases from three percent among families with five children to 24 percent among those with two children (United Nations Population Fund, 2012).

While foetal sex-determination technology has become increasingly available and family size preferences have declined considerably, changes in patriarchal norms have not kept pace, and strong son preference continues to prevail in India and much of South Asia. Indeed, the availability of the technology has enabled couples to achieve a small family size while ensuring the birth of their desired number of sons. For example, an analysis of National Family Health Survey (NFHS) data highlights that where the first-born child is female, the sex ratio of the second child is highly skewed towards males; in contrast, where the first-born child is male, the sex ratio of the subsequent child is not affected (Kishor and Gupta, 2009). Further, sex ratios at birth were most distorted at parity two (as low as 762), clearly, the consequence of small family size preferences accompanied by persisting son preference and the need to ensure that at least one child is a boy. The link to sex selection is also evident from data suggesting that women who had undergone ultrasound testing during pregnancy reported a far lower sex ratio at birth than did those who had not done so (850 versus 943) (Arnold and Parasuraman, 2009). Similar evidence comes from other countries of South Asia. In Pakistan, for example, while sex ratios were largely within the normal range for lower parities, they increased substantially at parity three and four (Zaidi, 2013). In Nepal, where the overall sex ratio at birth has not reached levels experienced by India and Pakistan, sex ratios at birth for second- and third-order children where previous births were females, were substantially higher than the sex ratio at birth of first-order children in most regions (Frost, Puri and Hinde, 2013).

Of concern, moreover, is evidence that the desired sex ratio at birth far exceeds the actual sex ratio at birth in most countries of the South Asia region and in the states of India, including those (such as Pakistan and the Indian states of Haryana and Punjab) in which sex ratios at birth are highly skewed, and those (such as Bangladesh, and the Indian states of Bihar, Madhya Pradesh and Uttar Pradesh) that currently display normal sex ratios at birth (Bongaarts, 2013).

Few countries characterised by strong patriarchal social systems, gender-biased sex selection and distorted sex ratios at birth have succeeded in reversing this trend. South Korea is an exception. Indeed, from a sex ratio at birth of 862 in 1993-1994 (Chung and Das Gupta, 2007), South Korea today, boasts a normal sex ratio at birth. This rapid normalisation of the sex ratio at birth is attributed to a combination of harsh penalties for the violation of the law prohibiting disclosure of the sex of the foetus, massive media campaigns intended to raise awareness of the law and penalties for its violation, and policies and programmes intended to reduce discrimination against females (Kim, 2013; Chung and Das Gupta, 2007). 


\section{Structure of the report}

This report is divided into six chapters, including this introductory chapter. Chapter 2 describes the laws and policies adopted by India to address gender-biased sex selection, as well as those intended to support and empower women and girls. Chapter 3 analyses the trends and geographic variation in the sex ratio at birth and in the child sex ratio. Chapter 4 briefly describes the socioeconomic differences and factors underlying distorted sex ratios and genderbiased sex selection in India, and the social consequences of these practices. Experiences in implementing the PCPNDT Act, initiatives intended to restrict and monitor the use of technology for prenatal sex-selection, those intended to build gender equality, and advocacy measures, are described in Chapter 5. Chapter 6 summarises the key findings and highlights promising areas for further research. 


\section{Chapter 2}

\section{Addressing gender-biased sex selection: laws and policies}

In this chapter, we summarise the PCPNDT Act (Pre-Conception and Pre-Natal Diagnostic Techniques Act) as well as other policies that hold promise, more indirectly, for reversing the adverse sex ratio at birth observed in India.

\section{The PCPNDT Act}

Legislation to prevent gender-biased sex selection was first passed in Maharashtra in the late 1980s, namely, the Maharashtra Regulation of Pre-natal Diagnostic Techniques Act 1988 (Ministry of Health and Family Welfare, 2006). At the national level, the Pre-Natal Diagnostic Techniques (Regulation and Prevention of Misuse) Act (the PNDT Act) was passed in September 1994 and implemented in 1996 to regulate the misuse of pre-natal diagnostic techniques for the purpose of pre-natal sex determination leading to the selective termination of pregnancies carrying a female foetus (Ministry of Health and Family Welfare, 2003). The PNDT Act was amended in 2003 to both emphasise the "prohibition" of sex selection and to widen its scope to include pre-conception techniques. It was renamed the Pre-Conception and Pre-natal Diagnostic Techniques (PCPNDT) (Prohibition of Sex Selection) Act (Ministry of Health and Family Welfare, 2003). The PCPNDT Act clearly differentiates between the legal use of diagnostic techniques to detect abnormalities in the foetus, and the prohibition of its use for sex selection purposes. The PCPNDT Act is intended "to provide for the prohibition of sex selection, before or after conception, and for regulation of prenatal diagnostic techniques for the purposes of detecting abnormalities or metabolic disorders or chromosomal abnormalities or certain congenital malformations or sex-linked disorders and for the prevention of their misuse for sex determination leading to female foeticide and for matters connected therewith or incidental thereto."

Under the PCPNDT Act, a number of statutory authorities were set up at the central, state and district levels (Singh, 2013). At the national level, the Central Supervisory Board is responsible for policy matters, review and oversight of implementation, and the development of the code of conduct. Also at the national level is the National Inspection and Monitoring Committee constituted by representatives from the Department of Women and Child Development, the National Commission for Women and the Indian Council of Medical Research; the role of this Committee is to assess ground realities through field visits to monitor the implementation of the Act in all states. Also intended to support the implementation of the PCPNDT Act is the Support and Monitoring Cell established by the government with assistance from the United Nations Population Fund (UNFPA); this Cell is responsible for capacity building of appropriate authorities at the district level.

At the state level, the State Supervisory Board is responsible for creating awareness about the Act, reviewing the appropriate authority's activities at state and district levels, monitoring implementation, and sending reports to the Central Supervisory Board. Membership of these State Supervisory Boards comprises government officials, specialists, medical practitioners and representatives of nongovernmental organisations (NGOs). Also at the state level are the State Appropriate Authority (SAA) and State Advisory Committee. While the SAA is responsible for implementing the Act at the state level, investigating complaints and filing of court cases, the State Advisory Committee serves as an advisor to the SAA in implementing the Act, providing advice on the registration of clinics, inspections and court complaints.

Similar structures are also available at the district level namely, the District Appropriate Authority (DAA), working under the advice of the District Advisory Committee. The DAAs implement the Act at the district level. Its responsibilities include the registration of clinics, investigation of cases about which a complaint is received, and filing of court cases at the district level. The District Advisory Committee serves as an advisory body, performing similar responsibilities as the State Advisory Committee, at the district level. At present, it is the Chief Medical Officer or the Civil Surgeon of a district who is designated as the Appropriate Authority for the district, and an officer of or above the rank of Joint Director in the Department of Health and Family Welfare as the Appropriate Authority for each State. Appropriate Authorities (both at the state and district levels) have the power of 
a civil court in such activities as conducting searches and seizures, and sealing machines, equipment and records of those violating the rules.

Several restrictions are imposed through the PCPNDT Act: for example, all genetic counselling centres must be registered under the Act; the sale of ultrasonography or imaging machines may only be made to facilities registered under the Act; all those conducting ultrasonography must declare that he or she has not disclosed the sex of the foetus to anyone; all those undergoing any such testing must declare that they do not wish to know the sex of the foetus, and all facilities are expected to prominently declare in writing that disclosure of the sex of the foetus is prohibited under the law. All facilities may be inspected for violations from time to time, and the authorised officer is empowered to seize equipment and seal facilities that violate the Act. Appropriate Authorities are empowered to suspend or cancel the registration of a facility without issuing a show cause notice if they perceive that it is necessary to do so in the public interest (Singh, 2013). While the PCPNDT Act is aimed at curbing sex selection through the misuse of technology, it must be emphasised that the Act in no way affects women's right to terminate a pregnancy in a host of conditions, as reflected in the Medical Termination of Pregnancy (MTP) Act of 1971 (Government of India, 1971).

The PCPNDT Act sets up a number of penalties aside from the suspension or cancellation of the registration of a clinic that the Appropriate Authority has reason to believe has violated the law. A person or organisation that advertises facilities for pre-natal sex determination faces three years imprisonment and a fine of Rs 10,000. If a medical officer, owner or employee of any clinic contravenes any of the provisions of the Act, that person can be punished with imprisonment of up to three years and a fine of up to Rs 10,000; the punishment for repeat offenders is five years and a fine of up to Rs 50,000 (Ministry of Health and Family Welfare, 2006). Finally, any person who "seeks the aid" of a facility for sex determination is liable for the same punishment as is the provider; recognising that women are often coerced into obtaining sex-determination tests, the husband and/or his family are penalised in such cases (Singh, 2013; Ministry of Health and Family Welfare, 2006).

Gender-biased sex selection (unfortunately, often determined by sex-selective abortion rather than the act of disclosing the sex of the foetus) is a crime under the Indian Penal Code under its Sections 315 and 316 and as such, is recorded by the National Crime Records Bureau (NCRB) (National Crime Records Bureau, 2013).

\section{Medical Termination of Pregnancy Act (MTP) 1971 and Amendment of 2002}

Given the close link between gender-biased sex selection and sex-selective abortion, a brief description of the Medical Termination of Pregnancy (MTP) Act of 1971 (Government of India, 1971) and the 2002 Amendment to the Act (Government of India, 2003) is necessary. The MTP Act has ensured women's right to terminate an unwanted pregnancy safely and confidentially. Pregnancies of up to 20 weeks may be terminated legally. However, the concurrence of at least two physicians is required for pregnancies of more than 12 weeks' gestation. In all cases, legally, abortion services can be provided only in registered facilities and by certified providers. The Act allows women to seek pregnancy termination in a wide range of circumstances such as when the mother's life is at risk or when her physical or mental health is compromised, in case of rape, if the pregnancy is likely to result in the birth of a child with physical or mental abnormalities, and if the pregnancy is the result of contraceptive failure. Notably, the Act does not allow women to seek pregnancy termination for sex-selection purposes.

\section{Code of Medical Ethics}

Supporting the PCPNDT Act is the Code of Medical Ethics constituted by the Indian Parliament, in the Medical Council Act, 1956, and (Amendment) Acts, 1964, 1993 and 2001 (Medical Council of India, 2002). The Code of Medical Ethics underscores that "on no account shall sex- determination tests be undertaken with the intent to terminate the life of a female foetus developing in her mother's womb, unless there are other absolute indications for termination of pregnancy as specified in the Medical Termination of Pregnancy Act, 1971." It goes on to indicate that any such practice will be considered as "professional misconduct on the part of the physician leading to penal erasure besides rendering him liable to criminal proceedings as per the provisions of this Act" (Clause 7.6) and that "the penalty for unindicated sex determination and female foeticide is striking off the name from the register apart from criminal action" (Medical Council of India, 2002). 


\section{Towards gender equality: key policies}

While the PCPNDT Act specifically targets the practice of gender-biased sex selection, India has a range of policies and laws that are intended to create a supportive environment for girls and women, and promote the narrowing of disparities between males and females, and thereby indirectly, reduce the practice of gender-biased sex selection.

Key policies that have an indirect bearing on reducing disparities between girls and boys, and women and men include the National Youth Policy, 2003 (Ministry of Youth Affairs and Sports, 2003), the recently passed National Youth Policy, 2014 (Ministry of Youth Affairs and Sports, 2014), and the National Policy for the Empowerment of Women, 2001 (Ministry of Women and Child Development, 2001). For example, the National Youth Policy, 2003, and the National Youth Policy, 2014, contain a number of recommendations for promoting gender justice and equality engaging youth clubs and youth volunteers to undertake educational programmes on such issues as female foeticide, domestic violence, girls' education, and early childbearing, for example. They also articulate the importance of life skills building programmes for youth as well as a commitment to enable youth to attain high levels of education, access employment opportunities, and address gender disparity in schooling and economic opportunities. Policy recommendations include creating educational opportunities for disadvantaged youth groups, including girls; paying special attention towards making higher education vocation-oriented, and setting up networks of training institutions providing technical and/or entrepreneurship training, financial institutions, voluntary organisations and the corporate sector to promote entrepreneurship among young women and men (Ministry of Youth Affairs and Sports, 2003; 2014).

The National Policy for the Empowerment of Women, 2001, acknowledges the widespread prevalence of gender disparity and discrimination against girls and women (Ministry of Women and Child Development, 2001). Its goals are wide-ranging and include creating social and economic opportunities that enable women to realise their full potential; enabling women to enjoy human rights and fundamental freedoms on an equal basis with men; ensuring equal access to participation and decision making for women in social, economic and political spheres; ensuring equal access to healthcare, quality education, career guidance, employment and so on; strengthening legal systems to eliminate discrimination against women; changing societal attitudes, and eliminating violence against women and girls. Specific policy prescriptions include efforts to enact or change existing laws, including in the area of ownership of property and inheritance and, more directly, to empower women economically and socially by strengthening microcredit opportunities, promoting affirmative action to ensure women's participation in decision making, and ensuring equal access to education. The elimination of all forms of violence against women is a key policy prescription, encompassing such concerns as the need to eliminate sexual harassment in the workplace and the persistence of dowry and dowry-related harassment. It argues strongly for the protection of the rights of girls, including the elimination of pre-natal sex selection, female foeticide and infanticide, child marriage, child abuse and child prostitution. It also identifies adolescent girls as a vulnerable group and highlights the need to pay attention to their education and nutrition.

The XIth and XIlth Five Year Plans set specific targets for improvements in the child sex ratio. The XIth Plan aimed to increase the child (0-6) sex ratio from 927 in 2001 to 935 by 2011-12; as seen earlier, the child sex ratio actually worsened in the decade 2001 to 2011 (Planning Commission, 2008). The Xllth Five Year Plan (2012-2017) noted that the decline in the child sex ratio is "an exceptionally worrying factor." It aims to raise the child sex ratio to 950; it has identified improvement in the child sex ratio as an issue in need of priority attention, and called for special attention to strengthening the implementation of the PCPNDT Act (Planning Commission, 2013). The XIIth Plan recognises that programmes must ensure women's basic entitlements, prioritise the education of girls and the economic empowerment of women, ensure that child marriages are eliminated, that women are free from all forms of violence and are adequately represented in political and policy-making spheres. It also calls for the establishment of a High Level Inter-ministerial Committee for the care and protection of the girl child, and a Girl Child Specific District Plan of Action that will focus on enhancing the status of girls (Planning Commission, 2013).

\section{Towards gender equality: key laws}

There are also a number of laws in India that have relevance, directly or indirectly, for narrowing gender role disparities and addressing women's empowerment. There are several laws for example, that aim to promote gender 
equality in terms of girls' rights within the family and reduce perceptions of daughters as a liability, and thereby indirectly affect son preference. The Dowry Prohibition Act, 1961, is one such Act that forbids the giving or taking of dowry or even abetting the giving or taking of dowry. It imposes such penalties for violation as imprisonment for five years and a fine equivalent to the value of the dowry; unfortunately, loopholes in the law have resulted in its indifferent implementation (Ministry of Women and Child Development, n.d., a; Singh, 2013).

The Hindu Succession (Amendment) Act, passed in 2005, legalises the right of daughters to inherit property in the same way as sons; it expands the rights of a married or unmarried daughter, and makes them equal to those of a son. As such, a daughter has the same rights and liabilities in the family property as a son; she is equally liable for debts of the joint family, and is equally entitled to dispose of her share of the property (Lawyers Collective Women's Rights Initiative, n.d.; Deininger, Goyal and Rangarajan, 2010; Agarwal, 2005). Additionally, the Maintenance and Welfare of Parents and Senior Citizens Act, passed in 2007, places the responsibility of caring for elderly parents, including in terms of food, shelter, health care and so on, on both sons and daughters, reducing perhaps parental perceptions about the inability of daughters to provide old age support (Ministry of Law and Justice, 2007).

Other Acts are also intended to promote women's rights. For example, the Child Marriage Restraint Act of 1929 (Ministry of Women and Child Development, n.d., b) and the Child Marriage Restraint Act of 1978 (Ministry of Women and Child Development, n.d., c) that prohibit the marriage of a girl before she reaches age 18 and of a boy before he reaches age 21. The more recent Prohibition of Child Marriage Act, 2006, has considerably strengthened legislation, placed stronger penalties on violations and called for activities to sensitise communities about early marriage (Ministry of Law and Justice, 2007a).

The Right of Children to Free and Compulsory Education Act, 2009, places responsibility on the state to ensure free and compulsory enrolment as well as regular attendance and completion of elementary school, and thereby has a significant role to play in ensuring that girls gain at least a primary education (Ministry of Human Resource Development, 2011). The Act also places responsibility on parents for ensuring that their daughters and sons are enrolled in an appropriate elementary school and remain in school until they have completed Class VIII.

The Women's Reservation Bill (The Constitution $108^{\text {th }}$ Amendment Bill), 2008, Amendments to the Constitution have focused more on ensuring greater participation of women in political processes. The $73^{\text {rd }}$ and $74^{\text {th }}$ Constitutional Amendments, passed in 1993, reserve one-third of all seats in Panchayats and municipal bodies for women. More recently, in 2010, the Women's Reservation Bill was passed by way of the $108^{\text {th }}$ Amendment to the Indian Constitution, by the Rajya Sabha, but is still to be passed in the Lok Sabha. This amendment reserves one-third of all seats in the parliament and in state legislative bodies for women. The Bill is to be effective for 15 years once passed, and aims to reduce gender disparities in representation at the state and national levels (Rajya Sabha, 2010).

A number of laws have focused on enabling women to gain greater exposure in the public domain. The Protection of Women against Sexual Harassment at Workplace Bill, 2010, seeks to ensure a safe environment for women at workplaces, both in public and private sectors, whether organised or unorganised (Press Information Bureau, 2010). The Bill proposes a definition of sexual harassment which is as laid down in the Vishaka judgment by the Supreme Court (any unwelcome sexually determined behaviour, including physical contacts and advances, a demand or request for sexual favours, sexually coloured remarks, showing pornography and any other unwelcome physical, verbal or non-verbal conduct of sexual nature). Additionally, it recognises the promise or threat to a woman's employment prospects or creation of a hostile work environment as "sexual harassment" at the workplace. The Bill provides protection not only to women who are employed but to any woman who enters the workplace as a client, customer, apprentice, daily wageworker, or in an ad-hoc capacity.

Laws have also been strengthened that address violence against women and girls. A recent amendment to the criminal law, namely, the Criminal Law (Amendment) Act, 2013, expanded the definition of sexual violence against women from a focus only on rape and vaginal penetration to such other acts of violence, such as, for example, acid attacks, sexual harassment, voyeurism, stalking, and trafficking of persons for commercial sexual exploitation. The Amendment has also stipulated a much greater quantity of punishment for offenders of sexual violence than did the original Bill. (Ministry of Law and Justice, 2013). 


\section{Laws and policies on limiting family size}

Finally, certain laws and policies that have focused on excluding individuals with more than two children from public office, and/or certain entitlements have been argued to have potential for enhancing gender discrimination and encouraging gender-biased sex selection (Buch, 2005; Anukriti and Chakravarty, 2014). For example, laws were enacted by state governments in the late 1990s and 2000s restricting political eligibility to candidates with two or less children. During this period, some 11 states passed laws disqualifying persons with more than two children from contesting Panchayat elections (although later, some states repealed this law). While clearly a violation of rights, the link of this law to gender-biased sex selection is unclear. ${ }^{3}$

\footnotetext{
${ }^{3}$ While the potential for this law to have affected gender-biased sex selection exists, evidence about this link remains slim. Evidence from a study using data from various rounds of the NFHS and District-Level Household Survey (DLHS) suggests a marked decline in the number of women in the general population reporting third births one year after the new policy was announced; it was also associated with a worsening of the sex ratio in these states, particularly among general caste and better off families whose first child was a daughter (Anukriti and Chakravarty, 2014). A study of policy makers, civil society representatives and disqualified candidates suggests, moreover, that many community members seemed to weigh the number and sex composition of children against the elected position in the village, with the importance of having a son outweighing concerns about disqualification, and elected husbands making their wife undergo an abortion if she is carrying a female foetus (Visaria, Acharya and Raj, 2006). At the same time, evidence suggests a secular decline in family size preferences and a convergence towards a two-child preference, along with unchanged preferences for at least one son (see, for example, John et al., 2008).
} 


\section{Chapter 3}

\section{Trends and geographic variation in the sex ratio at birth and the child sex ratio}

As mentioned earlier, in India the sex ratio is conventionally expressed in terms of females per 1,000 males. A normal sex ratio at birth is thus 952 female births to 1,000 male births and a fall in the ratio is interpreted as a shift towards masculinity or, in other words, a decline in the number of girls compared to the number of boys. Data on the sex ratio come from a number of sources such as the Census, the Sample Registration System (SRS), the Civil Registration System (CRS), and national surveys including the NFHSs and DLHSs. However, not all sources report both the sex ratio at birth and the child sex ratio, and not all provide data at the sub-national level or for all geographic regions. For example, the Census reports data on the child sex ratio but not on the sex ratio at birth, and the SRS and the CRS report data on the sex ratio at birth nationally. In this chapter we explore trends over time in the sex ratio at birth and the juvenile or child sex ratio (ages 0-6), and describe differentials by geography, as available. We also highlight the hotspots, that is, states and districts reporting low sex ratios.

\section{Trends in sex ratios at birth and among children}

India has long experienced an adverse population sex ratio, widely attributed to excess female mortality arising from discrimination against women and girls in feeding and health care (see, for example, Visaria, 1971; Caldwell and Caldwell, 2005; United Nations Population Fund, 2012). Indeed, the sex ratio of India's population actually worsened through the twentieth century, reaching a low of 930 females per 1,000 males in 1971 and 927 females per 1,000 males in 1991 (Table 3.1). While only marginal progress was seen in 2001 (933 females per 1,000 males), substantial improvement was reported in the 2011 Census (943 females per 1,000 males), an improvement largely attributed to recent gains in adult female mortality as a result of enhancing maternal health in the country. It may be noted that despite recent improvements in the population sex ratio, the current level is still more masculine than what is observed globally (Kulkarni, 2014).

\section{National trends}

While the overall sex ratio of the population has somewhat improved, the child sex ratio (ages 0-6), has become more unbalanced over the last three decades than ever before. As seen from Table 3.1, the child sex ratio fell drastically from 962 girls per 1,000 boys in 1981 to 945,927 , and 918 girls per 1,000 boys in the three successive Censuses of 1991, 2001, and 2011, respectively. These figures indicate some slowing down in the rate of decline in the child sex ratio, from a 17-18 point decline in the 1981-1991 and 1991-2001 decades to a nine point decline over the 2001-2011 decade.

Table 3.1: Trends in the child sex ratio, India, 1951-2011

\begin{tabular}{llc}
\hline \multirow{2}{*}{ Year } & \multicolumn{2}{c}{ Females per 1,000 males } \\
\cline { 2 - 3 } & All ages & Ages 0-6 \\
\hline 1951 & 946 & 983 \\
1961 & 941 & 976 \\
1971 & 930 & 964 \\
1981 & 934 & 962 \\
1991 & 927 & 945 \\
2001 & 933 & 927 \\
2011 & 943 & 918 \\
\hline
\end{tabular}

Source: UN Women, 2014.
As mentioned earlier, the worsening of the sex ratio in the $0-6$ age group may be attributed largely to the growing imbalance in the sex ratio at birth, for which there is evidence from the SRS (Figure 3.1). Estimates of three-year moving averages for India, drawn from SRS data (sampling errors for annual estimates are large and hence not reliable), suggest a secular decline in the sex ratio at birth between the early 1980 s and the mid-1990s, followed by a decade in which the sex ratio at birth hovered between 879 and 901 , reaching a low of 880 in 2005. Subsequently, it improved moderately, the 2012 SRS annual report showing a modest increase (901-908) in the sex ratio at birth to 908 during the period 2010-2012. 
Figure 3.1: Sex ratio at birth, three-year moving averages (females per 1,000 males), India, SRS, 1984-2012

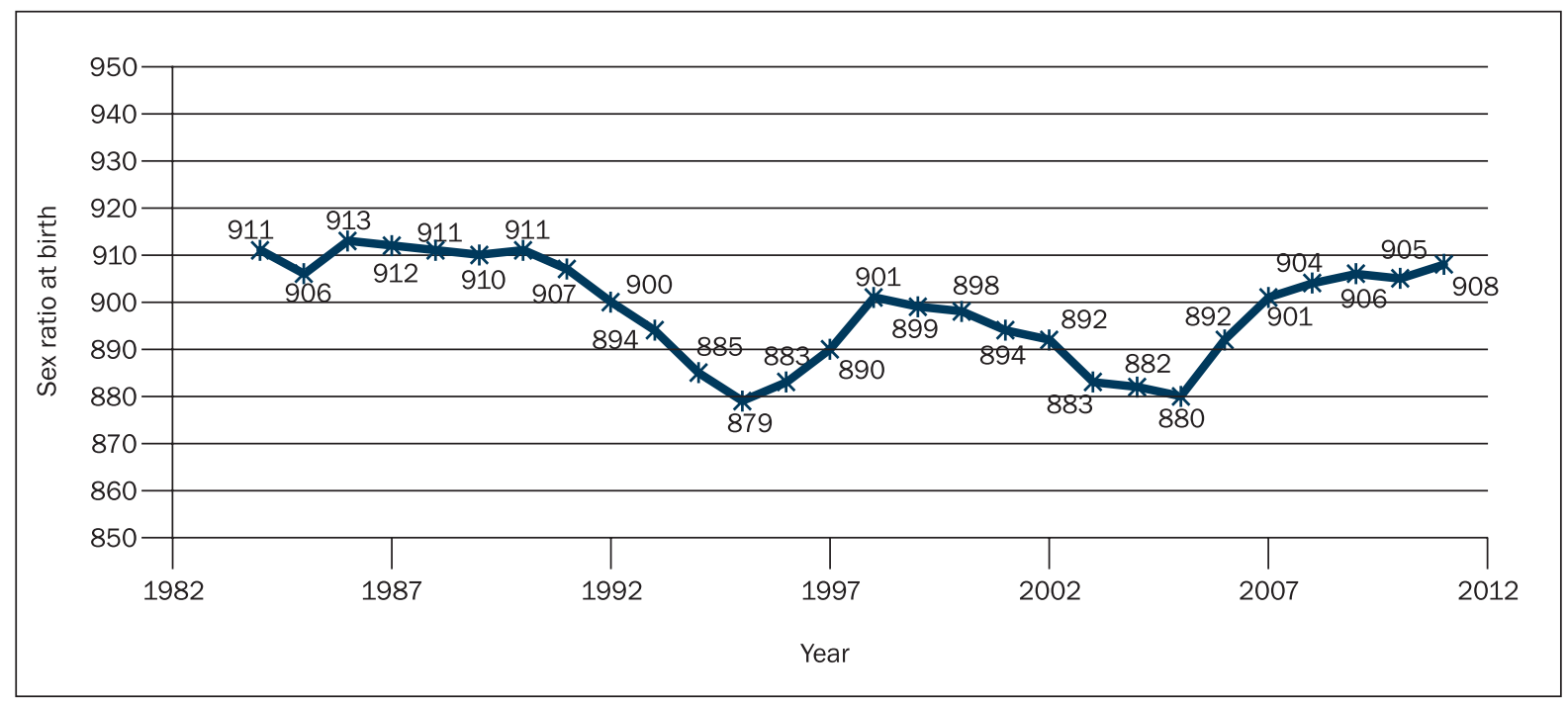

Source: Kulkarni, 2014.

Using male and female child survival probabilities obtained from life tables constructed from SRS data on agespecific death rates for the period 2004-2010, and applying the procedure of reverse survival, the sex ratio of 918 at ages 0-6 reported in the 2011 Census yields a sex ratio at birth of 923 for the cohort born during the sevenyear period prior to the 2011 Census (Kulkarni, 2014). Assuming a normal sex ratio at birth of 952, it is estimated that over 600,000 female births did not take place each year in the period 2001-2007 because of pre-natal sex selection, accounting for 4.8 per cent of all female births (United Nations Population Fund, 2010).

\section{Regional trends: state-level variation}

State-level variation in the child sex ratio and the sex ratio at birth is wide. In general, the ratios are most adverse in the north-western states and most 'normal' in the southern states (Bhat and Zavier, 2007; Jha et al., 2011; Kumar and Sathyanarayana, 2012; Bongaarts, 2013; United Nations Population Fund, 2010).

Indeed, the two states recording the lowest child sex ratios in 2011 (under 850 females per 1,000 males) are Haryana (834) and Punjab (846). A number of other major states have also recorded adverse child sex ratios. For example, as evident from Table 3.2, in 2011, there were six other states with child sex ratios below 900 per 1,000 males and they include, apart from Punjab and Haryana, Jammu and Kashmir (862), Delhi, (National Capital Territory, NCT) (871), Rajasthan (888), Gujarat (890), Uttarakhand (890) and Maharashtra (894). There are, in contrast, some states that show no signs of distortion in their child sex ratios. For example, the child sex ratio in 2011 was above 950 in four states West Bengal (956), Assam (962), Kerala (964) and Chhattisgarh (969)-and between 940 and 950 in four states-Odisha (941), Tamil Nadu (943), Jharkhand (948) and Karnataka (948).

The statewise picture with regard to the sex ratio at birth is similar (Table 3.2). Haryana and Punjab record extremely adverse sex ratios at birth, namely, 857 and 863 females per 1,000 males, respectively. Other states with substantially adverse sex ratios at birth (less than 900) include Uttar Pradesh (874), Delhi (NCT) (884), Rajasthan (893), Jammu and Kashmir (895) and Maharashtra (896). In eleven other states, sex ratios at birth range from 901 to 950 (Andhra Pradesh, Assam, Bihar, Gujarat, Himachal Pradesh, Jharkhand, Madhya Pradesh, Odisha, Tamil Nadu, Karnataka, and West Bengal). In contrast, in such states as Kerala (966) and Chhattisgarh (979), sex ratios at birth have exceeded 952.

Figure 3.2 and Figure 3.3 present trends in child sex ratios and sex ratios at birth, respectively. Between the three decadal censuses (1991-2011) for which child sex ratios are available, Figure 3.2 shows a clear shift among states from near normalcy to severely adverse child sex ratios. For example, in the year 1991, only two states-Punjab and Haryana-had child sex ratios below the 900 mark but above 850, while in 14 other major states child sex ratios 
Table 3.2: Child sex ratio, 2011, and sex ratio at birth, 2010-2012, major states, India

\begin{tabular}{lcc}
\hline State & $\begin{array}{c}\text { Child sex ratio, } \\
\mathbf{2 0 1 1}\end{array}$ & $\begin{array}{c}\text { Sex ratio at birth, } \\
\mathbf{2 0 1 0 - 2 0 1 2}\end{array}$ \\
\hline Andhra Pradesh & 939 & 914 \\
Assam & 962 & 922 \\
Bihar & 935 & 909 \\
Chhattisgarh & 969 & 979 \\
Delhi (NCT) & 871 & 884 \\
Gujarat & 890 & 909 \\
Haryana & 834 & 857 \\
Himachal Pradesh & 909 & 939 \\
Jammu and Kashmir & 862 & 895 \\
Jharkhand & 948 & 918 \\
Karnataka & 948 & 950 \\
Kerala & 964 & 966 \\
Madhya Pradesh & 918 & 921 \\
Maharashtra & 894 & 896 \\
Odisha & 941 & 948 \\
Punjab & 846 & 863 \\
Rajasthan & 888 & 893 \\
Tamil Nadu & 943 & 928 \\
Uttarakhand & 890 & NA \\
Uttar Pradesh & 902 & 874 \\
West Bengal & 956 & 944 \\
\hline
\end{tabular}

NCT = National Capital Territory. NA: Not available.

Source: Office of the Registrar General and Census Commissioner, India, 2013; Office of the Registrar General, India, $2013 a$. were 950 or above. By 2001, the child sex ratio had fallen below 900 in as many as five states (Delhi (NCT) Gujarat, Haryana, Himachal Pradesh and Punjab), with Haryana and Punjab moving further down below 850. Compared to 14 states in 1991, only six states had child sex ratios above 950 in 2001.

In the most recent Census in 2011, the distribution of states with a child sex ratio below 900 changed considerably-now, as many as eight states were in this group, including Punjab, Delhi (NCT), Gujarat, Haryana, Punjab, as in 2001, and several additional states, namely, Jammu and Kashmir, Maharashtra, Rajasthan and Uttarakhand. Only four states-Assam, Chhattisgarh, Kerala and West Bengalrecorded a child sex ratio above the 950 mark. Although states have shown a declining trend of the child sex ratio over the years, some states showed an upward shift over the decade 2001-2011. For example, Punjab gained 48 points during this period, recovering from a very low child sex ratio of 798 in 2001 to 846 in 2011; likewise, Haryana showed a 15-point increase from 819 to 834 .

When we inspect the sex ratio at birth for major states over the last decade (2002-2012) as available from the SRS, we observe that at the start of the period, during 2002-2004, as many as five states (Delhi (NCT), Haryana, Jammu and Kashmir, Punjab and Rajasthan) had sex ratios at birth below the 850 mark, with Punjab recording a sex ratio at birth even below 800. In addition, seven states (Bihar, Gujarat, Himachal Pradesh, Jharkhand, Kerala, Maharashtra and Uttar Pradesh) had sex ratios at birth between 850 and 900; Chhattisgarh was the only state in which it was over 950. By 2006-2008, the number of states with a sex ratio at birth below 850 had reduced to two (Haryana and Punjab) as Delhi (NCT), Jammu and Kashmir and Rajasthan moved up, and the number of states with a sex ratio at birth exceeding 900 also increased from eight to 12 , with Kerala joining Chhattisgarh in the 950+ group. The situation improved further over the next few years and the last available data in 2010-2012 showed that no state had a sex ratio at birth below 850 and 13 states had a sex ratio at birth of more than 900 .

\section{District-level variation in sex ratios at birth and among children: identifying hotspots}

To understand the micro-level picture we explored district-level data on the sex ratio at birth and child sex ratio. Even within states, sex ratios at birth vary. District-level estimates of the "implied sex ratio at birth" drawn from the 2011 Census for the period 2004-2010 suggest that the "implied sex ratio at birth" ${ }^{4}$ range from 783 to 1060 (Kumar and Sathyanarayana, 2012). Table 3.3 and Table 3.4 present the distribution of districts by levels of sex ratio at birth (2004-2010) and child sex ratio (2011), respectively.

\footnotetext{
${ }^{4}$ Kumar and Sathyanarayana (2012) used data from the Census 2011 to estimate district-level "implied sex ratios at birth" for the 2004-2010 period, using the reverse survival method. These estimates, however, do not match with SRS estimates for comparable years. In fact, for 13 out of 29 states, the implied sex ratio at birth was estimated to be higher than SRS estimates. This is due to large confidence intervals associated with estimates of implied sex ratios at birth.
} 
District-level analysis shows that in about 25 percent of India's 640 districts, the "implied" sex ratio at birth was lower than 900 in 2011. Moreover, about 35 of these districts were below the 850 mark (Kumar and Sathyanarayana, 2012). As observed earlier, at the state level, hotspots include districts in the north-western states, notably Delhi (NCT), Haryana, Jammu and Kashmir, Punjab, Rajasthan, Uttarakhand and Uttar Pradesh, as well as the western state of Gujarat. Districts with the most adverse sex ratios at birth were located in Haryana namely, in Jhajjar (783), Rewari (788) and Mahendragarh (789). Samba (794) in Jammu and Kashmir also recorded an "implied sex ratio at birth" below 800. Additionally, eight districts from Punjab and two districts from Rajasthan reported "implied sex ratios at birth" in the range of 800-849. The eastern part of the country that is not currently affected by the problem of sex selection contains a few hotspots as well-for example, the coastal districts of Odisha, namely, Aungul, Dhenkanal and Nayagarh (sex ratio at birth <850).

Figure 3.2: Trend in the child sex ratio of major states, India, 1991, 2001 and 2011
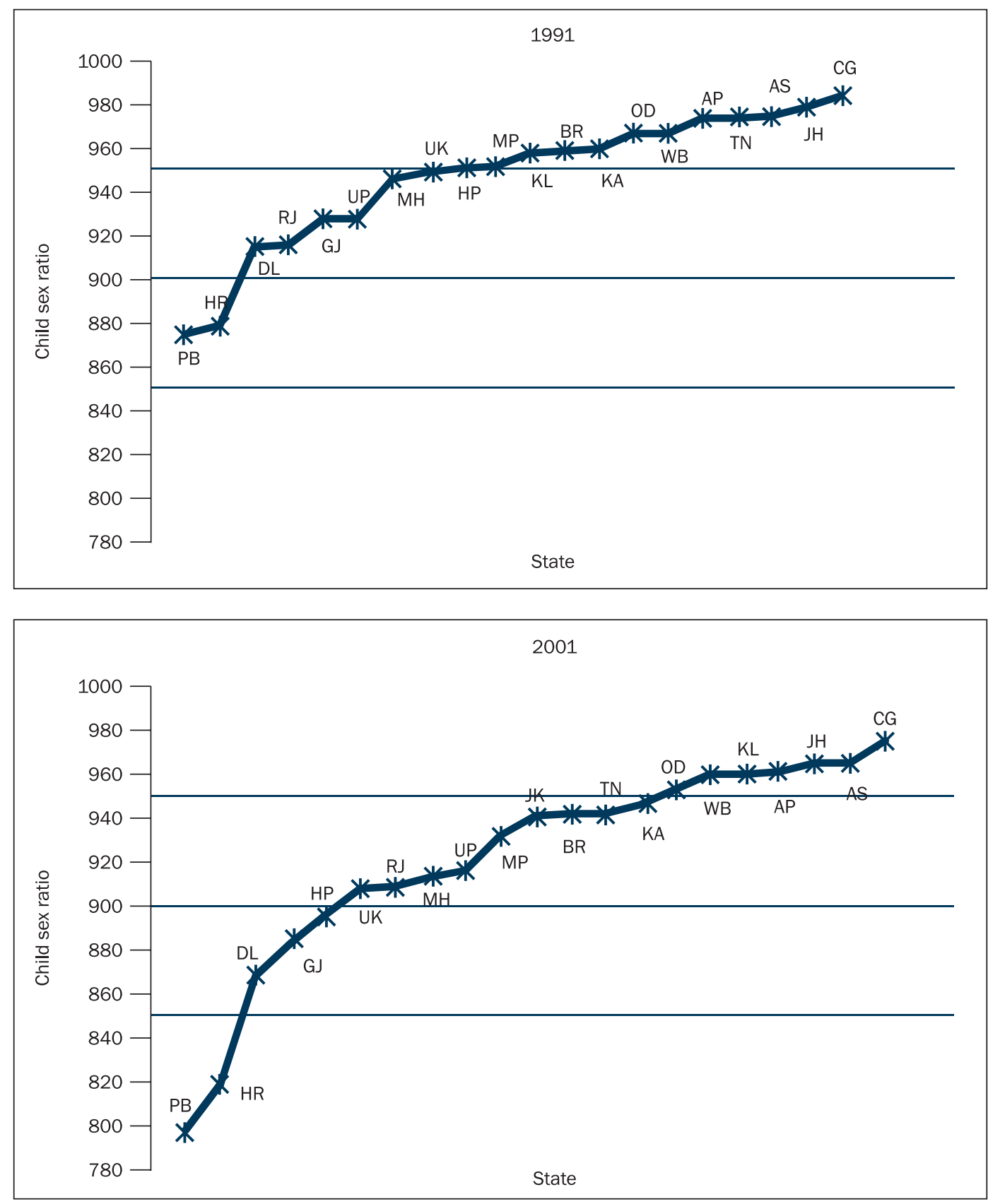


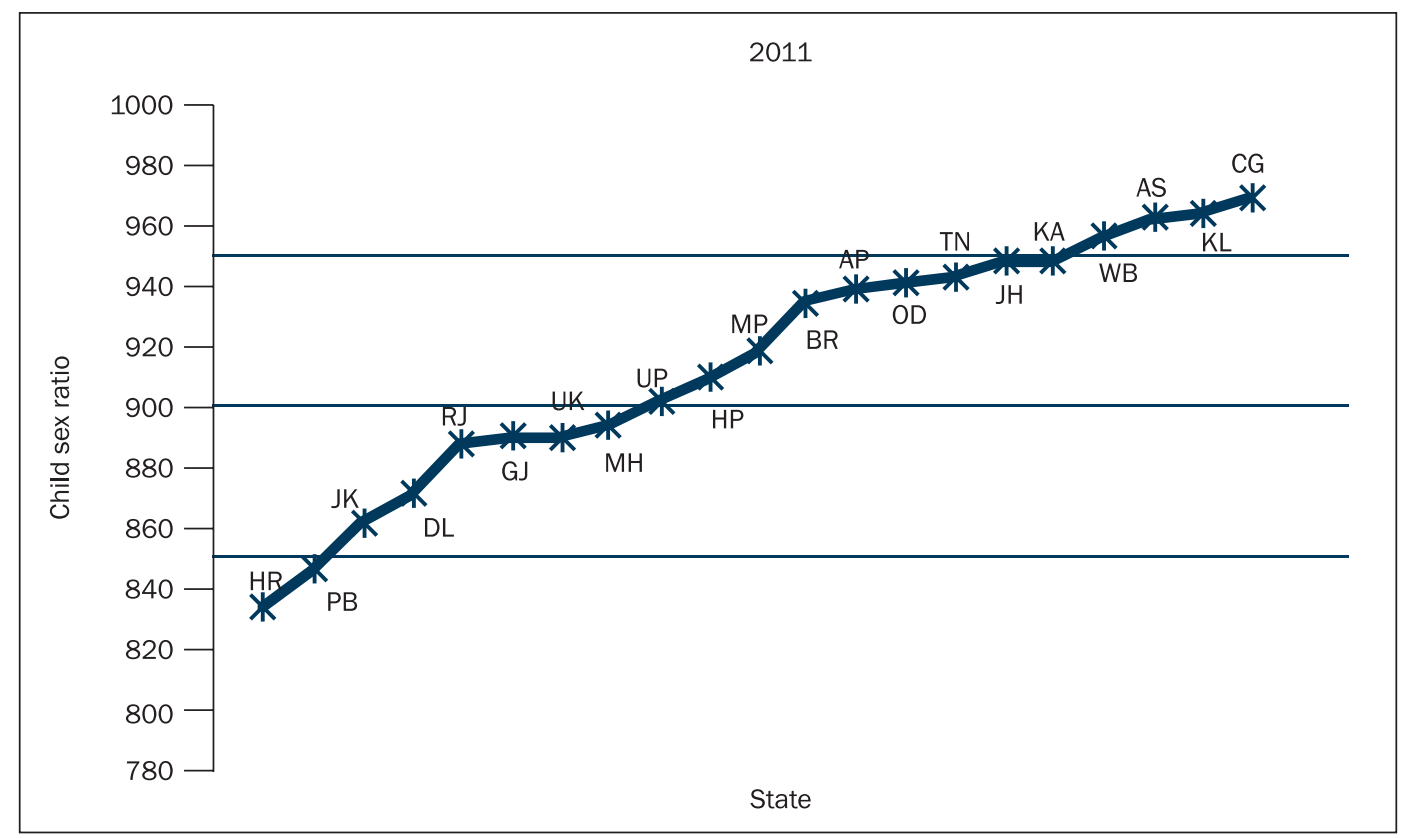

Source: Office of the Registrar General and Census Commissioner, India, 2004; 2013.

Note: AS: Assam; AP: Andhra Pradesh; BR: Bihar; CG: Chhattisgarh; DL: Delhi (NCT); GJ: Gujarat; HR: Haryana; HP: Himachal Pradesh; JK: Jammu and Kashmir; JH: Jharkhand; KA: Karnataka; KL: Kerala; MP: Madhya Pradesh; MH: Maharashtra; OD: Odisha; PB: Punjab; RJ: Rajasthan; TN: Tamil Nadu; UK: Uttarakhand; UP: Uttar Pradesh; WB: West Bengal.

NCT $=$ National Capital Territory.

Figure 3.3: Trend in the sex ratio at birth of major states, India, 2002-2004, 2006-2008 and 2010-2012

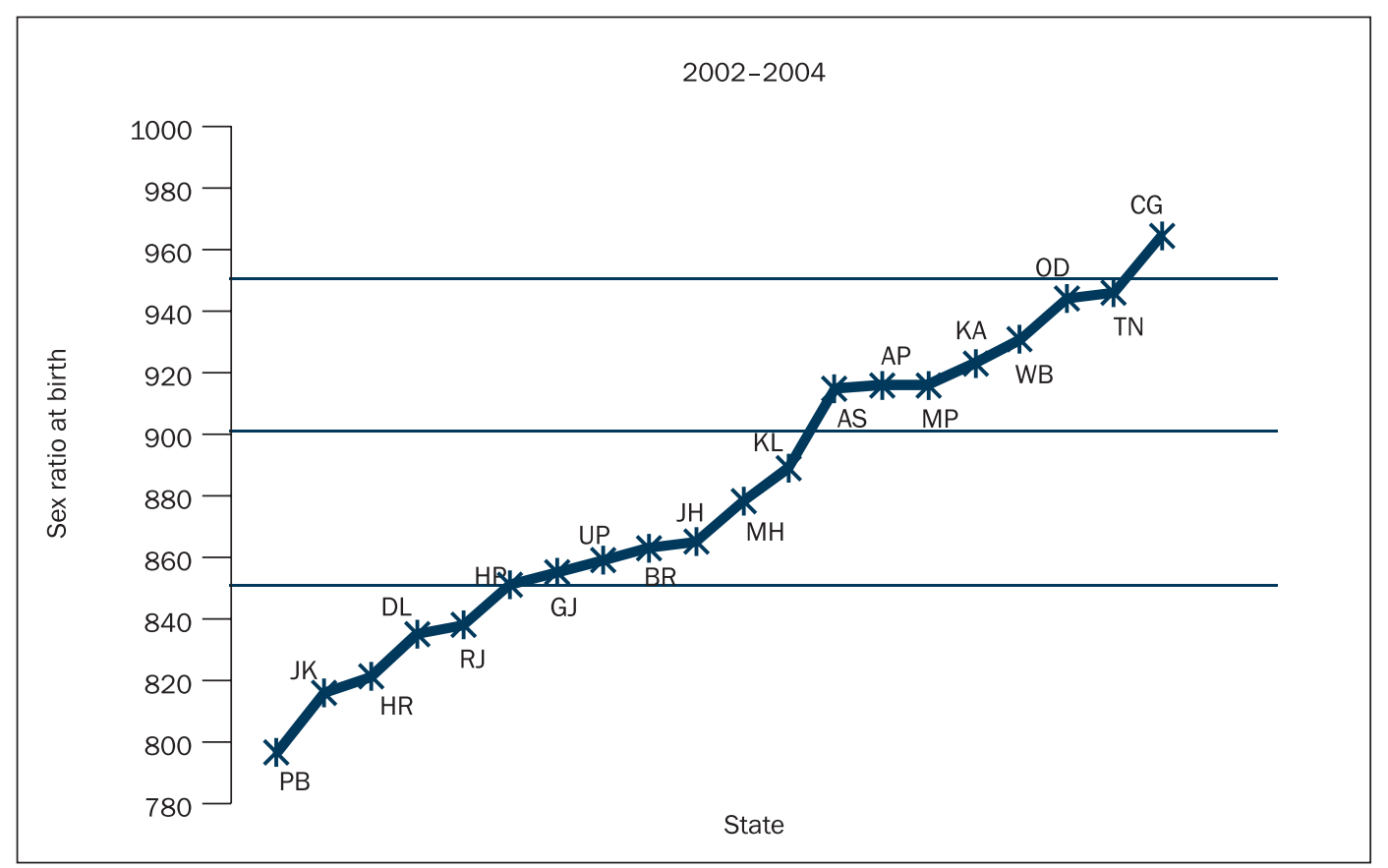



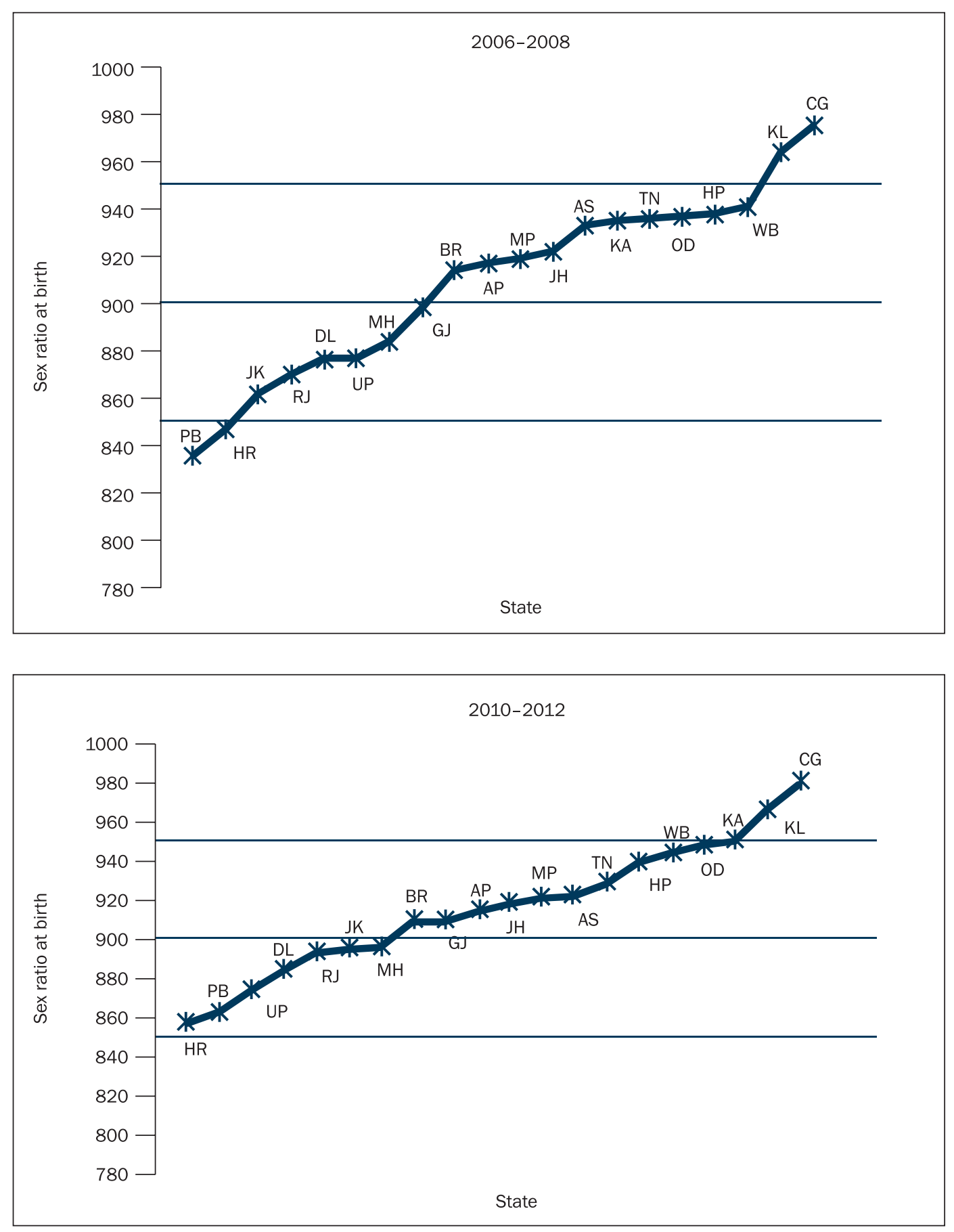

Source: Office of the Registrar General, India, 2006; 2009; $2013 a$.

Note: AS: Assam; AP: Andhra Pradesh; BR: Bihar; CG: Chhattisgarh; DL: Delhi (NCT) ; GJ: Gujarat; HR: Haryana; HP: Himachal Pradesh; JK: Jammu and Kashmir; JH: Jharkhand; KA: Karnataka; KL: Kerala; MP: Madhya Pradesh; MH: Maharashtra; OD: Odisha; PB: Punjab; RJ: Rajasthan; TN: Tamil Nadu; UP: Uttar Pradesh; WB: West Bengal.

NCT $=$ National Capital Territory. 


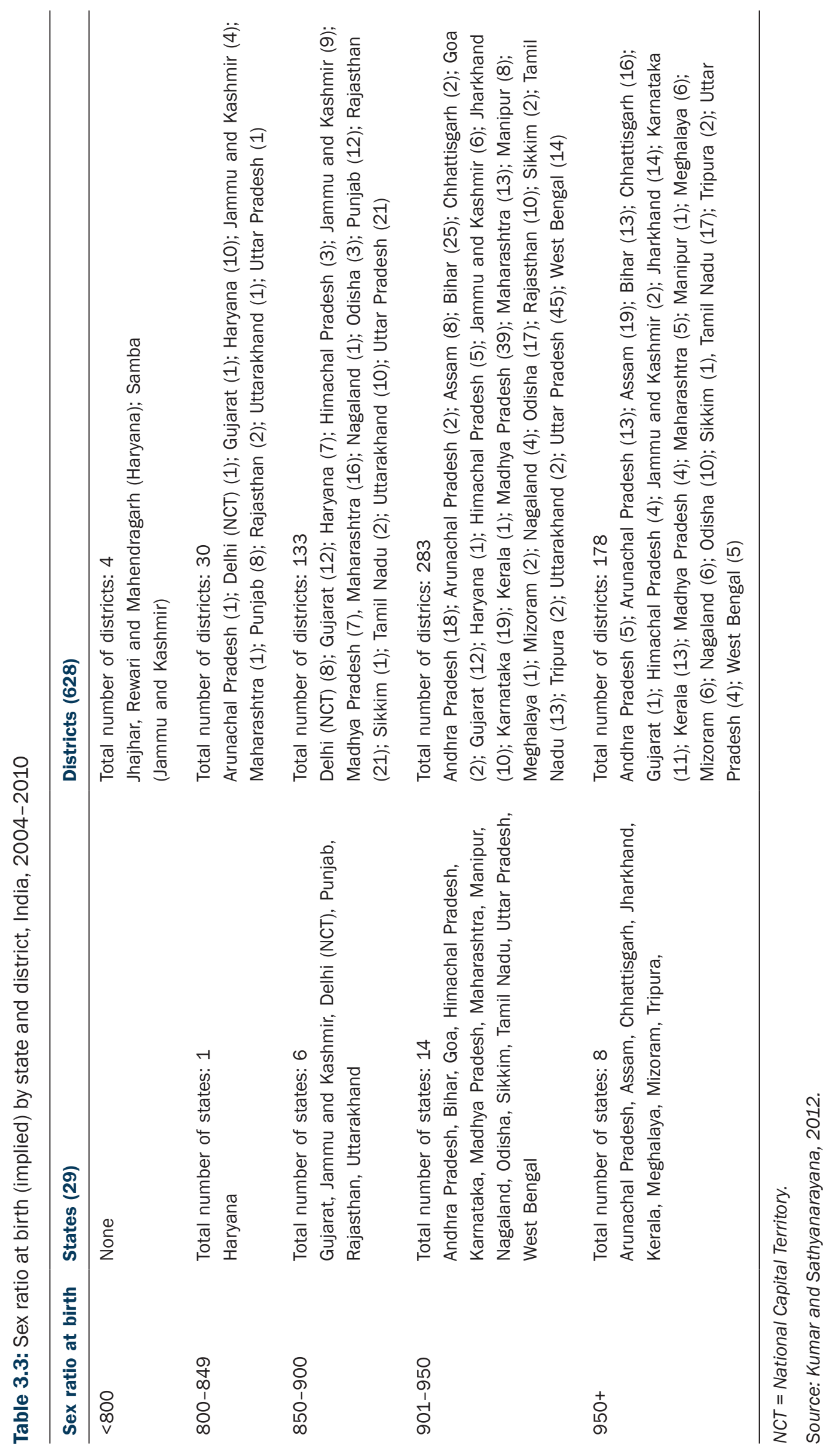


Table 3.4: Child sex ratio by state and district, 2011

\begin{tabular}{|c|c|c|}
\hline Child sex ratio & States (29) & Districts (628) \\
\hline$<800$ & None & $\begin{array}{l}\text { Total number of districts: } 6 \\
\text { Jhajhar, Rewari, Mahendragarh, Sonipat (Haryana); Samba, Jammu (Jammu } \\
\text { and Kashmir) }\end{array}$ \\
\hline $800-849$ & $\begin{array}{l}\text { Total number of states: } 2 \\
\text { Haryana and Punjab }\end{array}$ & $\begin{array}{l}\text { Total number of districts: } 52 \\
\text { Arunachal Pradesh (1); Delhi (NCT) (1); Gujarat (3); Haryana (13); Jammu } \\
\text { and Kashmir (5); Madhya Pradesh (3); Maharashtra (7); Punjab (11); } \\
\text { Rajasthan (3); Uttarakhand (1); Uttar Pradesh (4) }\end{array}$ \\
\hline $850-900$ & $\begin{array}{l}\text { Total number of states: } 6 \\
\text { Gujarat, Jammu and } \\
\text { Kashmir, Maharashtra, } \\
\text { Delhi (NCT), Rajasthan, } \\
\text { Uttarakhand }\end{array}$ & $\begin{array}{l}\text { Total number of districts: } 138 \\
\text { Bihar (2), Delhi (NCT) (7); Gujarat (13); Haryana (3); Himachal Pradesh (5); } \\
\text { Jammu and Kashmir (9); Madhya Pradesh (8); Maharashtra (14); Nagaland } \\
\text { (2); Odisha (4); Punjab (9); Rajasthan (21); Sikkim (1); Tamil Nadu (2); } \\
\text { Tripura (2); Uttarakhand (9); Uttar Pradesh (29) }\end{array}$ \\
\hline $901-950$ & $\begin{array}{l}\text { Total number of states: } 13 \\
\text { Andhra Pradesh, Bihar, } \\
\text { Goa, Himachal Pradesh, } \\
\text { Jharkhand, Karnataka, } \\
\text { Madhya Pradesh, Manipur, } \\
\text { Nagaland, Odisha, Sikkim, } \\
\text { Tamil Nadu, Uttar Pradesh }\end{array}$ & $\begin{array}{l}\text { Total number of districs: } 263 \\
\text { Andhra Pradesh (15); Arunachal Pradesh (3); Assam (5); Bihar (29); } \\
\text { Chhattisgarh (2); Delhi (NCT) (1); Goa (2); Gujarat (9); Haryana (1); } \\
\text { Himachal Pradesh (4); Jammu and Kashmir (5); Jharkhand (12); Karnataka } \\
\text { (19); Kerala (2); Madhya Pradesh (34); Maharashtra (13); Manipur (9); } \\
\text { Mizoram (2); Nagaland (3); Odisha (15); Rajasthan (9); Sikkim (3); Tamil } \\
\text { Nadu (12); Tripura (2); Uttarakhand (3); Uttar Pradesh (36); West Bengal } \\
\text { (13) }\end{array}$ \\
\hline $950+$ & $\begin{array}{l}\text { Total number of states: } 8 \\
\text { Arunachal Pradesh, Assam, } \\
\text { Chhattisgarh, Kerala, } \\
\text { Meghalaya, Mizoram, } \\
\text { Tripura, West Bengal }\end{array}$ & $\begin{array}{l}\text { Total number of districts: } 169 \\
\text { Andhra Pradesh (8); Arunachal Pradesh (12); Assam (22); Bihar (7); } \\
\text { Chhattisgarh (16); Gujarat (1); Himachal Pradesh (3); Jammu and Kashmir } \\
\text { (1); Jharkhand (12); Karnataka (11); Kerala (12); Madhya Pradesh (5); } \\
\text { Maharashtra (1); Meghalaya (7); Mizoram (6); Nagaland (6); Odisha (11); } \\
\text { Tamil Nadu (18); Tripura (2); Uttar Pradesh (2); West Bengal (6) }\end{array}$ \\
\hline
\end{tabular}

NCT $=$ National Capital Territory.

Source: Office of the Registrar General and Census Commissioner, India, n.d.

Evidence suggests that districts with low sex ratios at birth and low child sex ratios tend to be contiguous, a finding highlighted by other researchers (John, 2011; John et al., 2008; Oliveau and Guilmoto, 2005; Kumar and Sathyanarayana, 2012). In these instances, there seems to be an epicentre of very low sex ratio at birth with surrounding districts following the pattern, indicating a diffusion effect of the low sex ratio at birth to adjoining districts. For example, in Maharashtra, the district of Beed has an implied sex ratio at birth lower than 850 and may be said to lie at the centre of the surrounding districts with similar levels of sex ratio at birth.

Recent data from the third round of the Annual Health Survey conducted in 284 districts of nine Empowered Action Group states (Assam, Bihar, Chhattisgarh, Jharkhand, Madhya Pradesh, Odisha, Rajasthan, Uttarakhand, and Uttar Pradesh) indicate that over the three-year period 2010-2013, in 84 and 127 districts, respectively, the sex ratio at birth and child sex ratio (defined for the 0-4 age group) had shown a declining trend (Office of the Registrar General and Census Commissioner, India, 2014). Interestingly, as seen from Table 3.3 and Table 3.4, respectively, with the exception of Rajasthan and Uttarakhand, these states recorded normal or near normal sex ratios at birth (20042010) and among children in the 2011 Census. The recent trend of a declining sex ratio in many districts of these states could be an indication of potential areas of concern in the coming years.

Table 3.5 presents decadal changes in the child sex ratio (0-6 years) in districts of five states in which child sex ratios have been particularly skewed, as recorded in the 2001 and 2011 Censuses. It is evident from the table that 
Table 3.5: Decadal change in the child sex ratio, selected states, India, 2001 and 2011

\begin{tabular}{|c|c|c|c|c|}
\hline Sr. No. & State/District & Child sex ratio, 2001 & Child sex ratio, 2011 & Difference (2011-2001) \\
\hline & NCT of Delhi & 868 & 866 & -2 \\
\hline 1 & North West & 857 & 863 & 6 \\
\hline 2 & North & 886 & 872 & -14 \\
\hline 3 & North East & 875 & 875 & 0 \\
\hline 4 & East & 865 & 870 & 5 \\
\hline 5 & New Delhi & 898 & 884 & -14 \\
\hline 6 & Central & 903 & 902 & -1 \\
\hline 7 & West & 859 & 867 & 8 \\
\hline 8 & South West & 846 & 836 & -10 \\
\hline \multirow[t]{2}{*}{9} & South & 888 & 878 & -10 \\
\hline & Haryana & 819 & 830 & 11 \\
\hline 1 & Ambala & 782 & 807 & 25 \\
\hline 2 & Bhiwani & 841 & 831 & -10 \\
\hline 3 & Faridabad & 850 & 842 & -8 \\
\hline 4 & Fatehabad & 828 & 845 & 17 \\
\hline 5 & Gurgaon & 858 & 826 & -32 \\
\hline 6 & Hisar & 832 & 849 & 17 \\
\hline 7 & Jhajjar & 801 & 774 & -27 \\
\hline 8 & Jind & 818 & 835 & 17 \\
\hline 9 & Kaithal & 791 & 821 & 30 \\
\hline 10 & Karnal & 809 & 820 & 11 \\
\hline 11 & Kurukshetra & 771 & 817 & 46 \\
\hline 12 & Mahendragarh & 818 & 778 & -40 \\
\hline 13 & Panchkula & 829 & 850 & 21 \\
\hline 14 & Panipat & 809 & 833 & 24 \\
\hline 15 & Rewari & 811 & 784 & -27 \\
\hline 16 & Rohtak & 799 & 807 & 8 \\
\hline 17 & Sirsa & 817 & 852 & 35 \\
\hline 18 & Sonipat & 788 & 790 & 2 \\
\hline \multirow[t]{2}{*}{19} & Yamunanagar & 806 & 825 & 19 \\
\hline & Maharashtra & 913 & 883 & -30 \\
\hline 1 & Ahmadnagar & 884 & 839 & -45 \\
\hline 2 & Akola & 933 & 900 & -33 \\
\hline 3 & Amravati & 941 & 927 & -14 \\
\hline 4 & Aurangabad & 890 & 848 & -42 \\
\hline 5 & Beed & 894 & 801 & -93 \\
\hline 6 & Bhandara & 956 & 939 & -17 \\
\hline 7 & Buldana & 908 & 842 & -66 \\
\hline 8 & Chandrapur & 939 & 945 & 6 \\
\hline 9 & Dhule & 907 & 876 & -31 \\
\hline
\end{tabular}


Table 3.5: (Cont'd)

\begin{tabular}{|c|c|c|c|c|}
\hline Sr. No. & State/District & Child sex ratio, 2001 & Child sex ratio, 2011 & Difference (2011-2001) \\
\hline 10 & Gadchiroli & 966 & 956 & -10 \\
\hline 11 & Gondiya & 958 & 944 & -14 \\
\hline 12 & Hingoli & 927 & 868 & -59 \\
\hline 13 & Jalgaon & 880 & 829 & -51 \\
\hline 14 & Jalna & 903 & 847 & -56 \\
\hline 15 & Kolhapur & 839 & 845 & 6 \\
\hline 16 & Latur & 918 & 872 & -46 \\
\hline 17 & Mumbai & 922 & 874 & -48 \\
\hline 18 & Mumbai Suburban & 923 & 910 & -13 \\
\hline 19 & Nagpur & 942 & 926 & -16 \\
\hline 20 & Nanded & 929 & 897 & -32 \\
\hline 21 & Nandurbar & 961 & 932 & -29 \\
\hline 22 & Nashik & 920 & 882 & -38 \\
\hline 23 & Osmanabad & 894 & 853 & -41 \\
\hline 24 & Parbhani & 923 & 866 & -57 \\
\hline 25 & Pune & 902 & 873 & -29 \\
\hline 26 & Raigarh & 939 & 924 & -15 \\
\hline 27 & Ratnagiri & 952 & 940 & -12 \\
\hline 28 & Sangli & 851 & 862 & 11 \\
\hline 29 & Satara & 878 & 881 & 3 \\
\hline 30 & Sindhudurg & 944 & 910 & -34 \\
\hline 31 & Solapur & 895 & 872 & -23 \\
\hline 32 & Thane & 931 & 918 & -13 \\
\hline 33 & Wardha & 928 & 916 & -12 \\
\hline 34 & Washim & 918 & 859 & -59 \\
\hline \multirow[t]{2}{*}{35} & Yavatmal & 933 & 915 & -18 \\
\hline & Punjab & 798 & 846 & 48 \\
\hline 1 & Amritsar & 789 & 824 & 35 \\
\hline 2 & Bathinda & 785 & 854 & 69 \\
\hline 3 & Faridkot & 812 & 851 & 39 \\
\hline 4 & Fatehgarh Sahib & 766 & 843 & 77 \\
\hline 5 & Firozpur & 822 & 846 & 24 \\
\hline 6 & Gurdaspur & 788 & 824 & 36 \\
\hline 7 & Hoshiarpur & 812 & 859 & 47 \\
\hline 8 & Jalandhar & 805 & 874 & 69 \\
\hline 9 & Kapurthala & 784 & 872 & 88 \\
\hline 10 & Ludhiana & 816 & 865 & 49 \\
\hline 11 & Mansa & 781 & 831 & 50 \\
\hline 12 & Moga & 818 & 863 & 45 \\
\hline 13 & Muktsar & 811 & 830 & 19 \\
\hline 14 & Patiala & 776 & 835 & 59 \\
\hline
\end{tabular}


Table 3.5: (Cont'd)

\begin{tabular}{llccc}
\hline Sr. No. & State/District & Child sex ratio, 2001 & Child sex ratio, 2011 & Difference (2011-2001) \\
\hline 15 & Rupnagar & 794 & 866 & 72 \\
16 & Sangrur & 785 & 835 & 50 \\
\hline & Himachal Pradesh & $\mathbf{8 9 6}$ & $\mathbf{9 0 6}$ & $\mathbf{1 0}$ \\
\hline 1 & Bilaspur & 882 & 893 & 11 \\
2 & Chamba & 955 & 950 & -5 \\
3 & Hamirpur & 850 & 881 & 31 \\
4 & Kangra & 836 & 873 & 37 \\
5 & Kinnaur & 979 & 953 & -26 \\
6 & Kullu & 960 & 2 \\
7 & Lahul and Spiti & 961 & 1013 & 52 \\
8 & Mandi & 913 & -5 \\
9 & Shimla & 918 & 922 & -7 \\
10 & Sirmaur & 929 & 931 & -3 \\
11 & Solan & 934 & 899 & -1 \\
12 & Una & 900 & 870 & 33 \\
\hline
\end{tabular}

NCT $=$ National Capital Territory.

Source: Office of the Registrar General and Census Commissioner, India, 2004; n.d.

although the child sex ratio in many of the districts in these states was masculine at both times, in all districts of Punjab, most districts of Haryana, and about one-half of those in Himachal Pradesh, the child sex ratio improved substantially over the intercensal period 2001-2011. Districts displaying the greatest improvement included Fatehgarh Sahib, Kapurthala and Rupnagar in Punjab, and Kurukshetra in Haryana. In contrast, during this period, in most districts of Maharashtra and Delhi (NCT), the child sex ratio continued to slide and became more masculine than before. In Maharashtra, huge declines were observed in such districts as Ahmednagar, Beed, Buldana, Hingoli, Jalna, Latur, Mumbai, Parbani and Washim; just a few districts-Chandrapur, Kohlapur, Sangli and Satara-showed a marginal improvement in their child sex ratio over this decade.

\section{Rural-urban patterns and differentials of sex ratios at birth and among children}

Just as distorted sex ratios are more commonly observed in more developed and better off states than poorly developed ones, so also findings from India suggest that the sex ratio at birth and the child sex ratio are more distorted in urban than in rural areas, and among economically better off and better educated populations than others. Indeed, child sex ratios are consistently more masculine in urban than in rural areas (Jha et al., 2011). At the same time, evidence suggests that differences may be narrowing, suggesting that the practice of gender-biased sex selection and subsequent termination of female foetuses is spreading to rural areas, as the technology becomes increasingly available in these settings (Nandi and Deolalikar, 2013; Retherford and Roy, 2003), and to poorer and less educated groups.

For example, trends in the sex ratio at birth from data drawn from SRS rather than censuses, seen in Table 3.6, suggest that over the period 2002-2012, the urban-rural difference declined from 12 points to five points, with some fluctuation in the trend. Likewise, as shown in Table 3.7, census data confirm that rural-urban differences were wide in 2001 (27 points), but narrowed considerably, to 18 points, by 2011, despite a worsening of the child sex ratio. The narrowing of the child sex ratio by 2011 suggests that the practice of gender-biased sex selection, formerly concentrated in urban areas, may have expanded to rural areas as well. 
Table 3.6: Sex ratios at birth by rural-urban residence, India, SRS, 2002-2004 to 2010-2012

\begin{tabular}{lccccccc}
\hline & $\mathbf{2 0 0 2 - 2 0 0 4}$ & $\mathbf{2 0 0 5 - 2 0 0 7}$ & $\mathbf{2 0 0 6 - 2 0 0 8}$ & $\mathbf{2 0 0 7 - 2 0 0 9}$ & $\mathbf{2 0 0 8 - 2 0 1 0}$ & $\mathbf{2 0 0 9 - 2 0 1 1}$ & 2010-2012 \\
\hline Rural & 884 & 904 & 907 & 909 & 907 & 907 & 909 \\
Urban & 872 & 891 & 894 & 897 & 898 & 900 & 904 \\
\hline
\end{tabular}

Source: Office of the Registrar General, India, 2006; 2008; 2009; 2011; 2012; 2013a; 2013 b.

Table 3.7: Child sex ratios by rural-urban residence, India, 2001 and 2011

\begin{tabular}{lcc}
\hline & $\mathbf{2 0 0 1}$ & $\mathbf{2 0 1 1}$ \\
\hline Rural & 933 & 923 \\
Urban & 906 & 905 \\
\hline
\end{tabular}

Source: Office of the Registrar General and Census Commissioner, India. 2013.

Maps 3.1 and 3.2 show statewise sex ratios at birth (2010-2012) and child sex ratios (2011), respectively, in rural and urban areas of India using SRS data. Map 3.1 shows that sex ratios at birth are under 900 in both rural and urban areas in most of the states with the most masculine sex ratios at birth. In most states, irrespective of the overall sex ratio at birth (for example, Andhra Pradesh, Kerala, Madhya Pradesh, Maharashtra, Punjab, Uttar Pradesh and West Bengal), the urban sex ratio at birth is lower than the rural sex ratio. Maharashtra is an exception: in Maharashtra, not only is the rural-urban gap wide, but also, it is lower in rural than in urban areas (the gap between the urban and rural sex ratios at birth is 35 with a lower rural than urban sex ratio at birth).

Map 3.1: Statewise sex ratios at birth in rural and urban areas, India, SRS, 2010-2012
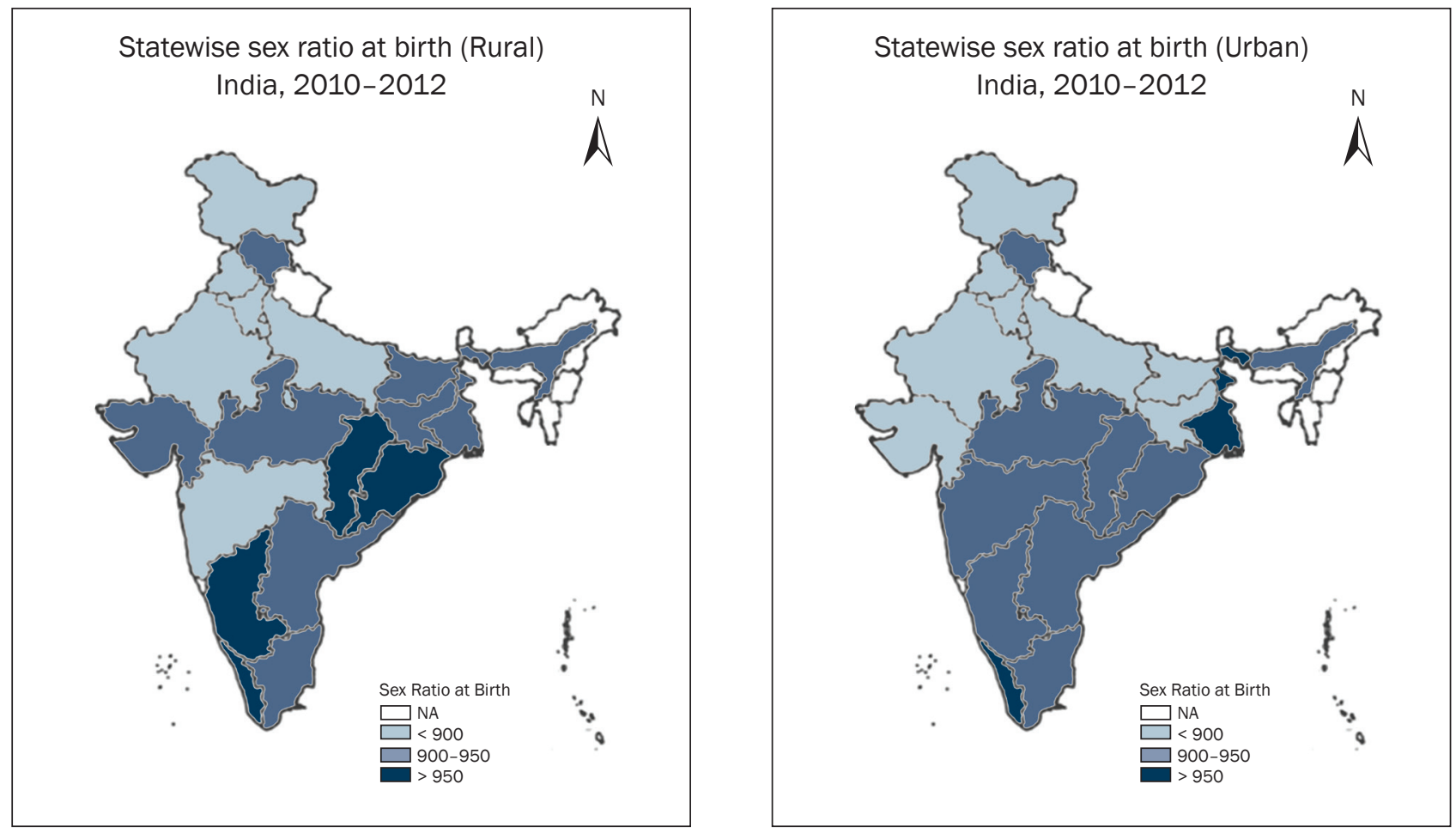

Source: Office of the Registrar General, India, 2013a. 
Additionally, if we look at the temporal variation between 2009-2011 and 2010-2012, the sex ratio at birth in rural Maharashtra has been stagnating at 881-882. Other notable changes in the sex ratio at birth during this period include sharp increases in rural Punjab and West Bengal, and a decline in rural Andhra Pradesh.

Map 3.2 clearly shows, moreover, that in most states in which the child sex ratio has been most distorted-Haryana, Jammu and Kashmir, Punjab, Rajasthan and Uttar Pradesh-child sex ratios are highly adverse in both rural and urban areas; in Maharashtra in contrast, the rural sex ratio is worse than the urban sex ratio.

Map 3.2: Statewise child sex ratios in rural and urban areas, India, 2011
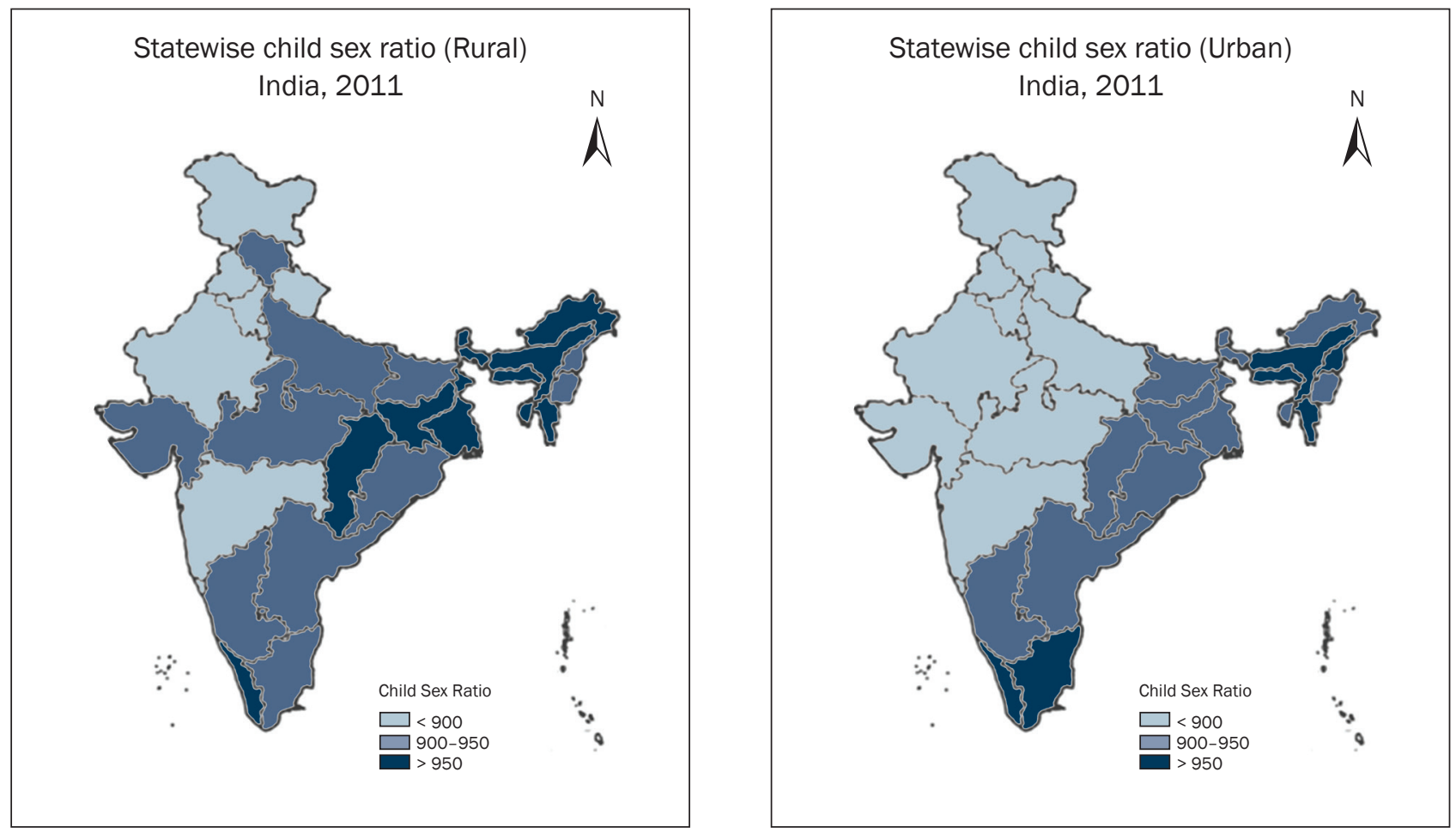

Source: Office of the Registrar General and Census Commissioner, India. 2013 


\section{Chapter 4 \\ Socioeconomic patterns, underlying factors and social consequences}

In this chapter, we provide a brief overview of the socioeconomic patterns, underlying factors and social consequences of distorted sex ratios and gender-biased sex selection.

\section{Socioeconomic patterns and differentials in sex ratios at birth and among children}

Social and economic differentials are observed in sex ratios at birth and among children. For example, socially excluded castes and tribes have higher sex ratios at birth and higher child sex ratios than general castes, and Muslims and Christians have higher child sex ratios than Hindus, Sikhs, Buddhists and Jains (Bhat and Zavier, 2007). Indeed, a recent study shows that child sex ratios were in the range of 564-724 among Hindus, Sikhs and Jains, 864 among Muslims and 966 among Christians (Pande and Astone, 2007). Likewise, sex ratios at birth have been found to be much higher among poorer households and poorly educated women than their better off counterparts (Jha et al., 2011; Bhalotra and Cochrane, 2010; Toppo, Diwakar and Pal, 2012; John et al., 2008), suggesting that it is not the economic need for sons but deeply entrenched patriarchal norms, along with easier access to technology, that drives gender-biased sex selection. There is also evidence that women from households with larger landholdings were more likely to have an ultrasound test, an induced abortion and a larger number of sons than other women (Arokiaswamy and Goli, 2012). Finally, differentials have been observed with birth order; child sex ratios and sex ratios at birth decrease rapidly with birth order (Retherford and Roy, 2003).

Nuances may be more evident from smaller in-depth studies. One such study, conducted in one district each of Haryana, Himachal Pradesh, Madhya Pradesh, Punjab and Rajasthan in which child sex ratios are particularly adverse, found no clear association with household economic status, although the wealthiest urban households revealed the lowest ratios, and a reversed U-shaped relationship, with those from both upper castes and scheduled castes showing a particularly distorted child sex ratio (John et al., 2009). Its authors suggest that economic constraints along with aspirations for upward mobility have led the poor as well as the wealthy to use sex-selection technologies to realise their 'daughter-aversion'. The study further observed distorted sex ratios even with respect to the first birth, thereby highlighting the strength of son preference and daughter aversion. Indeed, in some districts, significant numbers of families stopped childbearing if the first child was a son; in contrast if the first child was a daughter, major efforts were made to ensure that the second child was a son and that family size remains two (John et al., 2008).

\section{Underlying factors}

Distortions in sex ratios at birth have been attributed to the co-occurrence of three factors, namely, access to sex-selection technology, declining fertility and family size preferences, and an unchanging patriarchal context, characterised by age- and gender-stratified social systems, and a continuing strong preference for sons.

\section{Access to sex-selection technology}

While a number of pre-natal diagnostic techniques are available today, gender-biased sex selection in India is typically undertaken through the use of ultrasonography.

Ultrasonography is increasingly undertaken in India to assess foetal development. In 2005-2006, ultrasound was undertaken in almost one-quarter (24\%) of pregnancies experienced in the five years preceding the interview. As expected, it was far more likely to have been undertaken by better educated women, those from economically better off households, those from general castes and those from urban areas than poorly educated women, those from poorer households, those from socially excluded castes and those from rural areas. For example, while 44 percent of pregnancies taking place among urban women were reported to be associated with ultrasonography, just 16 percent 
of those occurring among rural women were so reported. Differentials by education, household economic status and social exclusion status were also wide (International Institute for Population Sciences and Macro International, 2007).

Nevertheless, a direct link between the use of ultrasonography and distorted sex ratios at birth is difficult to establish. Available findings suggest that the availability of the technology or even its use, in general, does not necessarily affect sex ratios at birth. For example, women in the southern states of India were considerably more likely than their northern counterparts to have undergone ultrasound during their last pregnancy, with no adverse effect on sex ratios at birth (Bhat and Zavier, 2007). In contrast, in states in which ultrasound was not so widely used (Haryana, Punjab and Himachal Pradesh, reporting 37\%, 45\% and 47\% of pregnancies associated with an ultrasound, respectively), sex ratios at birth were highly skewed. A link has also been observed between the density of ultrasonography centres and child sex ratios. For example, a district-level study in Maharashtra, exploring associations between the availability of ultrasonography centres and child sex ratios found that wealthier districts such as Mumbai, Nashik and Pune reported both a larger number of such facilities as well as more distorted sex ratios than did such poorer districts as Gadchiroli and Gondia (Nagarajan and Mulay, 2008).

Perceptions about the extent to which access to ultrasonography has spread in communities provides corroborating evidence that the practice is indeed widespread in settings in which sex ratios at birth and among children are skewed. A study in Delhi, for example, found that among men and women aged 15-40, more than three-quarters perceived that parents, regardless of financial background or social exclusion status, opted for sex selection; more than three-quarters reported that some parents in their own setting had undergone a sex-selection test (Dewan and Khan, 2009).

\section{Fertility and family size preferences}

Fertility and family size preferences have fallen consistently over the past two decades. Indeed, the current fertility scenario emphasises that not a single part of the country can be said to have high fertility (Kulkarni, 2014). For example, over the course of the three rounds of the NFHS, in 1991-92, 1998-99 and 2005-06, the total fertility rate fell from 3.4 to 2.9 and 2.7 , respectively. Over the same period, the ideal number of children desired by women aged $15-49$ fell from 2.9 to 2.7 and 2.4 , respectively. There is clearly a convergence to the two-child norm in terms of the number of children a couple wishes to have.

Fertility decline has occurred across all socioeconomic groups, among the poor and the rich, the illiterate and the educated, those in rural and in urban areas, those from socially excluded castes and general castes and those belonging to all religions. Trends also suggest a narrowing of socioeconomic gaps in fertility, implying that the fertility transition has been occurring across the board. By 2010, many states reported a total fertility rate below the 2.1 (replacement) mark. These states included states that have not displayed highly skewed sex ratios at birth, for example, the four southern states, Himachal Pradesh and West Bengal, and such states as Delhi (NCT), Jammu and Kashmir, Maharashtra and Punjab, which have succeeded in reducing their overall fertility levels but continue to demonstrate a strong son preference and consequent gender-biased sex selection. Total fertility rates of 3.0 and above are observed in the states of Bihar, Jharkhand, Madhya Pradesh, Meghalaya, Rajasthan and Uttar Pradesh, many of which have hitherto displayed "normal" sex ratios at birth.

The link between trends in the child sex ratio and total fertility suggests relatively little evidence of distortion in districts in which the total fertility rate is less than or equal to 2.1 and those in which it is 3.5 or higher; in contrast, it is states in transition, that is, those in which the total fertility rate lies in the range of 2.1 to 3.5 , that continue to exhibit distorted ratios.

\section{Patriarchy, gender norms, son preference and desired sex ratio at birth}

The persistence of patriarchy, traditional gender norms and a strong son preference, even in the face of declining family size preferences is clearly the factor that has fuelled the demand for gender-biased sex selection and the resulting distortion in the sex ratio at birth. Evidence of the acceptance of the small family norm together with a strong desire for sons comes also from a district-level study in Haryana, Himachal Pradesh, Madhya Pradesh, Punjab and Rajasthan (John et al., 2008). This study showed that a large proportion of women have accepted the two-child norm, and wish to have no more than two children but, at the same time, have a strong preference for 
at least one son. As a result, attitudes by and large condone gender-biased sex-selection practices; the small family norm, and approval of family planning and abortion practices were widespread, ranging from 80 percent to 99 percent of study respondents. Similar attitudes were reported in a study of men and women aged 15-40 in Delhi. In this study, for example, fear about marriage costs associated with daughters was the most frequently expressed reason justifying gender-biased sex selection, with almost one-half of all respondents so reporting. At the same time, most respondents exhibited hugely gendered attitudes about the roles of sons and daughters, with 77 percent believing that daughters are 'paraya dhan' ('somebody else's wealth' i.e., who, once married, belong to their husband's house), 77 percent believing that only a male child can provide old age security to parents, and 86 percent suggesting that a female child is a greater source of anxiety to parents than is a male child (Dewan and Khan, 2009).

There exists a rich body of evidence that probes in-depth the factors underlying the persistence of son preference, and the intensification of this preference in the face of declining family size preferences; the role of hypergamy, dowry, fears about dilution of family wealth and property and the cost of rearing daughters, and the perceived inability of daughters to provide support to parents in their old age, and the framework of violence against women, for example, have frequently been cited (see, for example, Miller, 1981; John et al., 2008; UN Women, 2014). Below, we briefly touch upon these underlying factors, and for a more in-depth discussion, refer readers to the above and other studies.

Studies in both north and south India have documented the strength with which son preference is typically articulated (John et al., 2008; Sekher and Hatti, 2010). A study among socially excluded castes in two low-fertility village settings in South India highlighted that such social changes as increased pressure on limited land, extensive investments in children, concerns that daughters are unable to support parents once married, and huge increases over time in dowry payments, resulted in an increased as well as intensified manifestation of discrimination against daughters; indeed, this study concluded that the rapid fertility decline, together with strong son preference, had intensified gender bias and resort to gender-biased sex selection (Sekher and Hatti, 2010).

In a study in northern India, between one-tenth and one-half of samples in rural and urban Rohtak (Haryana) and Fatehgarh Saheb (Punjab) favoured the practice of gender-biased sex selection (John et al., 2008). This study, however, observed some tension in prevailing attitudes. For the most part, son preference remained strong, and in some instances, the need for even one daughter was "no longer being articulated" so as to avoid distributing family property to daughters under new inheritance laws and to save on dowries (John et al., 2008). On the other hand, exceptions are evident and signs of a modest improvement in the desire for girls have been noted. For example, in districts of Haryana, Himachal Pradesh and Punjab, there was a growing realisation of the value of daughters for several reasons: girls did better than their brothers in school, job prospects for girl in urban areas had improved, girls' contributions to household income were substantial in some households, and mothers themselves had aspirations about investing in their daughters. At the same time, while expectations from sons remained strong, several parents realised that support from sons was not always forthcoming. Consequently, there appeared to be the beginnings of a greater acceptance of and value placed on daughters.

As a result of this persistent preference for sons over daughters, desired sex ratios at birth far exceed actual sex ratios at birth in many states (Bongaarts, 2013). The desired sex ratio at birth is calculated from the data on the number of male and female children that parents deem ideal for their family, and displays the extent to which couples desire a child of a particular sex (Bongaarts, 2013). Table 4.1 presents the distribution of states displaying skewed and more "normal" desired sex ratios at birth by the difference between the desired and actual sex ratio at birth. Findings suggest that desired sex ratios at birth exceed actual sex ratios at birth in most Indian states characterised by strong son preference, including in settings such as Haryana and Punjab in which sex ratios at birth are already highly skewed, as well as in those-such as Bihar and Madhya Pradesh-that currently display largely normal sex ratios at birth. The large gap between desired and actual sex ratios implies that there is potential for further distortion in the sex ratios. This analysis argues that the number of sex-selective abortions in India could grow substantially, if the actual sex ratio were to reach the level desired in 2005 (Bongaarts, 2013).

The findings of Table 4.1 further suggest that Haryana, Punjab and Uttarakhand comprise settings in which the desired sex ratio at birth is high, but the difference between the desired and actual sex ratio at birth is small, indicating that in these states, couples are successfully accessing the technology of sex selection to attain their desired sex composition of children. Other states, including the northern states of Madhya Pradesh, Rajasthan 
and Uttar Pradesh, and the eastern states of Bihar and Odisha, also display a strong preference for sons but are unable as yet to achieve their desires, resulting in largely normal sex ratios at birth and a large difference between their actual and desired sex ratios at birth. Indeed, a large gap between the actual and desired sex ratio at birth suggests that even where son preference is strong, some settings or some families may not have adequate access to sex-selection technology for achieving their desired sex composition of children. However, given the spread and increasing affordability of this technology, there is a clear potential in these settings for gender-biased sex selection and further skewing of the sex ratio at birth.

Table 4.1: Desired and actual sex ratio at birth by major states, India

\begin{tabular}{lll}
\hline Desired sex ratio at birth & $\begin{array}{l}\text { Large difference between desired and actual } \\
\text { sex ratio at birth }\end{array}$ & $\begin{array}{l}\text { Small difference between desired and actual } \\
\text { sex ratio at birth }\end{array}$ \\
\hline$>833$ & & $\begin{array}{l}\text { Andhra Pradesh, Delhi (NCT), Himachal Pradesh, } \\
\text { Karnataka, Kerala, Maharashtra, Tamil Nadu, }\end{array}$ \\
$<=833$ & West Bengal \\
& $\begin{array}{l}\text { Bihar, Chhattisgarh, Gujarat, Jammu and } \\
\text { Kashmir, Jharkhand, Madhya Pradesh, Odisha, } \\
\text { Rajasthan, Uttar Pradesh }\end{array}$ & Assam, Haryana, Punjab, Uttarakhand, \\
\hline
\end{tabular}

NCT $=$ National Capital Territory.

Source: Bongaarts, 2013.

\section{Social consequences}

Six interlinked consequences of distorted sex ratios, both observed and potential, have been identified in the literature, several of which have already been observed in India as well. These include the effect of the deficit of females on: (a) a marriage squeeze; (b) marriage patterns and practices, resulting from the marriage squeeze; (c) dowry payments and economic behaviour; (d) men's sexual behaviour and health; (e) crimes and violence against women resulting from surplus males, and finally, (f) women's status and gender equity (Kaur, 2013; Guilmoto, 2007; 2011).

The marriage squeeze refers to the imbalance between the availability of marriageable males and females, typically observed some twenty or more years after sex-selection practices take root. This squeeze has already been observed in some north-western states, and projections suggest that the cumulative number of additional men who may remain single during 2020-2080 will be close to 40 million (Guilmoto, 2012), assuming marriage practices do not change. Connected with arguments on the marriage squeeze are changing marriage patterns and practices, with such strategies as importing of wives, out-migration and so on increasingly being adopted in settings containing an excess of males. Particularly observed in north-western India is the practice of importing wives, known as 'long distance brides' from poorer states not affected by unbalanced sex ratios; evidence is mixed on whether these brides are more likely than others to be subjected to discrimination and violence. A study in Haryana and Rajasthan sought to examine the lives of women imported into these states for marriage; it found that the practice was particularly strong among Jats and Yadavs, and among them, those who were poorly educated, came from poorer households, were disabled or old; brides came from particularly poor households in sending states whose families were unable to meet dowry and other wedding-related demands. A second study in two villages of Sonepat, Haryana, reports that this practice had been ongoing for at least 20 years (Kaur, 2004). Both studies note that marriages were contracted through trafficking, marriage brokers, husbands of brides and brides themselves; most marriages involve some form of deception about the social and economic status of the husband. Women in these marriages are sought for reproduction and labour support; wide cultural differences exist in diets, customs, language and strength of patriarchy between these 'long distance brides' and the usual residents of the two villages (Kaur, 2004; 2013). Many face discrimination because of their different ethnic backgrounds or natal family poverty. Children of these unions may also face discrimination on the grounds of physical features, skin colour and 'questionable' lineage (Kukreja and Kumar, 2013). 
A related effect is on dowry and bride price, with findings that smaller dowries are demanded for girls in areas reporting shortages of brides; as seen above, moreover, the absence of dowry demands has motivated families in poor states to give their daughters in long-distance marriages (Kaur, 2013). While this effect on dowry may be a positive outcome, authors caution that such effects may be evident only among poorer families, and that the demand for dowry may not be affected among families seeking highly qualified bridegrooms irrespective of sex ratios. It is also true that dowries, overall, tend to remain high in hypergamous marriages involving better educated grooms with more promising earning prospects, and decline only among men with fewer resources (Kaur, 2013).

With regard to effects on increases in crime and violence, evidence from India is more tentative; associations have been observed between areas that are more violence-prone, and sex ratios and anecdotal evidence suggests that violence against women, both in the home and outside it, is exacerbated in settings in which sex ratios are unbalanced. Indeed, a district-level analysis found that the strongest correlate of the murder rate was the femalemale ratio: districts with higher female-male ratios have lower murder rates, suggesting a strong link between gender relations and violence in general (Dreze and Khera, 2000).

Finally, questions have been raised about whether the paucity of women will make them more valued or more vulnerable. One school of thought suggests that there will be less discrimination against girls and women; greater value placed on women, including in the marriage market, and greater agency. Others caution that shortages of women will result in societies reverting to focusing on women's traditional roles, with risks of a return to early marriage, domestic responsibilities, and generally limited life options; concerns about the security of girls and maintenance of virginity may result, moreover, in strengthening the restrictions imposed on girls' contact with the outside world (Kaur, 2013). Thus far, evidence on these social consequences remains tentative and anecdotal, and invites research that explores these associations in greater depth. 


\section{Chapter 5}

\section{Implementing the PCPNDT Act and other efforts to reverse the trend of adverse sex ratios at birth}

Recognising the need for effective implementation of laws preventing the misuse of sex-selection technologies, India and other countries, have launched a number of direct initiatives that translate such laws and policies into action. These initiatives have focused on programmes intended to affect the demand for gender-biased sex selection, and arrest the supply of mechanisms through which the misuse of technology and violation of the law are perpetuated. As indicated in the Office of the United Nations High Commissioner for Human Rights (OHCR), United Nations Population Fund (UNFPA), United Nations Children's Fund (UNICEF), United Nations Entity for Gender Equality and the Empowerment of Women (UN Women) and World Health Organization (WHO) interagency statement on the prevention of gender-biased sex selection (OHCR, UNFPA, UNICEF, UN Women and WHO, 2011), and by other scholars (Ganatra, 2008; Sen, 2009; United Nations Population Fund, 2012), legislation on its own is unlikely to be effective in reducing the imbalance in sex ratios at birth. Indeed, evidence suggests that "restricting access to technologies and services without addressing the social norms and structures that determine their use is likely to result in greater demand for clandestine procedures which fall outside regulations, protocols and monitoring" (OHCR, UNFPA, UNICEF, UN Women and WHO, 2011).

Measures have typically included imposing restrictions on the use of technologies used to detect the sex of the foetus, programmes geared towards improving the status of women and girls and changing deeply entrenched gender norms that discriminate against females, and advocacy and awareness generation activities to both raise awareness of laws and change attitudes towards girls. These approaches were responsible, for example, for reversing the adverse sex ratio at birth in Korea (Chung and Das Gupta, 2007). The example of Korea suggests that economic and cultural changes, urbanisation, and rising female education and employment combined with the three approaches described above, were successful in reversing the trend of adverse sex ratios at birth over a 25-year period. Korea's multipronged approach to eradicate gender-biased sex selection comprised a reorganisation of and greater controls applied on the health system and the imposition of harsh fines on doctors who did not comply with the ban; a mass media campaign launched in 1991 named "Love your daughter;" and considerable conditional and unconditional cash transfers to encourage parental investment in daughters (Ganatra, 2008; Chung and Das Gupta, 2007; Kim, 2013).

These three broad approaches have typically been employed in India as well: enforcing the implementation of the PCPNDT Act including initiatives intended to restrict and monitor the misuse of technology for prenatal sex selection, advocacy and community mobilisation to change attitudes about prenatal sex selection, and programmes aimed at empowering women and reducing gender disparities in access to education and economic resources. The UNFPA has played a key role in fostering many of the initiatives intended to address gender-biased sex selection (United Nations Population Fund, 2013).

This chapter describes India's experience and the challenges encountered in implementing these approaches.

\section{Implementation of the PCPNDT Act}

India has undertaken wide-ranging initiatives that attempt to ensure that the PCPNDT Act is effectively enforced; Table 5.1 summarises these efforts. The 2003 amendments, for example, have extended the responsibility from the woman to her husband and his family, allowed the individual to file complaints, made the offence non-bailable, created hotlines for anonymous reporting of sex-selection practices, and imposed severe sanctions by way of fines and imprisonment. At the same time, the Government of India has established 'Appropriate Authorities' at both state and district levels, (SAAs and DAAs, respectively), to monitor the implementation of the PCPNDT Act and audit records, and has also undertaken capacity building of the Appropriate Authorities to better understand the 
implications of the Act and the specific powers it invests in them for achieving its intended purpose in their respective areas of jurisdiction. It has also taken measures, for example, to bring the use of ultrasound machines within the purview of the PCPNDT Act so as to curb their misuse for gender-biased sex selection. At the same time, it has strengthened the monitoring role of Central and State Supervisory Boards, and empowered Appropriate Authorities to search and seal the machines and equipment of those violating the Act. Penalties have also been imposed, ranging from Rs. 10,000 to Rs. 100,000 and suspension of the registration of the violator. The Ministry of Health and Family Welfare is also engaged in strengthening the capacity of the State Appropriate Authorities (Ministry of Health and Family Welfare, 2013).

\section{Implementing the PCPNDT Act}

There have also been direct efforts to identify those violating the PCPNDT Act through sting operations (surprise inspection of a facility) or decoy operations (using a mystery client, a pregnant woman requesting a sex-selection test) conducted in facilities or among providers suspected to have violated the Act; evidence so gathered is then used to prosecute and make an example of providers who violate the Act (Joseph and Center for Youth Development and Activities, 2007; Birchall and Rao, 2012). Indeed, "conducting decoy operations" has been considered an essential step towards effective implementation of the PCPNDT Act by members of Appropriate Authorities, but the process is laden with challenges (Public Health Foundation of India, 2010).

There have been successes in tracking down unscrupulous providers. For example, a collector of Hyderabad district, who noted that Hyderabad had the most unfavourable child sex ratio in Andhra Pradesh, tracked down all 389 diagnostic clinics in the city and issued notices to 361 ultrasound scan centres for non-compliance with the PCPNDT Act; cancelled the licences of 91 centres, seized 83 machines (released 71 of these following an undertaking and a fine), and prosecuted three suppliers for supplying machines to clinics with no registration licenses (Gupta, n.d.); Association for Social Audit, Research \& Development Initiative, 2010). Also used in some settings, for example, Kolhapur District, Maharashtra, since 2009, is a controversial device known as the Active Tracker which is installed in registered sonography machines to enable remote monitoring of each machine. Findings about the success of this tracking system are unclear: according to one assessment, in the period following its installation in Kolhapur, there has been a modest improvement in the district's sex ratio at birth, and under-reporting of ultrasound cases has reduced (Magnum Opus, n.d.). According to an assessment commissioned by the state government with support from UNFPA, however, no significant changes were observed in the sex ratios at birth a year after the device was introduced. This report also noted that the method was neither tamper proof nor had the district administration taken action based on evidence generated by the device (State Health Systems Resource Centre, 2012, as quoted in UN Women, 2014).

Sting operations have also been conducted by individuals, for example, a Satara (Maharashtra)-based lawyer and social activist (a legal advisor to the District Appropriate Authority). Indeed, the sting operations and subsequent cases she filed against the concerned medical practitioners are reported to have had some success (Menon, 2006). These sting operations and subsequent legal action have demonstrated to practitioners that the PCPNDT Act can indeed be enforced against those who violate it and, at the same time, have raised awareness among legal functionaries at the district level about the legal processes and likely loopholes in its implementation.

The Save the Girl Child Campaign or Beti Bachao Andolan is an important campaign launched in 2006 under the National Rural Health Mission of the Ministry of Health and Family Welfare with the key objective of promoting the successful implementation of the PCPNDT Act (Ministry of Health and Family Welfare, n.d.). Implementation activities include, for example, identifying violations of the PCPNDT Act through detailed audits of Form ' $F$ ' filled for pregnant women undergoing an ultrasound, regular monitoring of the implementation of the Act, maintaining records at the state level of all ultrasound machines sold in each state, and preparation of annual state and district plans to monitor the implementation of the Act, and so on. Also available is a toll free number that individuals may use to report violations of the Act, and to obtain support in registering clinics as well as information about or assistance in interpreting the PCPNDT Act (Toll Free Number: 1800-110-500). Besides, inspection visits are conducted at the district level for monitoring the implementation of the Act and the appropriate maintenance of records of village, Panchayat and district-level pregnancies, medical termination of pregnancies (MTPs) and birth registration by Angawadi Workers and Accredited Social Health Activists (ASHAs) tasked with tracking these events; reports of the visits are submitted to the central authorities for monitoring (Ministry of Health and Family Welfare, n.d.). 
Instances of state-specific innovations under the Save the Girl Child Campaign have also been documented. For example, in Rajasthan under the Mukhvir Yojana, those who provide information about gender-biased sex selection and those who provide confirmed information about unregistered ultrasonography machines may report anonymously and are awarded Rs. 50,000 and Rs. 25,000, respectively (Forum against Sex Selection, 2012). Since 2010, Rajasthan also has a provision for online registration of complaints (Department of Medical, Health and Family Welfare, Government of Rajasthan, n.d.).

A compilation and analysis of case law on the PCPNDT Act notes that there have been few prosecutions, and that the majority of cases booked under the PCPNDT Act are pending for trial and are more likely to focus on licensing and registration of ultrasonography centres than on the problem of sex selection per se (Phansalkar-Joshi, 2013). Key judgements fall into four categories. First, decisions have been passed that relate to and issue directives for the implementation of the PCPNDT Act; in these cases, the judiciary took on the task of giving effect to the Act and passing orders for creating public awareness and implementing the Act. A second area relates to petitions challenging the constitutional validity of the PCPNDT Act and arguing for a couple's right to terminate pregnancies carrying a female foetus, petitions overturned by the courts. A third area relates to appeals against acquittal or conviction and highlights the difficulties faced in establishing PCPNDT Act violations. Finally, and by far the most common cases have dealt with procedural issues, such as, for example, the qualifications of the person conducting the ultrasonography test, improper maintenance of records, appeals against the suspension of registration of a medical practitioner by the State Medical Council, the sealing of ultrasonography machines or suspension of the registration of clinics, advertisements for sex selection, and challenges to procedures for search and seizure of premises and equipment (Phansalkar-Joshi, 2013).

Notwithstanding the PCPNDT Act and the provisions made for its enforcement, its implementation has been less than satisfactory (Luthra, 1994; Jha et al., 2006; Arnold, Kishor and Roy, 2002; Visaria, 2007). Effective implementation of regulations has faced a number of challenges. For example, the functioning of Appropriate Authorities has been variable at best (see, for example, Joseph and Center for Youth Development and Activities, 2007). Lapses in enforcement have included poor regulation of the misuse of these technologies, difficulties in establishing and proving that a crime was committed and the general indifference of the Appropriate Authorities in implementing the Act, all of which have resulted in limiting the effect of legislation. ${ }^{5}$ (see, for example, United Nations Population Fund, 2013).

Second, as the analysis of case law discussed earlier has pointed out, the records of the Ministry suggest that the registration of violations of the PCPNDT Act have focused on technicalities rather than specifically on disclosure of the sex of the foetus. For example, nationally, some 1,272 cases were ongoing up to June 2012, most of which related to non-maintenance of records and non-registration of the clinic; just 114 cases related to disclosure of the sex of the foetus, and 41 to advertising pre-natal diagnostic facilities. In addition, just 111 convictions were secured, of which 99 were from just three states (Haryana, Maharashtra and Punjab); 33 medical licences were suspended (half from Maharashtra) and 980 machines were sealed (535 from Maharashtra) (Ministry of Health and Family Welfare, 2013).

In addition, the practice of sting operations and surprise inspection visits has raised several concerns. Key is the unintended effect of such practices on limiting women's legal right to safe abortion as safeguarded under the MTP Act (Ganatra, 2008; Ipas, 2013). Providers-including genuine abortion care providers and sonographers-have reported harassment by authorities and sting operators that has affected their ability to provide genuine services to women. Many have reportedly declined to provide abortion services rather than face surprise inspection visits, minute scrutiny of their records and what is perceived as undue harassment about issues unrelated to the PCPNDT Act. Several activities of the Save the Girl Child Campaign suggest, moreover, a potential for violating women's rights, for example, using Anganwadi Workers and ASHAs to track pregnancies, MTPs and birth registration; and maintain records of these services at the district level (Ministry of Health and Family Welfare, n.d.).

Key challenges have included difficulties in monitoring a large number of private healthcare centres, the corruption of service providers and their collusion with their patients (Kishwar, 1993; Guilmoto, 2007; United Nations Population Fund, 2012). Such corruption of service providers and their collusion with their patients clearly poses a

\footnotetext{
${ }^{5}$ Similar concerns have also been raised in China (Wu, Viisainen and Hemminki, 2006; Junhong, 2001), although punitive measures were found to be highly successful in Korea where effective enforcement of laws has been identified as one factor contributing to the country's success in reversing sex ratio imbalances while preserving women's right to abortion (Kim, 2013).
} 
huge challenge in identifying violations of the Act. For example, women's own narratives (Singh, 2013) describe the use of code words and gestures by providers to convey the sex of the foetus, as follows:

If the doctor tells us to come and get the report on Monday we know it's a boy. Friday means a girl.

(The doctor's) Signature in red ink indicates a girl and blue indicates a boy. No words are exchanged. It's an unspoken thing; one doesn't even have to ask.

Given these challenges, it is not surprising that a review of case documentation and conviction concludes that implementation structures function poorly and there are few incidents of punitive action against those violating the provisions of the Act (Public Health Foundation of India, 2010). There is, however, one study that suggests that the PCPNDT Act had succeeded in reducing the slide of the child sex ratio; notably, this analysis of child sex ratios in the decade 1991-2001 using village- and town-level data from Maharashtra and its neighbouring states (namely, Andhra Pradesh, Chhattisgarh, Gujarat, Karnataka and Madhya Pradesh) suggested that in the absence of the PCPNDT Act, the child sex ratio would have declined by an additional 13-20 points (Nandi and Deolalikar, 2013).

While not under the PCPNDT Act, the NCRB records as "foeticide," under Section 315 and Section 316 of the Indian Penal Code, the number of cases of gender-biased sex selection that are registered and convicted. Data for the period 2001 to 2012 for the country as a whole, suggest some increase in the number of reported cases of genderbiased sex selection; nevertheless, the number is astoundingly small, even as recently as 2012 (National Crime Records Bureau, 2013). For example, as shown in Figure 5.1, in 2012, the NCRB reported just 210 cases of genderbiased sex selection followed by abortion ("foeticide"); while this indicates a 59.1 percent increase over 2011, the small numbers reflect the failure of the system to identify and report the practice. Also disturbing are statewise disparities in reporting: NCRB data come from just a few states. In 2012, for example, the largest number of crimes reported under this crime-head came from Madhya Pradesh, with just six other states reporting any cases (Andhra Pradesh, Chhattisgarh, Maharashtra, Punjab, Rajasthan and Uttar Pradesh) (National Crime Records Bureau, 2013).

Disposal of cases under Section 315 and Section 316 of the Indian Penal Code is also dismal. For example, in 2012, a total of 192 cases were investigated by the police (including pending cases from 2011), and in only 131 of these cases, a final report was submitted and 48 chargesheets issued. As far as court cases are concerned, of a total of 149 cases that were up for trial during 2012, the trial was completed in just 20 cases and in only five of these cases was the accused convicted (National Crime Records Bureau, 2013).

It is no surprise, therefore, that despite the widespread practice of gender-biased sex selection, relatively few cases of violation of the PCPNDT Act have been prosecuted.

Figure 5.1: Incidence of sex-selective abortions registered under the PCPNDT Act, India, 2001-2012

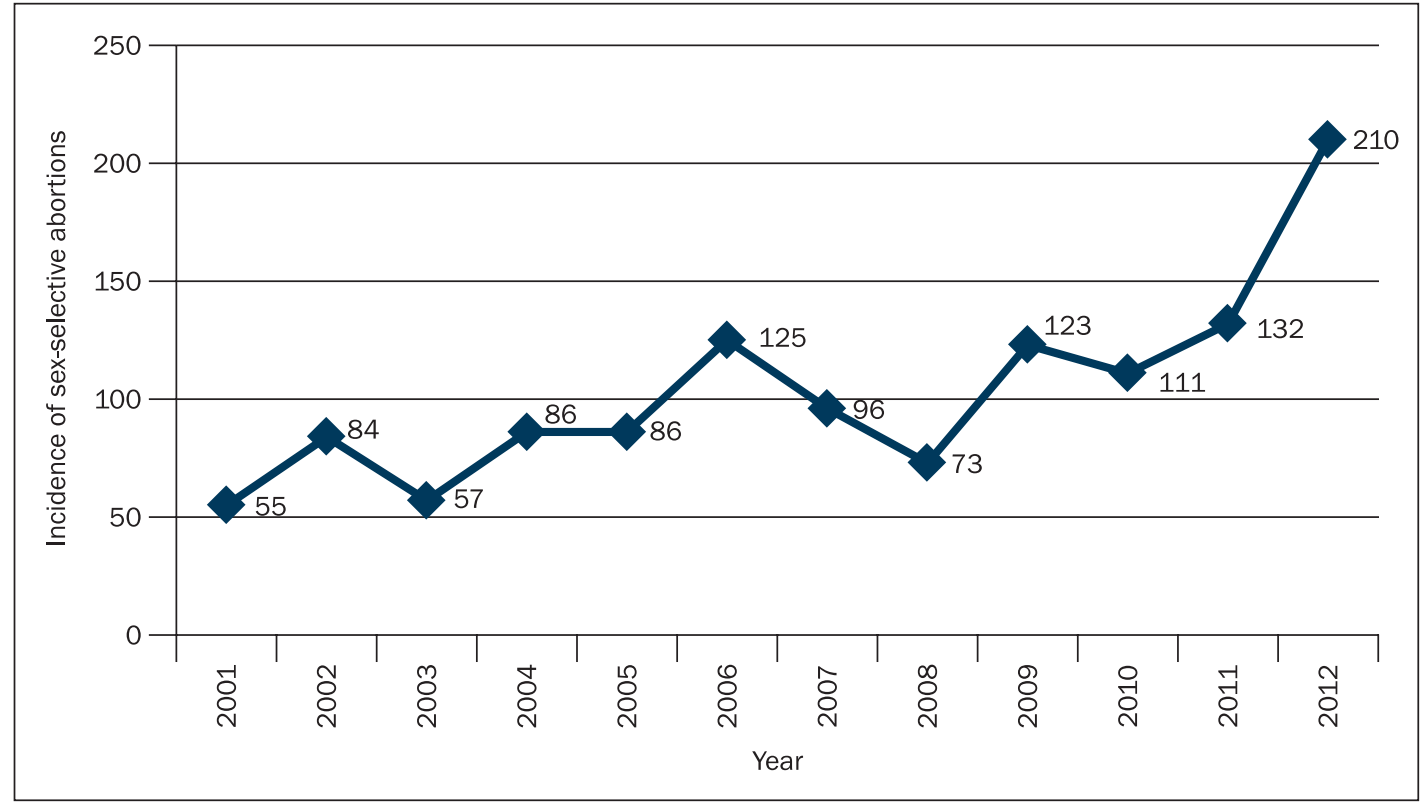

Source: National Crime Records Bureau, 2006; 2010; 2013. 
Table 5.1: Initiatives to ensure that the PCPNDT Act is implemented

\begin{tabular}{|c|c|c|c|c|}
\hline $\begin{array}{l}\text { Programme/ } \\
\text { Intervention }\end{array}$ & Objective & Mechanism/s & Effectiveness & Source \\
\hline $\begin{array}{l}\text { Tracking down } \\
\text { of all diagnostic } \\
\text { clinics and issuing } \\
\text { notices to those } \\
\text { that did not comply } \\
\text { with the PCPNDT } \\
\text { Act; cancelling the } \\
\text { licences, seizing } \\
\text { machines, etc }\end{array}$ & $\begin{array}{l}\text { To monitor } \\
\text { the use of } \\
\text { ultrasonography } \\
\text { machines }\end{array}$ & $\begin{array}{l}\text { - Tracking down all centres } \\
\text { violating reporting requirements } \\
\text { of the PCPNDT Act }\end{array}$ & $\begin{array}{l}\text { - Not specified, but } \\
\text { positive results } \\
\text { observed in } \\
\text { Hyderabad }\end{array}$ & $\begin{array}{l}\text { - Gupta, n.d. } \\
\text { Association for } \\
\text { Social Audit, } \\
\text { Research \& } \\
\text { Development } \\
\text { Initiatives, } 2010\end{array}$ \\
\hline Active Tracker & $\begin{array}{l}\text { To monitor } \\
\text { the use of all } \\
\text { ultrasonography } \\
\text { machines }\end{array}$ & $\begin{array}{l}\text { Device attached to all } \\
\text { ultrasonography machines, } \\
\text { tracks ultrasounds performed } \\
\text { on pregnant women and links } \\
\text { to reporting in Form ' } F \text { ' }\end{array}$ & - Mixed & $\begin{array}{l}\text { - Magnum Opus, } \\
\text { n.d. } \\
\text { - UN Women, } \\
2014\end{array}$ \\
\hline $\begin{array}{l}\text { Sting or decoy } \\
\text { operations }\end{array}$ & $\begin{array}{l}\text { To apprehend } \\
\text { violators of the } \\
\text { PCPNDT Act } \\
\text { red-handed }\end{array}$ & $\begin{array}{l}\text { - Surprise inspection of a facility } \\
\text { - Mystery client visits }\end{array}$ & $\begin{array}{l}\text { - Anecdotal evidence } \\
\text { of success in terms } \\
\text { of demonstration that } \\
\text { the PCPNDT Act can } \\
\text { be enforced, raising } \\
\text { awareness about } \\
\text { legal processes etc } \\
\text { - Unintended effect } \\
\text { on limiting women's } \\
\text { legal right to safe } \\
\text { abortion }\end{array}$ & $\begin{array}{l}\text { - Population } \\
\text { Health } \\
\text { Foundation of } \\
\text { India, } 2010 \\
\text { - } \text { Ganatra, } 2008 \\
\text { Ipas, } 2013\end{array}$ \\
\hline $\begin{array}{l}\text { Save the Girl Child } \\
\text { Campaign/Beti } \\
\text { Bachao Andolan }\end{array}$ & $\begin{array}{l}\text { To promote the } \\
\text { implementation } \\
\text { of the PCPNDT } \\
\text { Act }\end{array}$ & $\begin{array}{l}\text { - Identifying violations of the } \\
\text { PCPNDT Act; detailed audits of } \\
\text { Form 'F' } \\
\text { - Maintaining records at state } \\
\text { level of all ultrasonography } \\
\text { machines } \\
\text { - Preparing annual state and } \\
\text { district plans to monitor the } \\
\text { implementation of the PCPNDT } \\
\text { Act } \\
\text { - Providing a toll free number to } \\
\text { report violations of the PCPNDT } \\
\text { Act, registration and other } \\
\text { issues } \\
\text { Maintaining records of village-, } \\
\text { Panchayat- and district- level } \\
\text { pregnancies, MTPs and } \\
\text { birth registration; Anganwadi } \\
\text { Workers and ASHAs tasked } \\
\text { with tracking these events }\end{array}$ & $\begin{array}{l}\text { Not available, but } \\
\text { use of Anganwadi } \\
\text { Workers and ASHAs } \\
\text { to track pregnancies } \\
\text { and MTPs has been } \\
\text { recognised for its } \\
\text { potential in violating } \\
\text { women's rights }\end{array}$ & $\begin{array}{l}\text { Ministry of } \\
\text { Health and } \\
\text { Family Welfare, } \\
\text { n.d. }\end{array}$ \\
\hline
\end{tabular}


Table 5.1: (Cont'd)

\begin{tabular}{|c|c|c|c|c|}
\hline $\begin{array}{l}\text { Programme/ } \\
\text { Intervention }\end{array}$ & Objective & Mechanism/s & Effectiveness & Source \\
\hline $\begin{array}{l}\text { State-specific } \\
\text { interventions under } \\
\text { the Save the Girl } \\
\text { Child Campaign } \\
\text { incentivising the } \\
\text { provision of confirmed } \\
\text { information about } \\
\text { violations of the } \\
\text { PCPNDT Act, eg., } \\
\text { Mukhvir Yojana, } \\
\text { Rajasthan }\end{array}$ & $\begin{array}{l}\text { To expand } \\
\text { sources through } \\
\text { which violations } \\
\text { of the PCPNDT } \\
\text { Act are reported }\end{array}$ & $\begin{array}{l}\text { - Offering awards of Rs. } 50,000 \\
\text { and Rs. } 25,000 \text {, respectively, } \\
\text { for anonymous reporting of } \\
\text { any instance of disclosure of } \\
\text { the sex of the foetus and of } \\
\text { unregistered ultrasonography } \\
\text { machines, if confirmed }\end{array}$ & - Not available & $\begin{array}{l}\text { - Forum against } \\
\text { Sex Selection, } \\
2012 \text {. } \\
\text { - Department } \\
\text { of Medical, } \\
\text { Health and } \\
\text { Family Welfare, } \\
\text { Government of } \\
\text { Rajasthan, n.d. }\end{array}$ \\
\hline
\end{tabular}

\section{Advocacy, communication initiatives and community mobilisation efforts}

As in other countries, ${ }^{6}$ in India too, a number of interventions have focused on changing existing patriarchal gender norms that underlie son preference through campaigns directed at raising awareness about the PCPNDT Act, on the one hand, and the value of women and girls in society, on the other, as well as through communication and community mobilisation activities focused on generating awareness, and showcasing successful women and the contributions they have made at the family, community and national levels. These interventions are summarised in Table 5.2 .

Campaigns have typically been multipronged. A number of diverse initiatives have been undertaken across the country to raise the profile of gender-biased sex selection and engage government and communities in reversing the trend in unbalanced sex ratios at birth and among children. While posters, hoardings and television advertisements have been used to raise awareness of the PCPNDT Act, television serials have been aired to convey the value of daughters (Naqvi, 2006: Population Foundation of India, n.d.). There is, however, a suggestion that television serials focusing on sex selection have been less popular than those that continue to portray women in traditional ways (Naqvi, 2006). Moreover, NGOs have held direct interactions on gender-biased sex selection by way of meetings and discussions with youth, religious groups and communities (Joseph and Center for Youth Development and Activities, 2007).

The Save the Girl Child Campaign or Beti Bachao Andolan discussed above also plays an important advocacy function (Ministry of Health and Family Welfare, n.d.). Specifically, the campaign aims to address gender egalitarian community attitudes, in general, and those relating to sex selection, in particular, through activities focusing on raising awareness and changing attitudes among medical professionals and communities, more generally. Campaign activities have thus been wide-ranging and are implemented at the national, state and district levels; activities include:

- Capacity building programmes for advocates, the judiciary, members of medical associations and professionals, District Appropriate Authorities and others associated with the implementation of the PCPNDT Act.

- Youth campaigns for the Save the Girl Child Campaign along with awareness-building and sensitisation programmes in schools and colleges.

- Engagement with communities, including both awareness-raising activities through NGOs as well as involving communities in monitoring the implementation of the PCPNDT Act.

\footnotetext{
6 Internationally, campaigns have included, for example, the 'Love your Daughter' campaign in Korea, and the 'Care for Girls' movement in China. In South Asia, there have been numerous advocacy and communication activities that have focused both on changing attitudes towards girls and, more specifically, on raising awareness of laws against sex selection. In Nepal, the Nepal Society of Obstetricians and Gynaecologists has produced educational audio-visual materials that focus on sex selection (Tamang, personal communication).
} 
- Engaging frontline health workers (Anganwadi Workers, ASHAs etc) and locally elected officials (members of Panchayati Raj Institutions or PRIs) in monitoring the implementation of the PCPNDT Act and identifying violations.

- Information, Education and Communication (IEC) campaigns, including signature campaigns, media (electronic and press) campaigns, e-campaigns (on Yahoo and Facebook), television spots, advertisements in the print media and on FM radio, youth campaigns and public rallies, as well as preparation and distribution of IEC materials in various languages.

- Programmes and schemes for girls, including those at the district level through PRIs.

Advocacy efforts have also been undertaken by state authorities under the Save the Girl Child Campaign. In Maharashtra, the district administration of Satara district identified 282 girls named Nakoshi ("unwanted") and renamed them in a drive to mobilise communities and raise awareness about equal treatment of girls and boys (Byatnal, 2011). Madhya Pradesh has a Facebook page providing information and inviting communication about the Beti Bachao Andolan (Government of Madhya Pradesh, n.d.).

Advocacy and community mobilisation efforts have also been undertaken at the non-governmental level. For example, with UNFPA support, Women Power Connect implemented the "Support to community mobilisation and a people-driven response in preventing sex selection and arresting child sex ratio decline." The goals of this programme were to raise awareness about the PCPNDT Act and reinforce activities intended to strengthen its implementation, change attitudes discriminating against daughters and towards the acceptability of sex selection, and mobilise communities to counter gender-biased sex selection in various ways. A range of stakeholders was identified: civil society and community-based organisations, including faith-based and community leaders as well as self-help groups and local self-government (PRIs) members; legal services authorities, including protection officers and child development authorities; PCPNDT Cells and state government authorities, and so on. The programme nurtured a network of 31 civil society organisations across 11 states, and strengthened their capacity to implement advocacy, communication and community mobilisation activities in their settings. Several activities were implemented that reached five lakh households and forged links with over 400 Gram Panchayats in 51 districts (Women Power Connect, 2013; 2013a; United Nations Population Fund, 2013). Advocacy, community mobilisation and capacity building efforts included, for example:

- Raising awareness about the PCPNDT Act as well as sensitising people about discrimination against women, women's rights, and gender-biased sex selection: Various constituencies were addressed, ranging from local bodies to women's and youth groups, and efforts made to enable them to act as drivers of change; diverse means were employed including face-to-face discussions, rallies, puppet shows and other culturally acceptable media approaches. Community watch groups were formed that were responsible for coordinating and implementing activities aimed at raising awareness about discrimination against girls and the adverse consequences of sex selection.

- Focusing on young people and youth organisations: Several strategies were employed, including reaching youth through peer educators, and working through such established structures as the National Service Scheme and the Nehru Yuvak Kendra Sangathan.

- Collaborating with religious leaders: Partnerships were successfully forged with religious groups such as the Art of Living Foundation led by Sri Sri Ravi Shankar and the Sant Kabir group, and Muslim religious leaders.

- Sensitisation of PRI representatives and support to representatives (Gram Panchayat members) to raise the issue of sex selection and violence against women as governance issues in their areas.

- Capacity building of health care providers ranging from ASHAs and Anganwadi Workers to the medical fraternity to the Chief Medical Health Officer. For example, Women Power Connect held special training programmes for local authorities as well as at the state level to raise their awareness of the PCPNDT Act and their responsibilities in its implementation; these activities reportedly resulted in greater coordination between NGOs and government officials.

- Coordination with the Save the Girl Child programme and strengthening Save the Girl Child Committees.

Like Women Power Connect, Plan International has implemented advocacy activities through its Because I Am a Girl campaign. This campaign has addressed the issue of gender discrimination around the world, including India 


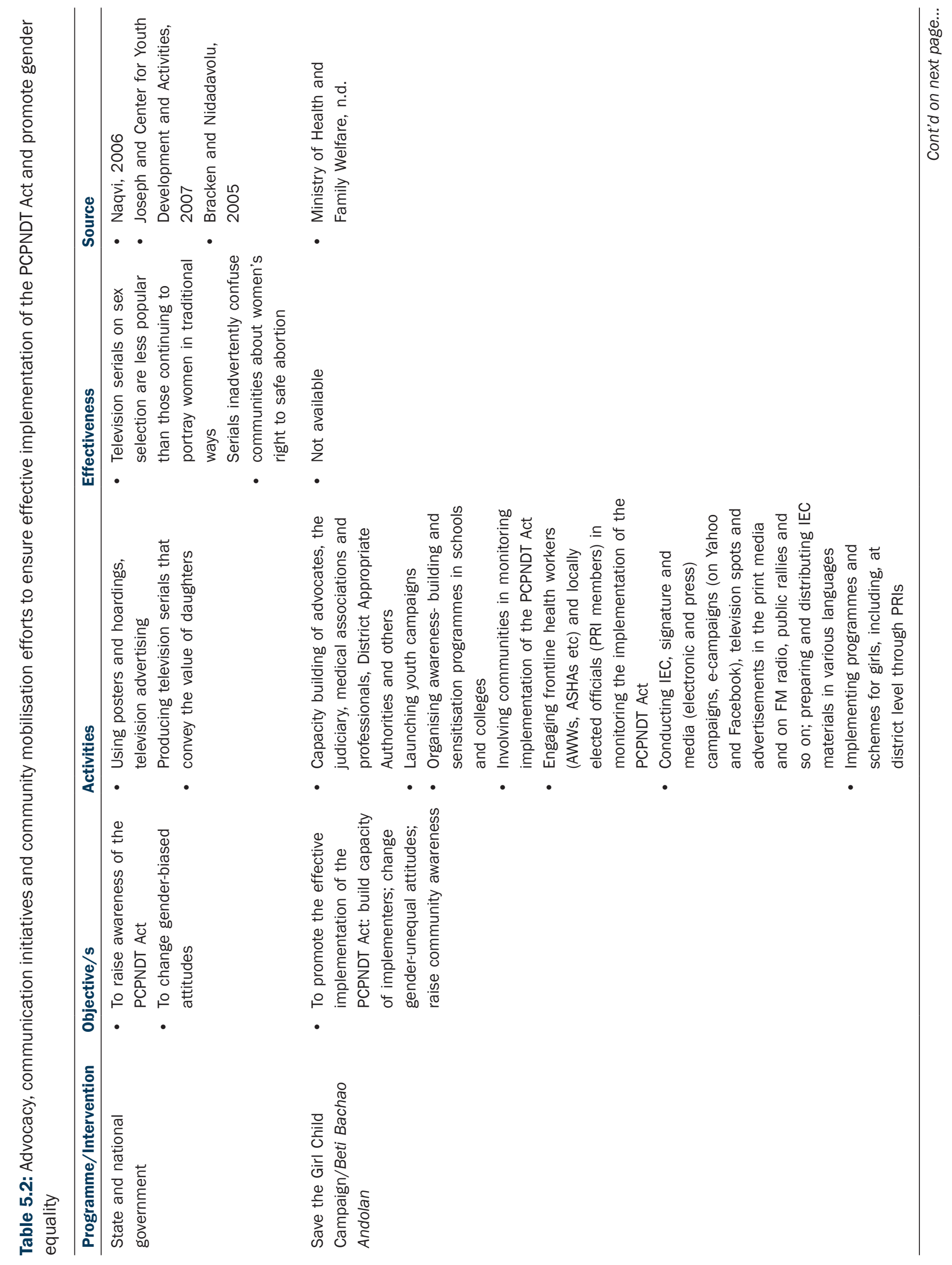




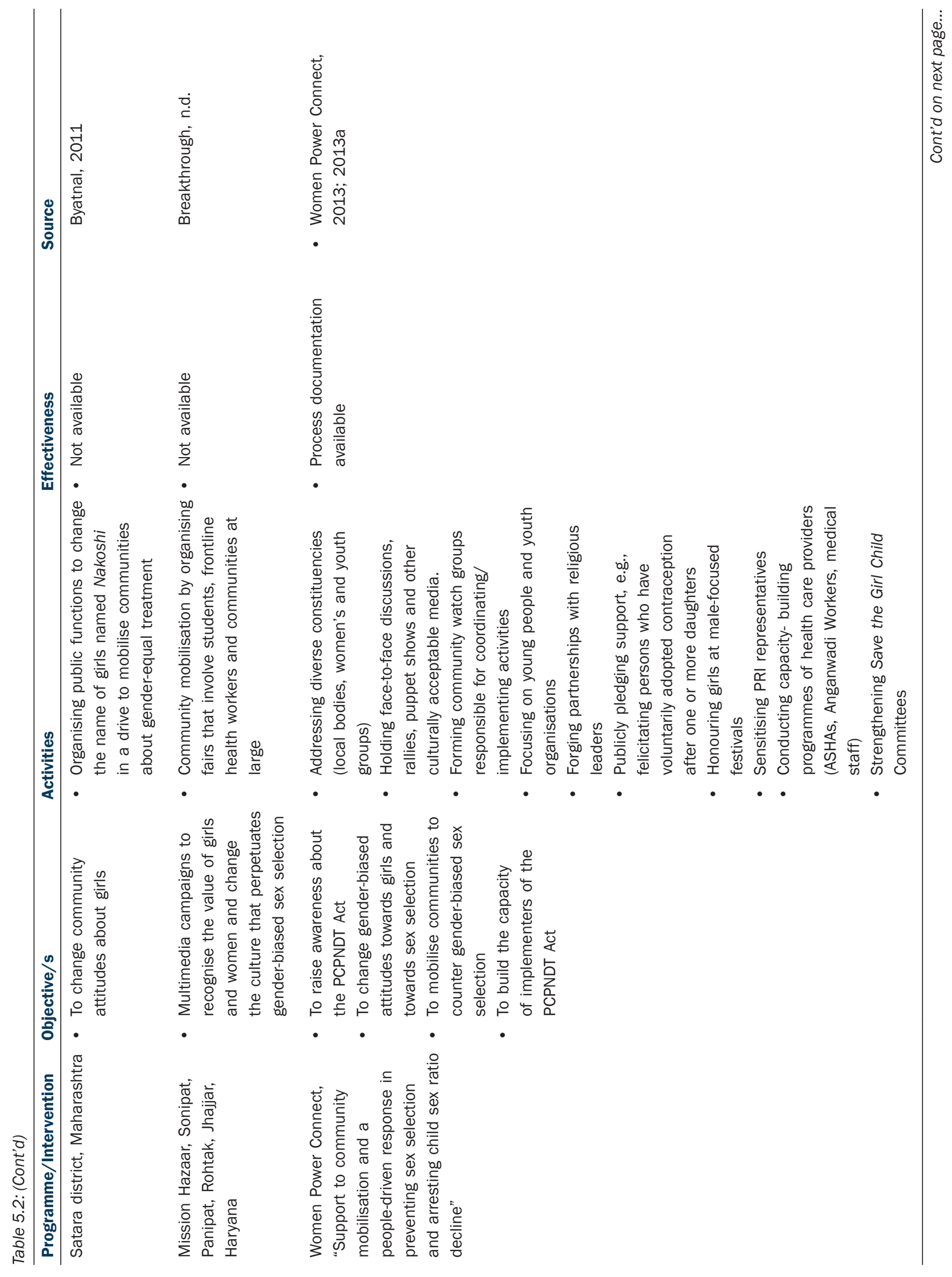




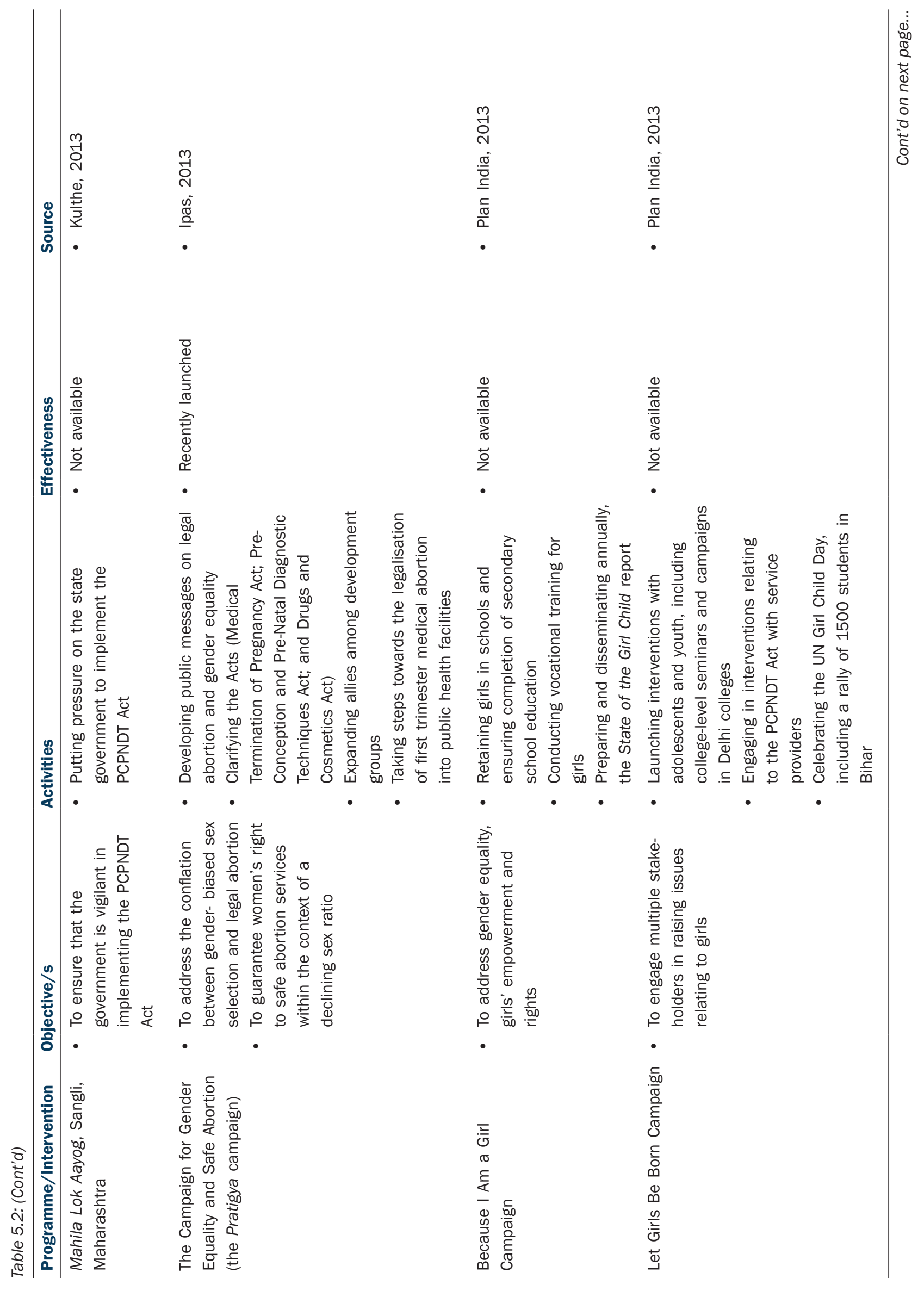




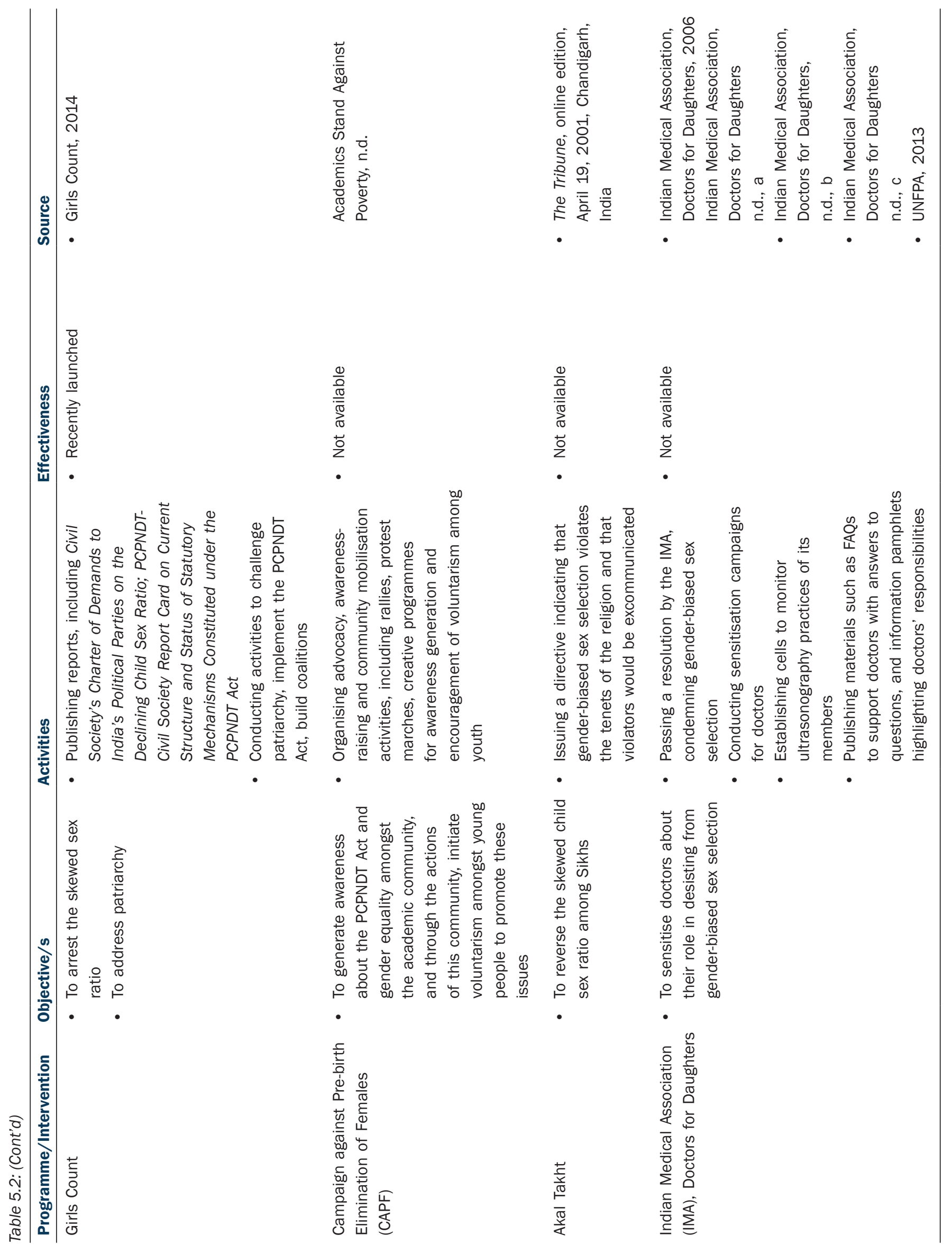


(Plan India, 2013). Plan International has also initiated the Let Girls be Born project that focuses specifically on PCPNDT issues among multiple stakeholders in various states, notably young people and service providers, and includes celebration of the United Nations Girl Child Day, seminars, campaigns and orientation of service providers (Plan India, 2013).

In Maharashtra, a coalition, the Forum against Sex Selection was established in the wake of findings of the 2011 Census confirming the state's adverse child sex ratio. The Forum comprises an informal network of over 50 organisations and individuals, and has conducted advocacy with government and communities at large to raise awareness and reverse misconceptions about gender-biased sex selection (UN Women, 2014). Advocacy efforts have also been pioneered by individual campaigners, for example, the Mahila Lok Aayog which aims to put pressure on the state government to implement the PCPNDT Act (Kulthe, 2013).

In four districts of Haryana, Breakthrough, a human rights organisation based in India and the US, is engaged in implementing a campaign aimed at changing attitudes towards women and girls on the one hand, and gender biased sex selection on the other. Community mobilisation activities focus on students, frontline health workers and communities at large (Breakthrough, n.d.).

Other efforts have focused on engaging specific groups, for example, particular religious groups, the medical fraternity and the academic community. For instance, given the very unbalanced child sex ratios observed in Punjab and among the Sikh community, Sikh religious leaders issued a directive notifying the Sikh community that genderbiased sex selection violates Sikh principles and that offenders would be excommunicated (The Tribune, 2001). A multi-faith conclave of religious leaders was also held in which religious leaders appealed to their followers to 'restore the value of daughters' and pledged to ensure the well-being of daughters (United Nations Population Fund, 2013).

At the same time, the Indian Medical Association passed a resolution to fight against sex selection (Indian Medical Association (IMA), Doctors for Daughters, 2006; United Nations Population Fund, 2013) expressing concern over India's adverse child sex ratio, condemning the practice of prenatal sex determination, and advising its members to desist from the practice. The IMA has played a key role in sensitising doctors about the practice including its gender, legal, ethical and rights dimensions; it has published and disseminated pamphlets and booklets that answer doctors' questions about gender-biased sex selection and their role in desisting from the practice (see, for example, Indian Medical Association, Doctors for Daughters. n.d., a; n.d., b; n.d., c; United Nations Population Fund, 2013). The UNFPA has organised regional and district-level workshops across the country to sensitise medical practitioners, more generally, about this issue; the workshops resulted in a few participants taking on the task to become ambassadors for IMA's work on raising awareness about gender-biased sex selection and monitoring compliance with the Act (United Nations Population Fund, 2013).

Also important are efforts to sensitise the next generation of health care professionals and teachers about genderbiased sex selection and the PCPNDT Act. With support from UNFPA, efforts have been made by, for example, the Indian Association for Preventive and Social Medicine and the Maharashtra Nursing Council to sensitise teachers, on the one hand, and integrate topics relating to these issues into the curriculum, on the other (United Nations Population Fund, 2013). Likewise, the Campaign against Pre-birth Elimination of Females was launched in 2002 to generate awareness amongst the academic community and, through the actions of this community, initiate voluntarism amongst young people on this issue. Activities have focused on advocacy, awareness-raising and community mobilisation, including through rallies, protest marches, creative programmes for awareness generation and encouragement of voluntarism among youth population (Academics Stand against Poverty, n.d.). Workshops and seminars have also been held to sensitise faculty and students of journalism in many states (New Delhi) (United Nations Population Fund, 2013; Population First, n.d.). Finally, efforts have been undertaken to strengthen the capacity of the judiciary and the legal profession to address the implementation of the Act, through colloquia and orientation programmes (United Nations Population Fund, 2013).

With impetus from UNFPA, activities have also been conducted to promote media engagement. Perhaps the bestknown are Population First's Ladli Media Awards for Gender Sensitivity which felicitate media professionals for challenging gender stereotypes and highlighting women's concerns; the award is made annually and provides an opportunity for bringing the issue into various forms of media as also in diverse settings (United Nations Population Fund, 2013; Population First, n.d.). 
Of serious concern is the confusion that has been generated between the illegality of gender-biased sex selection and women's right to obtain safe abortion (the PCPNDT Act and the MTP Act). Concerns have been raised that advocacy activities intended to enforce the PCPNDT Act have inadvertently confused communities about women's right to safe abortion; for example, posters displayed in the early 2000s through state governments to 'save the girl child' or 'ban foeticide' (bhrunhathya) inadvertently equated abortion with murder, and were interpreted to suggest that abortion is illegal (Bracken and Nidadavolu, 2005; Ipas, 2013). Efforts have also been made to address this confusion. For example, the Campaign for Gender Equality and Safe Abortion (the Pratigya campaign) was launched in 2013 as a network of over twenty key national-level stakeholders led by Ipas with the intention of guaranteeing women's right to universal access to safe abortion services within the context of a declining sex ratio, placing these issues within the framework of gender equality and rights. The Campaign identified four key strategic objectives, namely, the development of public messages on legal abortion and gender equality; clarification of distinctions among the Acts namely, the Medical Termination of Pregnancy Act, the Pre-Conception and Pre-Natal Diagnostic Techniques Act, and the Drugs and Cosmetics Act; the expansion of allies among development groups; and finally, taking steps towards making first trimester medical abortion widely available in public health facilities (Ipas, 2013).

A second alliance, the Girls Count initiative, launched in 2012, includes a number of civil society organisations that focus on responding to gender-biased sex selection and the declining child sex ratio, as well as patriarchy, more generally, seen as the root cause of gender-biased sex selection. As such, the campaign takes a two-pronged approach, one on the PCPNDT Act and the other on patriarchy. As such, it works with government, and human rights and other civil society groups working on gender issues, in general, and/or gender-biased sex selection, in particular (Girls Count, 2014).

As in the case of efforts to ensure that the PCPNDT Act is implemented, the effectiveness of advocacy, communication and capacity-building efforts has not been adequately assessed. In general, there has been little evaluation of the content, reach or effect of various advocacy and capacity-building activities.

\section{Initiatives to build gender equality}

A favourable social environment, notably with regard to norms about gender roles and efforts towards gender equality, is essential for the successful implementation of laws and policies to curb gender-biased sex selection (United Nations Population Fund, 2012). The need for initiatives intended to promote egalitarian gender norms are widely acknowledged (Ganatra, 2008; OHCR, UNFPA, UNICEF, UN Women and WHO, 2011; United Nations Population Fund, 2012; Bongaarts, 2013).

A number of initiatives have been implemented across Asian countries that provide incentives to parents of girls and are intended to counter the disadvantages faced by girls. ${ }^{7}$ It is, however, in India that a plethora of these cash and non-cash transfer schemes have been proposed or implemented (see, for a detailed review, Sekher, 2010). Programmes have been initiated both at national and at individual state levels that explicitly or implicitly aim to increase the value of the girl child or to counter the disadvantages faced by girls in education, marriage and gender roles. Most available programmes provide conditional cash and non-cash transfers at various milestones in a girl's life, for example, birth, school enrolment, secondary school completion, and delayed marriage. Table 5.3 summarises selected central government initiatives as well as initiatives implemented in states, including Haryana, Himachal Pradesh, Punjab, Madhya Pradesh and Tamil Nadu.

At the national level, the Ministry of Woman and Child Development has launched two major programmes. The first is the Balika Samridhi Yojana, an investment scheme launched in 1997 throughout the country, to improve the status of the girl child by providing monetary incentives for completing school education and postponing marriage till the age of 18 . The objective of this programme is to address gender-biased sex selection as well as, more generally, to promote girls' education, raise their age at marriage and enhance their access to livelihood skills

\footnotetext{
${ }_{7}$ While cash incentives have been criticised as reinforcing unequal perceptions of sons and daughters and perpetuation of perceptions of girls as liabilities, these schemes have been credited for contributing to a gradual change in community attitudes and are acknowledged as having an effect on both transforming the gender system as well as providing obvious benefits to girls in terms of health, education and opportunities, more generally. In China, programmes were implemented that provided scholarships and incentives to girls, and assistance to parents of daughter-only families (Xinhua, 2006; Li, 2007). In most countries, including Nepal, Bangladesh and Pakistan, special incentive schemes have been introduced to keep girls in school (United Nations Educational, Scientific and Cultural Organization, 2000; 2007; Holmes and Upadhya, 2009).
} 
and income-generating activities (Ministry of Women and Child Development, n.d., d). In the period 1997-1998 to 2003-2004, between 2,500 and 9,500 girls were registered under this scheme each year. Although initiated by the Government of India, the scheme has, since 2006, been taken over by state governments, and in some cases, been renamed (Sekher, 2012).

A second scheme introduced on a pilot basis in 2008 is the Dhanalakshmi Scheme, also a conditional cash transfer programme for girls and the only scheme which is fully supported by the Government of India (Ministry of Women and Child Development, 2011; Sekher, 2010; Planning Commission, n.d.). Under this scheme, cash transfers are made to the family (preferably the mother) at the birth of a girl and when the girl fulfils certain specific conditions, such as birth registration, immunisation, school enrolment and retention up to Class VIII, and delay in marriage till the age of 18. The scheme is being implemented in eleven blocks across seven states (Andhra Pradesh, Bihar, Chhattisgarh, Jharkhand, Odisha, Punjab and Uttar Pradesh) in the country (Ministry of Women and Child Development, 2011). Several state governments have introduced similar state-specific programmes, including conditional cash transfer programmes (Sekher, 2010). Details of these two schemes are provided in Table 5.3. Unfortunately, neither scheme has been evaluated.

Numerous schemes have been implemented at state level. Perhaps the earliest such scheme to be implemented was the Jayalalitha Protection Scheme for the Girl Child, launched in Tamil Nadu in 1992. Under this scheme, a poor family with one or two daughters and no sons is eligible for cash transfers if one parent was sterilised before age 35, transfers comprised a fixed deposit that matured when the girl reached 21 years of age (Rs 10,000 when initiated and increased thereafter), and periodic grants to cover the girl's educational expenses (Srinivasan and Bedi, 2009; 2012).

Two schemes, in particular, stand out as focusing most prominently on arresting trends in gender-biased sex selection-the Apni Beti Apna Dhan and the Ladli Schemes initiated by the Ministry of Women and Child Development and implemented differently in different states. The Apni Beti Apna Dhan Scheme is a long-standing scheme implemented in Haryana, which offers payments for girls at birth and on the achievement of various milestones (varying from birth registration to delayed marriage). The Ladli Scheme is more recent and has also been implemented differently in various states with considerable financial commitment. For example, in Haryana, the Haryana Government's Women and Child Development Department website indicates that as of 2007-2008, a total of 49,558 girls were registered under the Ladli Scheme and a total of Rs. 235,935,000 had been disbursed (Department of Women and Child Development, Government of Haryana, n.d., a). In each state, as shown in Table 5.3 from the examples of Delhi (NCT), Haryana, Himachal Pradesh, Madhya Pradesh and Punjab, incentive amounts differ, eligibility criteria differ, and the milestones at which money is transferred to the girl or her family differ.

Evaluation of these schemes has been patchy and, overall, it is difficult to assess their impact (Das Gupta et al., 2008; Sekher, 2012). Information available is mixed. A review of 15 schemes suggests, for example, that they have a multiplicity of objectives, eligibility criteria and milestones at which time transfers are made (Sekher, 2012). As a result, the key objective of enhancing the value of daughters is somewhat diffused: for instance, an eligibility criterion that parents should have just two children and either parent should have been sterilised is clearly mixing goals of spreading the small family norm and increasing contraceptive use as well as affecting the value of daughters, and these mixed objectives may dilute the effect on the latter (Sekher, 2012; Srinivasan and Bedi, 2009; 2012). Indeed, restricting benefits to first and second daughters may also have potential for differential valuing of girls of different parity (Sekher, 2012). Concerns have also been raised that the fact that the deposited amount matures around the time of a girl's marriage may help to perpetuate the practice of dowry (George, 1997; UN Women 2014). At the same time, concerns have been raised about the limited awareness of these schemes, implementation and monitoring failures in these schemes, as also their relevance, given that they target the poor although sex selection is concentrated among better-off families (United Nations Population Fund, 2012; Sekher, 2012). Both state government officials and beneficiaries have noted the difficulties in registering for the schemes: some recognised that stringent requirements such as domicile certificates and other prerequisites deter registration of migrants and the poorest households; also noted were corrupt practices resulting in beneficiaries reporting having to make payments to officials, and the registration of ineligible households for benefits (Sekher, 2012). Delays in making payments have also been reported (George, 1997).

Nevertheless, successes have also been reported. In an assessment of the Ladli Scheme in Delhi (NCT), officials reported that following the implementation of the scheme, birth registration and the enrolment of girls in school had 
improved (Sekher, 2010). Many beneficiaries acknowledged that the cash transfers had enabled them to keep girls in school, and appeared to have modified their perceptions of girls as a liability (Sekher, 2012). An assessment of the Apni Beti Apna Dhan Scheme, likewise, pointed to such effects as increases in the registration of beneficiaries and opening of bank accounts for these beneficiaries, population-level increases in girls' age at marriage, an improved sex ratio at birth and increases in awareness of the legal minimum age at marriage at the community level; it also succeeded in increasing the value of girls, as evident from improved sex ratios at birth (Nanda, n.d.; Das Gupta et al., 2008). While the Ladli Scheme, implemented differently in different states, is relatively recent, it appears to have been widely used in areas with particularly skewed sex ratios at birth. Indeed, there appears to be evidence of a reversal of adverse sex ratios at birth in parts of north-west India in which they were most adverse (United Nations Population Fund, 2012).

Other programmes have aimed, more generally, to raise the status of women or keep girls in school, and are not always linked with cash transfers. For example, implemented through the Ministry of Human Resource Development is the Mahila Samakhya Scheme. This scheme was started in 1989 to translate the goals enshrined in the National Policy on Education into a programme intended to educate and empower women in rural areas, particularly those from socially and economically marginalised groups. The scheme works through women's collectives at the village level that provide women a space to meet, reflect, ask questions and articulate their thoughts and needs and make informed choices; its activities also focus on changing women's attitudes about the value of daughters and emphasising the importance of education for girls (Ministry of Human Resource Development, 2008).

Several initiatives have focused specifically on overcoming obstacles to girls' schooling. For example, the Kasturba Gandhi Balika Vidyalaya, Mahila Samakhya (Ministry of Human Resource Development, 2008), the National Programme for Education of Girls at the Elementary Level, and the National Scheme of Incentives to Girls for Secondary Education (Ministry of Human Resource Development, n.d.) have all focused on keeping girls in school, including by defraying the cost of their education. Likewise, in Bihar (Department of Education, Government of Bihar, n.d.), Madhya Pradesh (Madhya Pradesh Education Portal, n.d.) and several other states have provided bicycles free of cost to girls attending secondary school in order to increase their physical mobility and retention in secondary school. For example, in Madhya Pradesh, in the period 2004-2005 to 2010-2011, a total of about 15 lakh girls from scheduled caste or tribe households or households below the poverty line benefitted from the scheme (Classes 6 and 9) (Madhya Pradesh Education Portal, n.d.). In Bihar, in the period 2007-2008 to 2009-2010, a total of Rs. 1,743,600,000 was disbursed through this scheme to 8.71 lakh girls (Nitish Kumar, 2010).

As in the case of the schemes discussed earlier, there have hardly been any evaluations of the effectiveness of these schemes in increasing secondary school enrolment or completion among girls. By and large, as described in Table 5.3, as these schemes are available only to girls in selected classes (6 or 9, etc), the cash and bicycles awarded more likely serve to keep girls in school than affect gender-biased sex selection. For example, an evaluation of the bicycle scheme in Bihar found that the cycle programme was indeed more cost effective than other conditional cash transfers in increasing girls' enrolment and completion of Class 9, and in enhancing girls' mobility or freedom of movement at least to access secondary education (Murlidharan and Prakash, 2013).

In short, while not conclusive, evidence does suggest that conditional cash transfer programmes may have succeeded in promoting birth registration, immunisation, school enrolment and delayed marriage. What is less clear is the extent to which these transfers have affected gender-biased sex selection. As mentioned earlier, these schemes target poor and socially excluded families among whom sex ratios are close to normal, rather than better off families among whom the practice of gender-biased sex selection is most pervasive. Registration processes remain cumbersome and incentive amounts may not be sufficient to act as a serious deterrent to gender-biased sex selection. In short, it is not clear whether or how these schemes have led to a change in parental preferences for and attitudes towards having daughters (Sekher, 2012). 


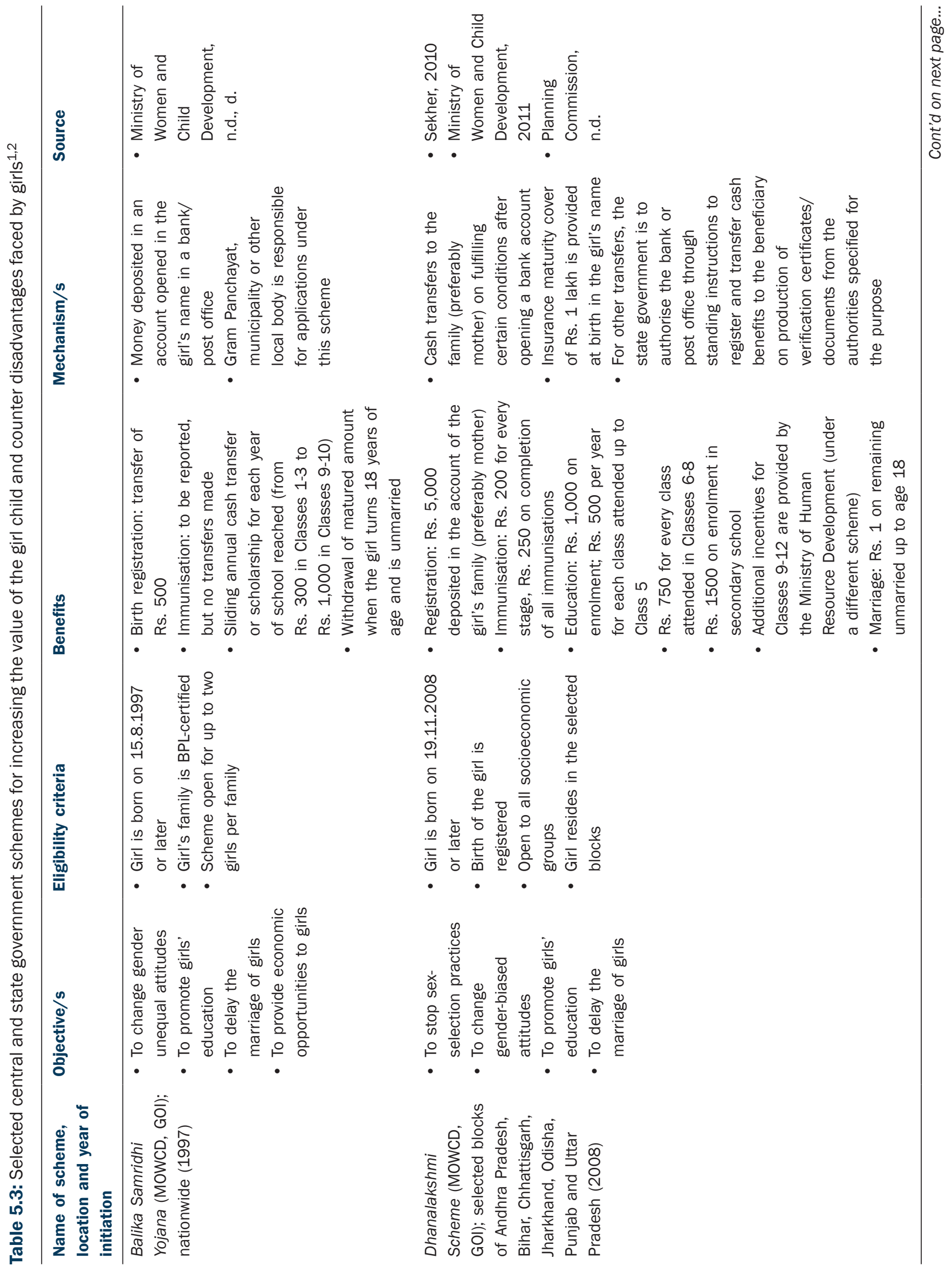




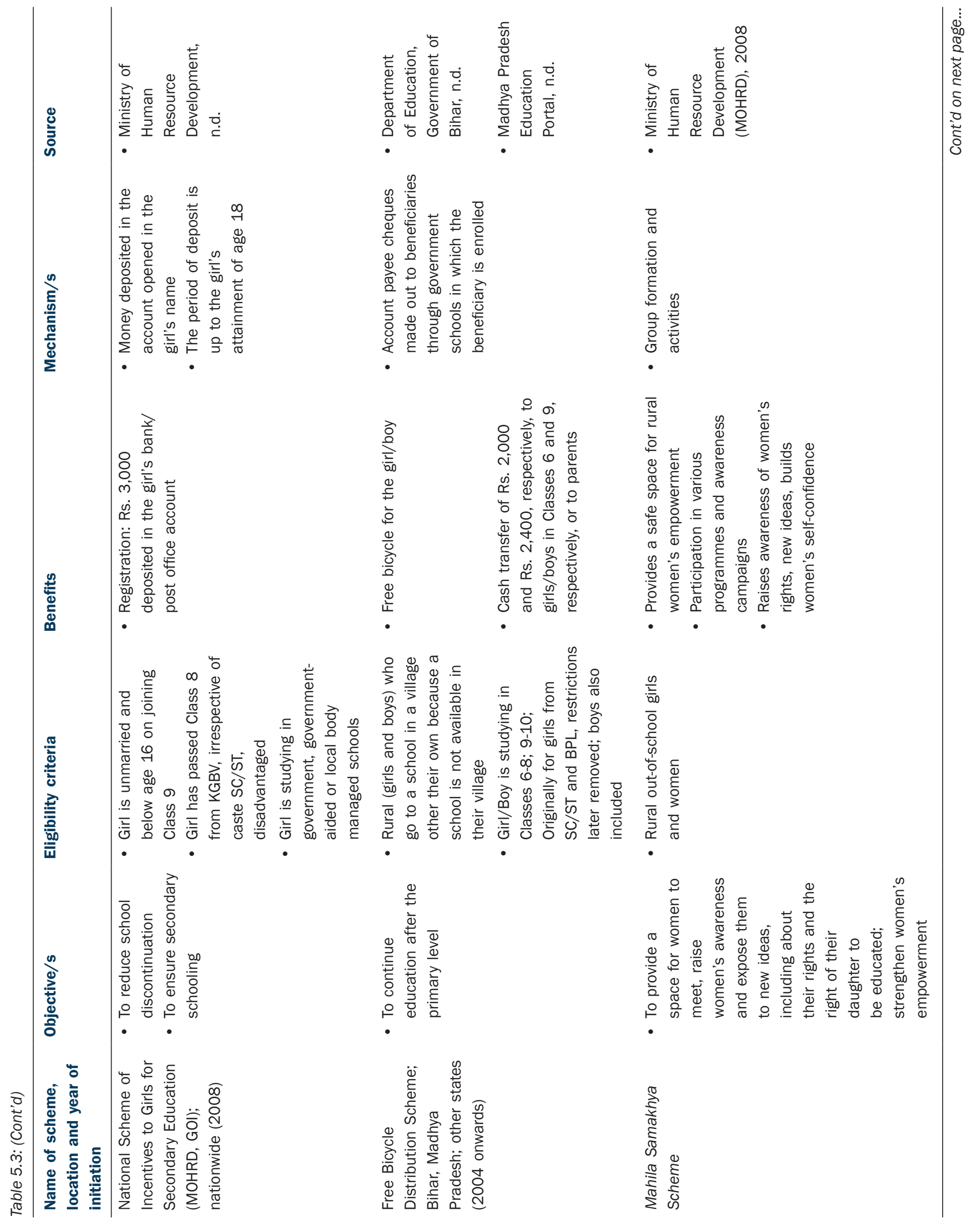




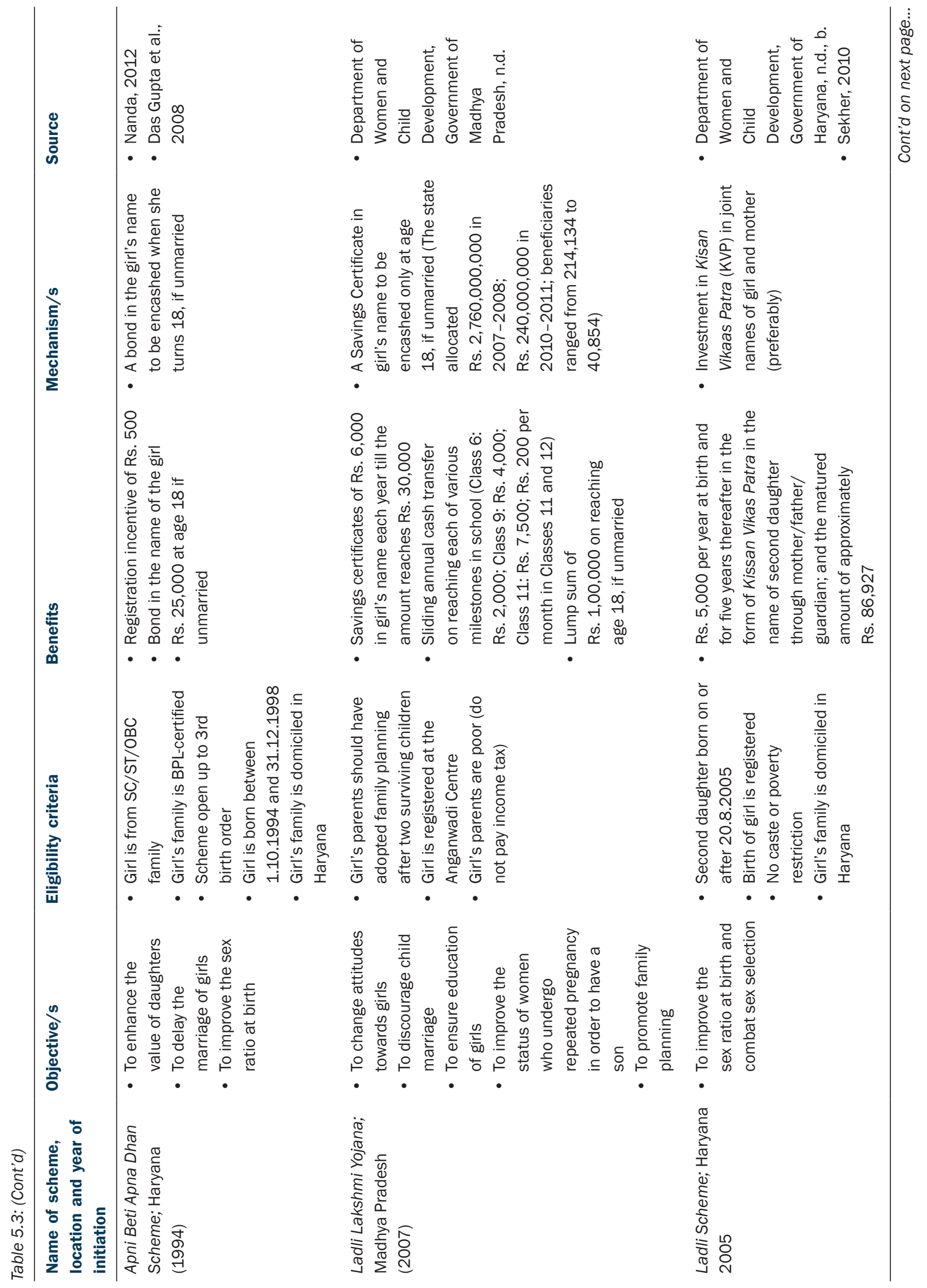




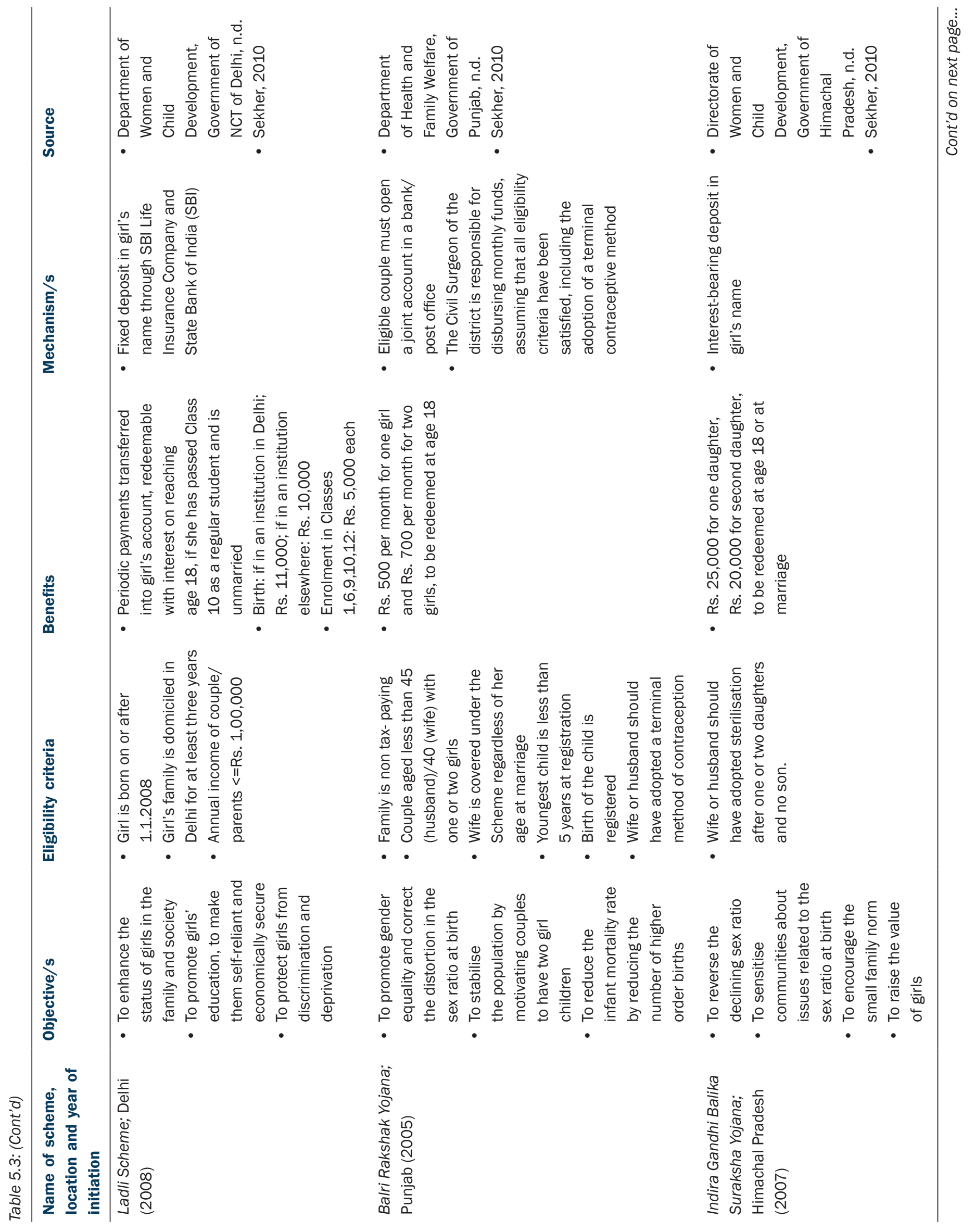




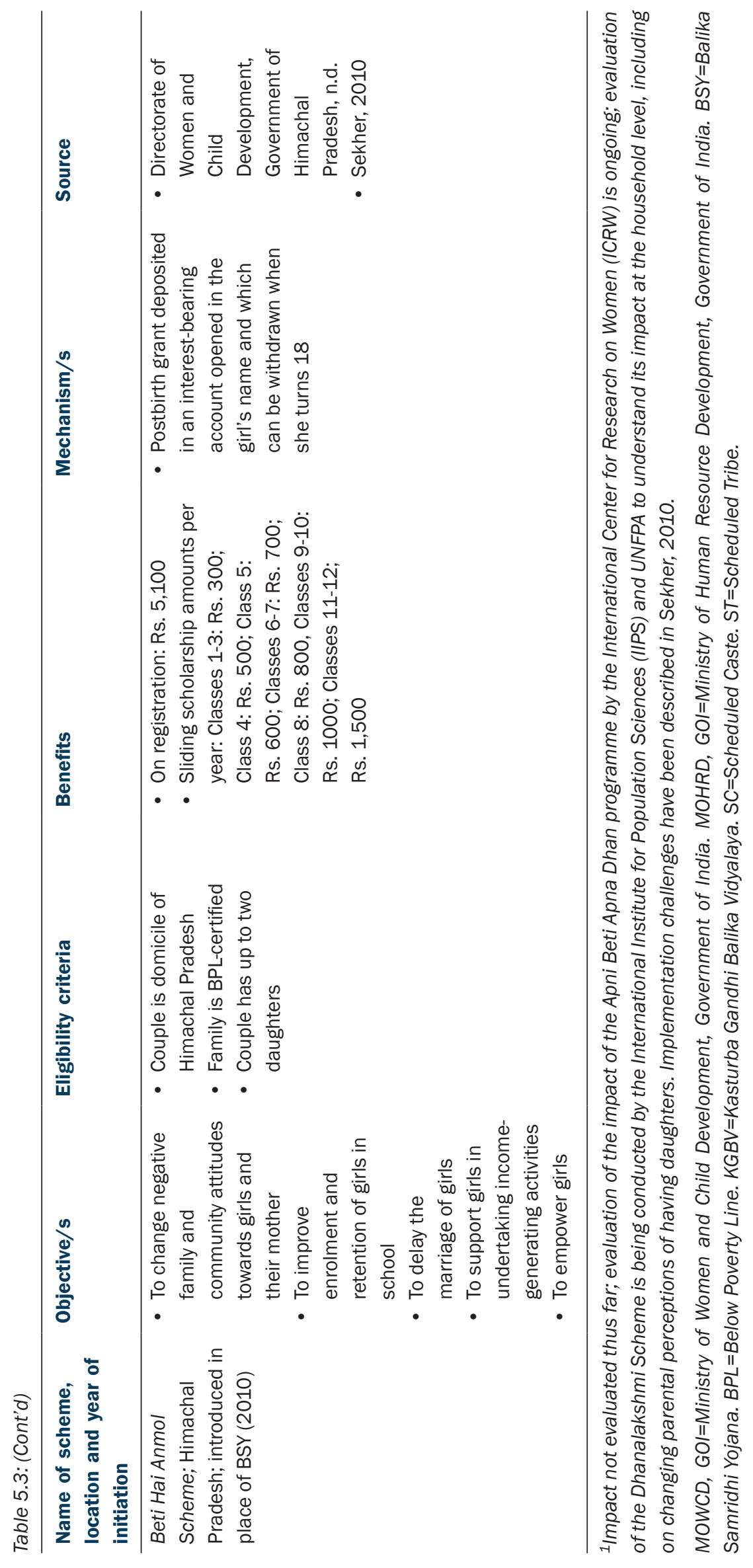




\section{Chapter 6 Concluding remarks}

This chapter summarises the main findings of this review and highlights evidence gaps with regard to the efforts made to counter the practice of gender-biased sex selection and to arrest and reverse trends in adverse sex ratios at birth and among children in India.

\section{Summary}

The findings of this review underscore the persistence of unbalanced sex ratios at birth and among children even as recently as 2011. While there are wide disparities, with adverse sex ratios concentrated in a few states, among better off sub-populations and those in urban areas, there is a narrowing of these disparities and a suggestion that adverse sex ratios may encompass larger segments of the population as sex-selection technologies become more widely available. At the same time, there are signs of a turnaround in a few states (Gujarat, Haryana, Punjab, Uttar Pradesh), that, while incipient, are signals of hope.

Unbalanced child sex ratios have been evident in India for decades, with post-birth disparities in feeding and health care patterns elevating the mortality of daughters as compared to sons. Since the 1980s, post-birth discrimination has given way increasingly to prenatal gender-biased sex selection. Underlying these trends is India's patriarchal social system and the resulting gender inequality and strong preference for sons over daughters, along with a growing preference for small family size and the means, through inexpensive and widely available technology, to ensure the birth of sons even while ensuring small families.

The PCPNDT Act (and the PNDT Act that preceded it) has prohibited the disclosure of the sex of the foetus and the indiscriminate use of pre-natal diagnostic technologies for gender-biased sex-selection, and has applied strict penalties for those found to have violated the Act (Ministry of Health and Family Welfare, 2003). At the national, state and district levels, the PCPNDT Act empowers statutory bodies, by way of Appropriate Authorities, to enforce the Act. Although the Act has been enforced since 1994, sex ratios have remained adverse and have even worsened in the twenty years following its enactment. The failure of the Act to curb adverse sex ratios has been attributed to the persistence of gender inequalities and norms favouring sons at any cost, unscrupulous clients and providers willing to violate the Act, and difficulties in or indifference about enforcing the Act in many settings.

The weak implementation of the PCPNDT Act in and of itself is well recognised and three broad categories of initiatives have been undertaken to better translate policies and legislation into action. These have included initiatives to ensure that the Act is implemented; interventions focused on communication, advocacy and community mobilisation that aim to build a better understanding of the PCPNDT Act and the implications of violating it, and change gendered norms and attitudes; and measures to build greater gender equality and reverse strong son preferences. Initiatives have been undertaken both by the government as well as by civil society organisations. While these are promising, efforts to identify the challenges and successes they have experienced have been limited, and what is available suggests that gaps in understanding persist.

For example, a number of measures have been undertaken to strengthen enforcement of the PCPNDT Act. These have included efforts to ensure that the provisions of the Act are implemented and that monitoring of facilities and identification of violations take place. They have also included efforts to identify those violating the provisions of the Act through sting or decoy operations conducted in facilities or among providers suspected to have violated the Act; evidence so gathered is then used to prosecute and make an example of providers who violate the Act. While some success has undoubtedly resulted, the process is laden with challenges. Efforts have been successful in that unscrupulous providers have been named and shamed and, in some cases, their practices being affected, imprisonment and the prospect of lengthy court cases, perhaps, have acted as a deterrent for other providers. At the same time, sting and decoy operations have been hampered by the fact that detection is difficult, authorities are indifferent, and many cases against violators do not proceed to court. Disturbing evidence has also emerged, that stings and other such actions have served to harass safe abortion providers and, as a result, have compromised access to safe abortion among women in genuine need. 
A second set of initiatives focuses on communications, advocacy and community mobilisation efforts that aim to raise community and provider awareness about the dangers of a gender-unbalanced society, about the value of girls, and about the PCPNDT Act, including public messaging and national campaigns to "save the girl." While these efforts have not been evaluated in their entirety, what is available suggests that their effects are mixed, On the one hand, there is some indication that public messaging has not been particularly effective or may have served to confuse perceptions about the right to safe abortion and the illegality of sex-selective abortion. On the other hand, efforts have served to reach a range of change-makers aside from the medical establishment, such as, for example, the law and the judiciary, religious leaders, academics and so on, as well as the young and communities at large, whose direct effects on the practice of gender-biased sex selection are difficult to assess.

Finally, there have been a range of initiatives promoted by the government to reduce the demand for genderbiased sex selection, namely initiatives that provide cash and non-cash transfers to girls and families of girls on the achievement of various milestones ranging from birth registration to delayed marriage. Although fraught with implementation challenges, these initiatives have had some success in increasing birth registration, immunisation of girls, and school enrolment and continuation, but the link to gender-biased sex selection has been weak, at best.

These findings highlight several gaps in our understanding of the persistence of gender-biased sex selection in India, and the promising and challenging features of available initiatives to reverse the trend. The paragraphs that follow highlight issues that may help enhance understanding of these promising and challenging features. We must caution readers, however, in respect of the lessons from Korea, perhaps the only country in the world that has reversed its adverse sex ratio at birth, that while similar initiatives were undertaken in Korea, researchers have observed that the key to the rapid reversal of the sex ratio was its rapid socioeconomic development; however, a strict and committed crackdown of the law, a minimum of corruption in the implementation of the law, a strong 'Love your Daughter' campaign and huge incentives to invest in daughters may have accelerated the pace of the reversal.

\section{Recommendations}

We focus here on the promising areas of primary research that will either highlight the experiences of a particular intervention in building the environment for a more balanced sex ratio at birth, the obstacles that an initiative may have experienced in achieving a balanced sex ratio at birth, or other potentially positive efforts in doing so.

Breaking down gender inegalitarian norms and son preference: Of the three sets of initiatives implemented, the most research has been conducted on the effectiveness and challenges associated with efforts to provide conditional cash and non-cash transfers for girls (for example, Sekher, 2012; International Center for Research on Women, 2013; Nanda, n.d.). Available evaluations have explored the implementation issues associated with conditional cash transfers, and have focused on assessing the impact of one such programme (Apni Beti Apna Dhan) in Haryana. Given these insights, it is not clear that there is a rationale for additional research investment in exploring the effectiveness of other such programmes. However, some research may be of interest:

- A number of studies commenting on the experience of Korea have suggested that it was the change in social norms fuelled largely by young people that provided the environment for a reversal of the sex ratio at birth. It may be useful to explore the extent to which such trends are apparent in India by focusing research on the attitudes and reproductive decisions of the young; for example, those recently married and those about to be married.

- While many conditional cash transfer programmes have been evaluated, several recent programmes described in the previous chapter have not been evaluated (Sekher, 2010). Indeed, Sekher identifies some seven programmes, including the Dhanalakshmi Scheme and the Ladli Scheme, specifically implemented with an eye on influencing gender-biased sex selection, as worthy of further and more in-depth research attention. Research is needed that documents the perceptions of implementers of these schemes in various capacities and states, assesses the extent to which the schemes are known to potential beneficiaries and explores the experiences of those benefitted by it, to better understand implementation issues as well as perspectives of reach and impact.

- The extent to which laws and policies aimed at empowering women and girls and reducing gender disparitiesfor example, inheritance laws-have had their intended effect, and others, intended to correct gender injustice, such as dowry, or address population stabilisation issues, such as policies preventing those with more than two children from contesting in local elections, have had an adverse effect on gender-biased sex selection. 
Advocacy, communication and community mobilisation efforts: As discussed in the previous chapter, there have been several efforts aimed at raising awareness, changing attitudes among different constituencies about the acceptability of gender-biased sex selection, and engaging the media. The experiences of these efforts have not been well documented or their effectiveness assessed. Research addressing these issues is, therefore, called for. For example:

- Physicians' associations have conducted training programmes for providers but their experience has not been documented: for instance, has there been follow up and would more indepth evidence from trainee providers provide insights into the usefulness of this approach?

- Research is needed that assesses how messaging about gender-biased sex selection (through posters, banners, television, newspapers, etc) has been perceived at the community level among those in the process of family building: whether they are aware of these messages, whether exposure has affected family building plans etc.

- Insufficient insights are available about the influence of media exposure-on the one hand, are soap operas, films, radio spots etc designed specifically to counter gender-biased sex selection, and on the other, more subtle messages about women's status that may result in new ideas about marriage, spousal relations, aspirations and so on.

- Is there potential at the local level (Panchayats, local religious leaders) to promote credible messages or are local leaders unlikely to perceive gender-biased sex selection as a concern?

Enforcement of the PCPNDT Act: A number of efforts have been made to enforce the Act, some by Appropriate Authorities and others by NGOs and civil society groups. Several issues emerge for documentation and research. For example:

- The Beti Bachao Andolan programme operates a helpline. Research is needed to determine the experience of this programme, whether communities know about and use the helpline, whether they are aware of other media activities and how they perceive these activities, and what is the experience of those who deliver these programmes-do they find them useful and potentially effective?

- Reviews of state-level initiatives-for example, anonymous reporting opportunities, helplines and so on, to assess their use by civil society and the extent to which they have resulted in action.

- Case studies of selected Appropriate Authorities would be useful; questions that such case studies could address include: What has been the functioning of Appropriate Authorities at the district level? What are the challenges they face? What are the attitudes of members? What have been their experiences and what support do they need?

- Assessments of sting operations and their positive and negative effects through interviews with those who have conducted sting operations and providers targeted by these operations (if possible).

- Case studies assessing the role of the PCPNDT Act enforcement authorities, understanding their perspectives about the reasons for non-compliance with the PCPNDT Act, including, for example, lack of awareness, complicit police, indifferent attitudes among the police and judiciary, etc.

- To what extent have measures intended to enforce the PCPNDT Act compromised women's right to access safe abortion?

Understanding the context of persistent gender-biased sex selection: Also of interest is research that sheds more light on the context of gender-biased sex selection. For example, not enough is known about such diverse issues as, for example, the decision making process with regard to the composition of children and resort to gender-biased sex selection; costs associated with gender-biased sex selection and termination of pregnancies carrying female foetuses; the extent to which the narrowing of gender disparities in schooling, and greater exposure to the media and new technologies on the one hand, and concerns about the safety of girls in public places on the other, have affected decisions about children and expectations from sons and daughters; and the extent to which daughters are indeed perceived as able to support their parents

Understanding the social consequences of adverse sex ratios: The effects of adverse sex ratios have already been felt in the north-western states of India in terms of the paucity of brides and the consequent importation of brides 
from poorer eastern and north-eastern states. Research is needed that describes the adjustments of social systems to sex imbalances among adolescents and adults, notably with regard to marriage, sexuality, gender-based violence, and the agency and opportunities of women.

Understanding factors underlying improvements in child sex ratios: As previous chapters have shown, while India's sex ratio at birth and among children continue to be disturbing, there have been positive shifts in some states and districts, particularly in the north-western states, such as Delhi (NCT), Haryana, Himachal Pradesh and Punjab, and the western state of Gujarat. Indeed, in several districts in which the child sex ratio was particularly adverse in 2001, improvements were observed in 2011, while no such trend was observed in similar and often contiguous districts. Our knowledge base about why these changes took place, however, remains sparse. Research that explores the situation in districts in which sex ratios improved impressively over the last decade or two, with neighbouring or similar districts in which such a decline did not take place may provide some answers to questions about what works to reverse adverse sex ratios; research would explore the extent to which selected districts differ in terms of implementation of initiatives intended to enforce the Act; build gender equality and promote advocacy, communication and community mobilisation, and the extent to which the reversal was effected without denying women their right to safe abortion. Research would also show the extent to which gender role attitudes have indeed become more egalitarian and son preference declined, as compared with such other possible changes as concerns about the limited availability of potential brides, difficulties in locating providers willing to disclose the sex of the foetus, or fears of arrest and imprisonment. Finally, ongoing research evaluating the impact of such programmes as the Apni Beti Apna Dhan (Haryana) and the Dhanalakshmi Schemes conducted, respectively, by the International Centre for Research on Women, and the International Institute for Population Sciences (IIPS) and UNFPA will provide insight into the extent to which such transfers have succeeded in changing parental perceptions about having daughters.

In short, imbalances in the sex ratio at birth and among children remain a huge challenge in India and call for urgent action that counters gender-biased sex selection while preserving women's right to access safe abortion. While a number of factors responsible for gender-biased sex selection have been identified and programmes implemented, evidence remains weak with regard to both the implementation of the PCPNDT Act proscribing gender-biased sex selection and the effectiveness of direct and indirect policies and interventions. 


\section{References}

Academics Stand Against Poverty. n.d. “Academics Campaign on India’s Missing Girls”. Accessed on 30 October, 2014, at http://academicsstand.org/2012/06/missing-girls-nanda/

Agarwal, B. 2005. “Landmark step to gender equality”. The Hindu. September 25, 2005 (newspaper article).

Anukriti, S. and A. Chakravarty. 2014. "Fertility limits on local politicians in India". Accessed on 30 October, 2014 at http://www. isid.ac.in/ epu/acegd2014/papers/AbhishekChakravarty.pdf

Arnold, F., S. Kishor and T.K. Roy. 2002. “Sex-selective abortion in India.” Population and Development Review, 28(4): 759-85.

Arnold, F. and S. Parasuraman. 2009. "The effect of ultrasound testing during pregnancy on pregnancy termination and the sex ratio at birth in India”. Paper presented at the XXVI International Population Conference, International Union for the Scientific Study of Population (IUSSP), Marrakech, Morocco, 27 September-2 October.

Arokiaswamy, P. and S. Goli. 2012. "Explaining the skewed child sex ratio in rural India: Revisiting the landholding-patriarchy hypothesis”. Economic and Political Weekly, 47(42): 85-94.

Association for Social Audit, Research \& Development Initiative (ASARDI), Bhubaneswar. 2010. “State-level Judicial Colloquium on Pre-conception \& Pre-natal Diagnostic Techniques Act, 1994". Jointly organised by the Department of Health and Family Welfare, Government of Orissa, Orissa State Legal Services Authority, Orissa High Court Legal Service Committee, and United Nations Population Fund (UNFPA), India.

Bhalotra, S.R. and T. Cochrane. 2010. "Where have all the young girls gone? Identification of sex selection in India". IZA Discussion Paper No. 5381. Bonn: The Institute for the Study of Labour (IZA). Accessed on 24 January, 2014 at http://ftp.iza. org/dp5381.pdf

Bhat, P.N.M. 2002. "On the trail of “missing' Indian females: II: Illusion and reality”. Economic and Political Weekly, 37(52): 5244-5263.

Bhat, P.N.M. and A.J.F. Zavier. 2007. "Factors influencing the use of prenatal diagnostic techniques and the sex ratio at birth in India”. Economic and Political Weekly, 42(4): 2292-2303.

Birchall, J. and S. Rao. 2012. Interventions to tackle sex selection in Asia (GSDRC helpdesk research report). Accessed on 14 March, 2014 at http://www.gsdrc.org/docs/open/HDQ856.pdf.

Bongaarts, J. 2013. "The implementation of preferences for male offspring". Population and Development Review, 39(2): 185-208.

Bracken, H. and V. Nidadavolu. 2005. "Mixed messages? An analysis of communication materials on abortion and sex determination in Rajasthan”. Economic and Political Weekly, 40(35): 3856-3862.

Breakthrough. n.d. “Mission Hazaar”. Accessed on 13 February, 2015 at http://www.breakthrough.tv/missionhazaar-hi/

Buch, N. 2005. "Law of two-child norm in panchayats: Implications, consequences and experiences". Economic and Political Weekly, 20(20): 2421-2429.

Byatnal, A. 2011. “Satara renames its “unwanted’ girls”. The Hindu, Satara, October 23, 2011 (newspaper article).

Caldwell, B.K. and J.C. Caldwell. 2005. "Family size control by infanticide in the great agrarian societies of Asia”. Journal of Comparative Family Studies, 36(2): 193-253.

Central Bureau of Statistics (CBS). 2012. National Population and Housing Census 2011 (National Report). Central Bureau of Statistics, National Planning Commission Secretariat, Government of Nepal: Kathmandu.

Chung W. and M. Das Gupta. 2007. "The decline of son preference in South Korea: The roles of development and public policy". Population and Development Review, 33(4): 757-783.

Das Gupta, M. 1995. “Fertility decline in Punjab, India: Parallels with historical Europe”. Population Studies, 49(3): 481-500.

Das Gupta, S., S. Mukherjee, S. Singh et al. 2008. Knot Ready: Lessons from India on delaying marriage for girls. New Delhi: International Center for Research on Women (ICRW). 
Deininger, K., A. Goyal and H. Rangarajan. 2010. "Inheritance law reform and women's access to capitals". Policy Research Working Paper 5538. The World Bank. Accessed on $14^{\text {th }}$ February, 2014, at http://elibrary.worldbank.org/doi/ pdf/10.1596/1813-9450-5338

Department of Education. Government of Bihar. n.d. “Mukhyamantri Balika Cycle Yojana (MBCY)." Accessed on 3 February, 2015, at http://www.biharonline.gov.in/Site/Content/Government/Schemes.aspx?u=MBCY\&In=en.

Department of Medical, Health and Family Welfare, Government of Rajasthan. n.d. "What is Sex Selection”. Accessed on 10 March, 2014, at www.hamaribeti.nic.in

Department of Women and Child Development, Government of Haryana. n.d., a. "Ladli”. Accessed on 10 March, 2014 , at http:// wcdhry.gov.in/Ladli/Ladli2008.pdf

Department of Women and Child Development, Government of Haryana. n.d., b. “Ladli” Accessed on 10 March, 2014, at http:// www.wcdhry.gov.in/ladli.htm.

Department of Women and Child Development, Government of Madhya Pradesh. n.d. "Ladli Laxmi”. Accessed on 17 March, 2014, at http://ladlilaxmi.com/

Department of Women and Child Development, Government of NCT of Delhi. n.d. "Ladli Scheme, 2008". Accessed on 18 March, 2014, at http://wcddel.in/ladli.html

Department of Health and Family Welfare, Government of Punjab. n.d. "New Strategies: Balri Rakshak Yojana”. Accessed on 24 March, 2014, at http://www.pbhealth.gov.in/sch1.htm

Dewan, B.S. and A.M. Khan. 2009. “Socio-cultural determinants of female foeticide." Social Change, 39(3): 388-405.

Directorate of Women and Child Development, Government of Himachal Pradesh. n.d. "Schemes pertaining to Welfare of Women". Accessed on 18 March, 2014, at http://agisac.gov.in/welfaregis/

Dreze, J. and R. Khera. 2000. "Crime, gender, and society in India: Insights from homicide data”. Population and Development Review, 26(2): 335-352.

Forum against Sex Selection (FASS). 2012. "Mukhbir Yojna scripts a success story in state”. Forum against Sex Selection. India. Accessed on 12 February at https://fassmumbai.wordpress.com/2012/03/24/mukhbir-yojna-scripts-a-success-storyin-state/.

Frost, M., D. Maheshpuri and P.R.A. Hinde. 2013. "Falling sex ratios and emerging evidence of sex-selective abortion in Nepal: Evidence from nationally representative survey data”. BMJ Open, 3(5):1-7.

Ganatra, B. 2008. "Maintaining access to safe abortion and reducing sex ratio imbalances in Asia". Reproductive Health Matters, 16 (31 Supplement): 90-98.

George, S. M. 1997. “Female infanticide in Tamil Nadu, India: From recognition back to denial?" Reproductive Health Matters, 5(10): 124-132.

George, S. M. 2002. “Sex selection/determination in India: Contemporary Developments". Reproductive Health Matters, 10(19): 190-192.

Girls Count. 2014. A Civil Society Initiative Against the Declining Child Sex Ratio. Accessed on 14 March, 2014, at http://www.girlscount.in.

Government of India. 1971. The Medical Termination of Pregnancy Act (Act. No. 34). New Delhi: Government of India.

Government of India. 2003. The Medical Termination of Pregnancy Rules (Amendment). New Delhi: Government of India

Government of Madhya Pradesh. n.d. "Beti Bachao Abhiyan (Initiative of MP Govt, Scrabble Media)". Accessed on 3 February, 2015, at https://www.facebook.com/pages/Beti-Bachao-Abhiyan-Initiative-of-MP-Govt-Scrabble-Media/290402007641003? sk=timeline

Guilmoto, C. Z. 2007. "Sex-ratio imbalance in Asia: Trends, consequences and policy responses”. Symposium at The 4th Asia Pacific Conference on Sexual and Reproductive Health and Rights, Hyderabad, India, October, 2007.

Guilmoto, C. Z. 2011. Sex imbalances at birth: Trends, consequences, and Policy Implications. Accessed on 28 March, 2014 , at https://www.unfpa.org/webdav/site/global/shared/documents/Guilmoto Revised presentation Hanoi Oct2011.pdf 
Guilmoto, C. Z. 2012. "Skewed sex ratios at birth and future marriage squeeze in China and India, 2005-2100". Demography, 49: $77-100$.

Gupta, A. n.d. "Female foeticide in India". Media Centre, UNICEF India. Accessed on 3 February 2015, at http://www.unicef.org/ india/media_3285.htm

Hesketh, T, L. Lu, and Z. W. Xing. 2011. "The consequences of son preference and sex-selective abortion in China and other Asian countries". Canadian Medical Association Journal, 183(12): 1374-1377. DOI: 10.1503/cmaj.101368.

Holmes, R. and S. Upadhya. 2009. The role of cash transfers in post-conflict Nepal. London: Overseas Development Institute (ODI).

Indian Medical Association, Doctors for Daughters. 2006. “IMA Resolution to Fight against Sex Selection”. Accessed on 28 October, 2014, at http://countryoffice.unfpa.org/india/drive/IMAResolutiontofightagainstsexselection.pdf

Indian Medical Association, Doctors for Daughters. n.d., a “Doctors' Dilemmas: Questions doctors face in communicating about pre-natal sex selection”. Accessed on 3 February, 2015, at http://countryoffice.unfpa.org/india/drive/Doctors'Dilemmas.pdf

Indian Medical Association, Doctors for Daughters. n.d., b. “Making Your Clinic and Hospital PCPNDT Act compliant”. Accessed on 3 February, 2015, at http://countryoffice.unfpa.org/india/drive/MakingYourClinic\&HospitalPCPNDTActCompliant.pdf

Indian Medical Association, Doctors for Daughters. n.d., c. "Why do daughters go missing? Frequently asked questions on pre-natal sex selection in India”. New Delhi: Indian Medical Association.

International Institute for Population Sciences (IIPS) and Macro International. 2007. National Family Health Survey (NFHS-3)-India, 2005-06. Mumbai: IIPS.

Ipas. 2013. "Preserving access to safe abortion while addressing gender-biased sex selection in India: Introducing the Campaign for Gender Equality and Safe Abortion". New Delhi: Ipas.

Jha, P., M.A. Kesler, R. Kumar et al. 2011. "Trends in selective abortions of girls in India: analysis of nationally representative birth histories from 1990 to 2005 and census data from 1991 to 2011”. The Lancet, 377(9781): 1921-1928.

Jha, P., R. Kumar, P. Vasa et al. 2006. “Low male-to-female sex ratio of children born in India: national survey of 1.1 million households". The Lancet, 367(9506): 211-218.

John, M.E. 2011. “Census 2011: Governing populations and the girl child”. Economic and Political Weekly, 46(16): 10-12.

John, M. E., R. Kaur, R. Palriwala et al. 2008. Planning Families, Planning Gender: The Adverse Child Sex Ratio in Selected Districts of Madhya Pradesh, Rajasthan, Himachal Pradesh, Haryana, and Punjab. New Delhi: ActionAid and Canada's International Development Research Centre (IDRC).

John, M.E., R. Kaur, R. Palriwala et al. 2009. “Dispensing with daughters: Technology, society, economy in North India”. Economic and Political Weekly, 44(15): 16-19.

Joseph, J. and Center for Youth Development and Activities (CYDA). 2007. Report on reflections on the campaign against sex selection and exploring ways forward. Pune: CYDA.

Junhong, C. 2001. "Prenatal sex determination and sex selective abortion in central China". Population and Development Review, 27(2): 259-280.

Kaur, R. 2004. “Across-region marriages: Poverty, female migration and the sex ratio". Economic and Political Weekly, 39(25): 2595-2603.

Kaur, R. 2013. "Mapping the adverse consequences of sex selection and gender imbalances in India and China." Economic and Political Weekly, 48(35): 37-44.

Kim, D.S. 2013. Son-selective reproductive behavior and policy responses: Korean experience. Working group meeting on Sex Selection and Access to Safe Abortion, Department of Reproductive Health and Research. WHO, Geneva, Switzerland, May, 2013.

Kishor, S. and K. Gupta. 2009. Gender Equality and Women's Empowerment in India. National Family Health Survey (NFHS-3), India, 2005-06. Mumbai: International Institute for Population Sciences; Calverton, Maryland, USA: ICF Macro.

Kishwar, M. 1993. “Abortion of female fetuses: Is legislation the answer?” Reproductive Health Matters, 1(2): 113-115.

Kukreja, R. and P. Kumar. 2013. Tied in a Knot: Cross-region Marriages in Haryana and Rajasthan: Implications for Gender Rights and Gender Relations. Kingston, Ontario and New Delhi, Tamarind Tree Films. 
Kulkarni, P.M. 2007. "Estimation of missing girls at birth and juvenile ages in India". A paper prepared for the United Nations Population Fund (UNFPA), India.

Kulkarni, P. M. 2014. “The population and development scenario in India”. In: Jejeebhoy, S. J., Kulkarni, P. M., Santhya, K. and Mehrotra, F. (eds.) Population and Reproductive Health in India: An Assessment of the Current Situation and Future Needs. New Delhi: Oxford University Press.

Kulthe B. 2013. “State to finally have a functional women's commission”. Sakal Times, 6 December, 2013 (newspaper article).

Kumar, S. and K. Sathyanarayana. 2012. "District-level estimates of fertility and implied sex ratio at birth in India”. Economic \& Political Weekly, 47(33): 66-72.

Lawyers Collective Women's Rights Initiative. n.d. “Mapping women's gains in inheritance and property rights under the Hindu Succession Act, 1956”. Accessed on 10 March, 2014, at http://www.lawyerscollective.org/files/LCWRI\%20INHERITANCE\%20 REPORT.pdf.

Li, S. 2007. “Imbalanced sex ratio at birth and comprehensive intervention in China”. Paper presented The $4^{\text {th }}$ Asia and Pacific Conference on Sexual and Reproductive Health and Rights, Hyderabad, India, October 2007.

Luthra, R. 1994. "A case of problematic diffusion ...? the use of sex determination techniques in India." Science Communication, 15(3): 259-272.

Madhya Pradesh Education Portal. n.d. "Cycle Distribution Monitoring”. Accessed on 3 February, 2015 at http://www. educationportal.mp.gov.in/Cycle/Public/Cycle Main.aspx

Magnum Opus, n.d. "Initiatives to save the baby girl and effectively implement healthcare schemes: Active Tracker". Available at digitalknowledgecentre.in/html/wp-content/.../save-the-baby-girl ppt.ppt

Medical Council of India. 2002. "Code of Ethics Regulations, 2002 (Amended up to December, 2009)". Gazette of India, Part III, Section 4, 6 April, 2002. (Available at http://www.mciindia.org/RulesandRegulations/CodeofMedicalEthicsRegulations2002. $\underline{\text { aspx }}$

Menon, M. 2006. “Widespread practice of sex selection techniques exposed.” The Hindu, March 31, 2006 (newspaper article).

Miller, B D. 1981. The Endangered Sex: Neglect of Female Children in Rural North India. Cornell University Press, Ithaca.

Miller, B.D. 1989. "Changing patterns of juvenile sex ratios in rural India, 1961 to 1971". 1989. Economic and Political Weekly, 20(20): 1229-1236.

Ministry of Health and Family Welfare (MOHFW). 2003. The Pre-natal Diagnostic Techniques (Regulation and Prevention of Misuse) Act, 1994 (Act no. 57 of 1994) and The Pre-Conception and Pre-natal Diagnostic Techniques (Regulation and Prevention of Misuse) Amendment Act, 2002 (no. 14 of 2003) New Delhi: MOHFW, Government of India.

Ministry of Health and Family Welfare (MOHFW). 2006. Handbook on Pre-Conception \& Pre-Natal Diagnostic Techniques Act, 1994 and Rules with Amendments. New Delhi: MOHFW, Government of India.

Ministry of Health and Family Welfare (MOHFW). 2013. Annual Report 2012-13. New Delhi: MOHFW, Government of India.

Ministry of Health and Family Welfare (MOHFW). n.d. "Action Plan, Save the Girl Child". New Delhi: MOHFW, Government of India. Accessed on 12 February at http://www.pndt.gov.in/index1.asp?linkid=12.

Ministry of Human Resource Development (MOHRD). 2008. Aide Memoire, First Joint Review Mission of Mahila Samakhya. New Delhi: MOHRD, Government of India. Available at http://mhrd.gov.in/sites/upload files/mhrd/files/upload document/1st Joint Review Mission 2008.pdf

Ministry of Human Resource Development (MOHRD). 2011. "The Right of Children to Free and Compulsory Education Act 2009." The Gazette of India, 23 March, 2011. New Delhi: MOHRD, Government of India. Accessed on January 14, 2014, at http:// mhrd.gov.in/sites/upload_files/mhrd/files/free_and_compulsory_NEW.pdf. -

Ministry of Human Resource Development (MOHRD). n.d. "Centrally Sponsored Scheme: Incentives to Girls for Secondary Education”. Accessed on 3 February, 2015, at http://mhrd.gov.in/sites/upload files/mhrd/files/upload document/scheme incentive.pdf

Ministry of Law and Justice. 2007. Maintenance and Welfare of Parents and Senior Citizens Act, 2007. The Gazette of India. Part II - Section I, December, 2007, New Delhi: Ministry of Law and Justice, Government of India. Accessed on 12 February, 2015 at http://socialjustice.nic.in/oldageact.php?format=print. 
Ministry of Law and Justice. 2007a. The Prohibition of Child Marriage Act, 2006. The Gazette of India, Part II - Section 1, January, 2007, New Delhi: Ministry of Law and Justice, Government of India. Accessed on 12 February, 2015 at http://wcd.nic.in/ cma2006.pdf

Ministry of Law and Justice. 2013. "The Criminal Law (Amendment) Act, 2013." The Gazette of India. Part II, Section 1. April 2, 2013. New Delhi: Ministry of Law and Justice, Government of India.

Ministry of Women and Child Development (MOWCD). 2001. National Policy for the Empowerment of Women 2001. New Delhi: MOWCD, Government of India. Accessed on January 14, 2014, at http://www.wcd.nic.in/empwomen.htm

Ministry of Women and Child Development (MOWCD). 2011. Annual Report 2010-2011. New Delhi: MOWCD, Government of India.

Ministry of Women and Child Development (MOWCD). n.d., a. The Dowry Prohibition Act, 1961 (Act No. 28 of 1961). New Delhi: MOWCD, Government of India. Accessed on 10 February, 2014, at http://wcd.nic.in/dowryprohibitionact.htm

Ministry of Women and Child Development (MOWCD), n.d., b. The Child Marriage Restraint Act, 1929. Gazette of India, 1927, Part V, page 28. New Delhi: MOWCD, Government of India. Accessed on 10 February, 2014, at http://wcd.nic.in/cmr1929.htm

Ministry of Women and Child Development (MOWCD), n.d., c. The Child Marriage Restraint Act, 1978. New Delhi: MOWCD, Government of India. Accessed on 10 February, 2014, at http://wcdhry.gov.in/Child Acts/ChildRestraintAct.pdf

Ministry of Women and Child Development (MOWCD). n.d., d. "Balika Samridhi Yojna." Accessed on 10 March, 2014, at http:// wcd.nic.in/BSY.htm

Ministry of Youth Affairs and Sports (MOYAS). 2003. National Youth Policy 2003. New Delhi: MOYAS. Accessed on 14 March, 2014, at http://www.youth-policy.com/Policies/IndiaNATIONALYOUTHPOLICY2003.pdf

Ministry of Youth Affairs and Sports (MOYAS). 2014. National Youth Policy 2014. New Delhi: MOYAS. Accessed on January 14, 2014, at http://yas.nic.in/sites/default/files/NYP\%20Brochure.pdf

Murlidharan, K. and N. Prakash. 2013. “Cycling to school: Increasing secondary school enrolment for girls in India." Working Paper, September 2013. London: International Growth Centre.

Nagarajan, R. and S. Mulay. 2008. "Ultrasound sonography centres and child sex ratios across Maharashtra: A district level analysis." Artha Vijnana, 1(4): 433-448.

Nanda, P. 2012. Changing the value of girls in Haryana: Evaluation of the Apni Beti Apna Dhan CCT. New Delhi: ICRW Asia Regional Office. Accessed on 9 April, 2014 at http://www.povertyactionlab.org/doc/changing-value-girls-haryana

Nandi, A. and A. B. Deolalikar. 2013. "Does a legal ban on sex-selective abortions improve child sex ratios? Evidence from a policy change in India." Journal of Development Economics, 103(Issue C): 216-228.

National Crime Records Bureau (NCRB). 2006. Crimes in India 1998-2006. Delhi: NCRB, Ministry of Home Affairs, Government of India.

National Crime Records Bureau (NCRB). 2010. Crime in India: Compendium. Delhi: NCRB, Ministry of Home Affairs, Government of India. Accessed on 20 March, 2014 at http://ncrb.nic.in/

National Crime Records Bureau (NCRB). 2013. Crime in India: Compendium. Delhi: NCRB, Ministry of Home Affairs, Government of India. Accessed on 20 March, 2014 at http://ncrb.nic.in/

National Institute of Population Studies (NIPS) [Pakistan] and ICF International. 2013. Pakistan Demographic and Health Survey 2012-13. Islamabad, Pakistan, and Calverton, Maryland, USA: NIPS and ICF International.

National Institute of Population Research and Training (NIPORT), Mitra and Associates, and ICF International. 2013. Bangladesh Demographic and Health Survey 2011. Dhaka, Bangladesh and Calverton, Maryland, USA: NIPORT, Mitra and Associates, and ICF International.

Naqvi, F. 2006. Images and icons: harnessing the power of mass media to promote gender equality and reduce practices of sex selection. New Delhi, India.

Nitish Kumar, 2010. Nitish Kumar's Blog. Accessed on 20 March, 2014 at http://nitishspeaks.blogspot.in/2010/04/ mukhyamantri-balika-cycle-yojna.html.

Office of the Registrar General, India. 2006. Sample Registration System Statistical Report, 2004. Report No. 1 of 2006. New Delhi: Office of the Registrar General, India. 
Office of the Registrar General. 2008. Sample Registration System Statistical Report, 2007. Paper No. 2 of 2008. New Delhi: Office of the Registrar General, India.

Office of the Registrar General, India. 2009. Sample Registration System Statistical Report, 2008. Paper No. 1 of 2009. New Delhi: Office of the Registrar General, India.

Office of the Registrar General, India. 2011. Sample Registration System Statistical Report, 2009. Report No. 1 of 2011. New Delhi: Office of the Registrar General, India..

Office of the Registrar General, India. 2012. Sample Registration System Statistical Report, 2010. Report No. 1 of 2012. New Delhi: Controller of Publications.

Office of the Registrar General, India. 2013a. Sample Registration System Statistical Report, 2012. Report 1 of 2013. New Delhi: Office of the Registrar General, India.

Office of the Registrar General, India. 2013b. Sample Registration System Statistical Report, 2011. Report 1 of 2013. New Delhi: Office of the Registrar General, India.

Office of the Registrar General and Census Commissioner, India. n.d. Primary Census Abstracts Data Tables (India and States/ UTs-District levels) (Excel Format). Accessed on 11 February, 2015 at http://www.censusindia.gov.in/pca/default.aspx

Office of the Registrar General and Census Commissioner, India. 2004. Primary Census Abstract Total Population: Table A-5 Census of India 2001. Series1-India. New Delhi: Office of the Registrar General, India.

Office of the Registrar General and Census Commissioner, India. 2013. Census of India 2011: Primary Census Abstract, Data Highlights, India, Series 1. New Delhi: Office of the Registrar General and Census Commissioner, India. Accessed on 25 March, 2014 at http://www.censusindia.gov.in/2011census/PCA/PCA Highlights/pca highlights file/India/Chapter-1.pdf

Office of the Registrar General and Census Commissioner, India, 2014. Annual Health Survey (AHS) Second Updation Bulletin 2012-13. Office of the Registrar General and Census Commissioner, India. Accessed on 12 February, 2015 at http://www. censusindia.gov.in/vital statistics/AHSBulletins/AHS Bulletin 2012-13 Presentation.pdf

Office of the United Nations High Commissioner for Human Rights (OHCR), United Nations Population Fund (UNFPA), The United Nations Children's Fund (UNICEF), United Nations Entity for Gender Equality and the Empowerment of Women (UN Women) and World Health Organization (WHO), 2011. Preventing gender-biased sex selection: An interagency statement OHCHR, UNFPA, UNICEF, UN Women and WHO. Geneva: WHO.

Oliveau, S. and C.Z. Guilmoto. 2005. "Spatial correlation and demography: Exploring India's demographic patterns." Published in XXVe Congres International de la Population, Tours: France (2005). Accessed on 13 March, 2014, at http://halshs. archivesouvertes.fr/docs/00/51/92/60/PDF/2005_Oliveau_Guilmoto_iussp.pdf

Pande, R. and N. M. Astone. 2007. "Explaining son preference in rural India: The independent role of structured versus individual factors." Population Research Policy Review, 26(1): 1-29.

Phansalkar-Joshi, S. 2013. Compilation and Analysis of Case-laws on Pre-conception and Pre-natal Diagnostics Techniques (Prohibition of Sex Selection) Act, 1994. Mumbai: Maharashtra Judicial Academy.

Plan India. 2013. Annual Report 2012-2013. Accessed on 31 March, 2014, at http://planindia.org/files/annual-report-2012-13.

Planning Commission. 2008. Eleventh Five Year Plan 2007-2012 Social Sector Volume II. New Delhi: Oxford University Press.

Planning Commission. 2013. Twelfth Five Year Plan (2012-2017): Social Sector. Volume III. New Delhi: SAGE Publications India Pvt. Ltd.

Planning Commission. n.d. Mid-term Appraisal for Eleventh Five Year Plan 2007-2012. Accessed on 12 February, 2015 at http:// planningcommission.gov.in/plans/mta/11th mta/chapterwise/chap11 women.pdf

Population First. n.d. "Laadli Media and Advertising Awards.” Available at http://www.populationfirst.org/Laadli\%20Media\%20 and\%20Advertising\%20Awards/M 18

Population Foundation of India (PFI). n.d. "Main Kuch Bhi Kar Sakti Hoon can now be heard on All India Radio News". New Delhi: PFI. Accessed on 12 February, 2015 at http://www.populationfoundation.in/news/main-kuch-bhi-kar-sakti-hoon-can-now-beheard-all-india-radio.

Premi, M. K. 2002. “The Girl Child: Some Issues for Consideration.” Paper presented at the Symposium on Sex Ratio in India, held at the International Institute for Population Sciences, Mumbai, 10-11 January, 2002. 
Press Information Bureau. 2010. "Integrated Child Protection Scheme”. Accessed on 30 September, 2013, at http://pib.nic.in/ newsite/erelease.aspx?relid=67659.

Public Health Foundation of India (PHFI). 2010. Implementation of the PCPNDT Act In India: Perspectives and Challenges. New Delhi: PHFI.

Rajya Sabha. 2010. Thirty Sixth Report on The Constitution (One Hundred and Eighth Amendment Bill, 2008). New Delhi: Rajya Sabha Secretariat, Parliament of India.

Retherford, R. D and T. K. Roy. 2003. Factors affecting sex-selective abortion in India and 17 major states. NFHS Series No. 21. Mumbai: International Institute for Population Sciences and Hawaii: East-West Centre.

Sekher, T. V. 2010. Special financial incentive schemes for the girl child in India: A review of select schemes. Mumbai: International Institute for Population Sciences, and New Delhi: United Nations Population Fund.

Sekher, T. V. 2012. “Ladlis and Lakshmis: Financial incentives schemes for the girl child”. Economic and Political Weekly, 47(17): 58-65.

Sekher, T.V. and N. Hatti. 2010. "Disappearing daughters and intensification of gender bias: evidence from two village studies in South India." Sociological Bulletin, 59(1):111-133.

Sen, A. 1990. More than 100 million women are missing. New York Review of Books, 1990.

Sen, G. 2009. "Gender-biased sex selection: Key issues for action." Accessed on 10 March, 2014, at http://www.dawnnet.org/ research-analyses.php?theme=2\&id=29.

Singh, K. 2013. Laws And Son Preference In India A Reality Check. New Delhi: UNFPA.

Snehi, Y. 2003. “Female infanticide and gender in Punjab.” Economic and Political Weekly, 38(41) :4302-4305.

Srinivasan, S. and A.S. Bedi. 2009. "Girl child protection scheme in Tamil Nadu: An appraisal." Economic and Political Weekly, 44(48): 10-12.

Srinivasan, S. and A.S. Bedi. 2012. "Tackling female infanticide and sex selection in Tamil Nadu: A failure?" Economic and Political Weekly, 47(45): 80-82.

The Tribune, 2001. Online edition, April 19, 2001, Chandigarh, India. Available at http://www.tribuneindia.com/2001/20010419/ main7.htm

Toppo, M., A. Diwakar and D.K. Pal. 2012. "A study of sex ratios in relation to birth order in Bhopal City." Healthline, 3(1): 45-49.

United Nations, Department of Economic and Social Affairs, Population Division. 2013. World Population Prospects: The 2012 Revision, Key Findings and Advance Tables. Working Paper No. ESA/P/WP.227.

United Nations Educational, Scientific and Cultural Organization (UNESCO). 2000. Incentive schemes for promoting girl's participation in primary education in Pakistan. Paris: UNESCO.

United Nations Educational, Scientific and Cultural Organization (UNESCO) 2007. EFA Global Monitoring Report 2008. Education for all by 2015 Will we make it? Paris: UNESCO.

United Nations Population Fund (UNFPA). 2010. Trends in Sex Ratio at Birth and Estimates of Girls Missing at Birth in India. New Delhi: UNFPA.

United Nations Population Fund (UNFPA). 2012. Sex Imbalances at Birth: Current trends, consequences and policy implications. Bangkok, Thailand: UNFPA.

United Nations Population Fund (UNFPA). 2013. Lest more girls go missing: Initiatives of UNFPA India to address gender-biased sex selection. New Delhi: UNFPA.

UN Women. 2014. Sex ratios and gender-biased sex selection: History, debates and future directions. New Delhi: UN Women and UNFPA.

Visaria, P. 1971. The Sex Ratio of the Population of India (Monograph 10-Census of India). New Delhi: Office of the Registrar General of India.

Visaria, L. 2007. “Deficit of girls in India: Can it be attributed to female selective abortion?” In T. Patel (Ed.), Sex-selective Abortion in India: Gender, Society and New Reproductive Technologies, (pp. 61-80). New Delhi: Sage Publications India Pvt. Ltd. 
Visaria, L., A. Acharya and F. Raj. 2006. “Two-child norm-victimising the vulnerable.” Economic and Political Weekly, 41(1): 41-48.

Women Power Connect. 2013. A multi-hued experience and a zig-zag journey on the quest for gender equality: Lessons learnt and experiences gained through the community based project on addressing sex selection. New Delhi: Women Power Connect.

Women Power Connect. 2013a. Support to community mobilisation and a people driven response in preventing sex selection and arresting child sex ratio decline: Process documentation of the project. New Delhi: Women Power Connect.

Wu, Z., K. Viisainen and E. Hemminki. 2006. "Determinants of high sex ratio among newborns: a cohort study from rural Anhui province, China." Reproductive Health Matters, 14(27): 172-180.

Xinhua. 2006. "China promotes girls to avoid glut of bachelors." China Daily. Accessed on 10 March, 2014, at http://www. chinadaily.com.cn/china/2006-08/08/content 660041.htm.

Zaidi, R.B. 2013. “Sex selection in Pakistan: uncovering the truth." Poster presented at the XXVII IUSSP International Population Conference, Busan, Korea, August 2013. Accessed on 10 March, 2014, at http://www.iussp.org/sites/default/files/event call for papers/SRB\%20Abstract\%20-\%20IUSSP\%202013 fin.pdf. 


\section{Authors}

Shireen J. Jejeebhoy, Senior Associate, Population Council, New Delhi

Sharmistha Basu, Programme Officer, Population Council, New Delhi

Rajib Acharya, Associate I, Population Council, New Delhi

A J Francis Zavier, Senior Programme Officer, Population Council, New Delhi 


\section{Technical Advisory Group Members}

Nupur Barua, DFID, New Delhi

Christophe Z Guilmoto, CEPED (UMR Paris Descartes-Ined-IRD), Paris, France

M. Kabir, Jahangirnagar University, Dhaka, Bangladesh

Sonali Khan, Breakthrough, New Delhi

P.M Kulkarni, Jawaharlal Nehru University, New Delhi

Sanjay Kumar, UNFPA, New Delhi

Vinoj Manning, Ipas, New Delhi

Priya Nanda, International Centre for Research on Women, New Delhi

Farah Naqvi, New Delhi

Francis Rathinam, DFID, New Delhi

Sonali Regmi, Center for Reproductive Rights, Kathmandu, Nepal

T. V. Sekher, International Institute for Population Sciences, Mumbai

Ena Singh, UNFPA, New Delhi 


\title{
Field Investigators
}

\author{
Sayra Bano \\ Hemraj Daima \\ Madhulata Gupta \\ Salma Khanam \\ Kundan Kumar \\ Davendra Kumar \\ Avadhesh Kumar \\ Ruchi Kumari \\ Bhaskar Mishra \\ Hrishikesh Pandey \\ Alok Kumar Pandey \\ Deepak Kumar Pandey \\ Poonam Saini \\ Laxmi Saini \\ Nanda M. Sahu \\ Brahmanand Saraswati \\ Anil Kumar Sinha \\ Jaishankar Tiwari \\ Priyanka Vaishnav \\ Zahida
}


Printed at :

systemsvision@gmail.com 
